IZA DP No. 6465

Benchmarking Regions:

Estimating the Counterfactual Distribution of Labor Market Outcomes

Bernd Fitzenberger

Marina Furdas

April 2012 


\title{
Benchmarking Regions: Estimating the Counterfactual Distribution of Labor Market Outcomes
}

\author{
Bernd Fitzenberger \\ Albert-Ludwigs University Freiburg, \\ IFS, ZEW and IZA \\ Marina Furdas \\ Albert-Ludwigs University Freiburg
}

Discussion Paper No. 6465

April 2012

IZA

P.O. Box 7240

53072 Bonn

Germany

Phone: +49-228-3894-0

Fax: +49-228-3894-180

E-mail: iza@iza.org

\begin{abstract}
Any opinions expressed here are those of the author(s) and not those of IZA. Research published in this series may include views on policy, but the institute itself takes no institutional policy positions.

The Institute for the Study of Labor (IZA) in Bonn is a local and virtual international research center and a place of communication between science, politics and business. IZA is an independent nonprofit organization supported by Deutsche Post Foundation. The center is associated with the University of Bonn and offers a stimulating research environment through its international network, workshops and conferences, data service, project support, research visits and doctoral program. IZA engages in (i) original and internationally competitive research in all fields of labor economics, (ii) development of policy concepts, and (iii) dissemination of research results and concepts to the interested public.
\end{abstract}

IZA Discussion Papers often represent preliminary work and are circulated to encourage discussion. Citation of such a paper should account for its provisional character. A revised version may be available directly from the author. 


\section{ABSTRACT \\ Benchmarking Regions: Estimating the Counterfactual Distribution of Labor Market Outcomes*}

This paper develops and implements a new benchmarking approach for labor market regions. Based on panel data for regions, we use nonparametric matching techniques to account for observed labor market characteristics and for spatial proximity. As the benchmark, we estimate the counterfactual distribution of labor market outcomes for a region based on outcomes of similar regions. This allows to measure both the rank (relative performance) and the absolute performance based on the actual outcome for a region. Our outcome variable of interest is the hiring rate among the unemployed. We implement different similarity measures to account for differences in labor market conditions and spatial proximity, and we choose the tuning parameters in our matching approach based on a crossvalidation procedure. The results show that both observed labor market characteristics and spatial proximity are important features to successfully match regions. Specifically, the modified Zhao (2004) distance measure and geographic distance in logs work best in our applications. Our estimated performance measures remain quite stable over time.

JEL Classification: $\quad$ C14, J68, R50

Keywords: matching function, regional employment offices, performance measurement, nonparametric matching, conditional quantile positions

Corresponding author:

Bernd Fitzenberger

Institute for Economic Research

Department of Applied Econometrics

Albert-Ludwigs-University

79085 Freiburg

Germany

E-mail: bernd.fitzenberger@vwl.uni-freiburg.de

\footnotetext{
${ }^{*}$ We thank Uwe Blien, Karsten Bunk, Wolfgang Dauth, Christian Gaggermeier, Joachim Möller, Ulrich Walwei, Katja Wolf, and participants in various seminars for comments and helpful discussions. We also thank Uwe Blien, Wolfgang Dauth, and Katja Wolf for providing the data used in this study. Financial support by the IAB through the project "Benchmarking-concept for individual comparison of agencies" is gratefully acknowledged. We thank Mehdi Hosseinkouchak for earlier work on this project. The responsibility for all errors is, of course, ours.
} 


\section{Contents}

1 Introduction 1

2 Literature 4

3 New Benchmarking Approach $\quad 7$

3.1 Conceptual Idea . . . . . . . . . . . . . . . . . . . . . . . . . . . 7

3.2 Formal Description . . . . . . . . . . . . . . . . . . . . . . 9

4 Data and Descriptive Statistics $\quad 12$

5 Results $\quad 14$

5.1 Regression Analysis . . . . . . . . . . . . . . . . . . . . . . . . 14

5.2 Comparison of Regions and Bandwidth Choice . . . . . . . . . . . . . . . . 14

5.3 Spatial Distribution of Benchmark Weights . . . . . . . . . . . . 16

5.4 Quantile Position as a Relative Performance Indicator . . . . . . . . . . . . 18

5.5 Matching Quality . . . . . . . . . . . . . . . . . 19

5.6 Absolute Performance . . . . . . . . . . . . . . . . . . . 20

6 Conclusions 21

$\begin{array}{ll}\text { References } & 22\end{array}$

$\begin{array}{ll}\text { Appendix } & 24\end{array}$

$\begin{array}{ll}\text { A Tables } & 24\end{array}$

$\begin{array}{ll}\text { B Figures } & 48\end{array}$ 


\section{Introduction}

The existence and persistence of regional labor market differences is widely acknowledged (OECD, 2000; Moretti, 2010). These differences affect the welfare of the local population and the effectiveness of local policy interventions. When assessing the labor market outcomes and the effectiveness of policies, it is important to benchmark regional outcomes by the outcomes of comparable regions. Thus, benchmarking has to account for differences in labor market characteristics. Put differently, when looking at the outcome of one region, it is useful to know the expected distribution of outcomes for a region with the same characteristics based on the outcomes of similar regions. This paper suggests to use nonparametric matching techniques to estimate the counterfactual distribution of labor market outcomes for a region. We account for both observed labor market characteristics and for spatial proximity, and we assess the labor market outcome for a region relative to the estimated counterfactual.

There already exists a large literature on frontier efficiency measurement (Battese and Coelli, 1995; Gong and Sickles, 1992; Worthington, 2001). The main idea of these techniques is to estimate the best possible outcome on some production frontier while accounting for differences in characteristics and decisions (henceforth, we refer both the characteristics and the decisions considered as covariates) which presumably affect the outcome. The problem is cast into a production process and technical efficiency of a unit of interest is measured relative to the 'best practice' on the production frontier, which is based on units that are sufficiently similar in the covariates considered. Important techniques applied in the literature are Data-Envelopment-Analysis (DEA) and Stochastic Frontier Analysis (SFA). DEA is a nonparametric deterministic approach relying on linear programming techniques (Gong and Sickles, 1992). SFA specifies a regression-type relationship which allows for frontier measurement in a stochastic setting by introducing a non-positive error term; the latter reflects the inefficiency relative to the expected efficient frontier (Battese and Coelli, 1995).

Both DEA and SFA have a number of disadvantages, that our suggested benchmarking method is able to address in a novel way. First, DEA and SFA have to specify some kind of production process by which efficiency is measured with regard to the specified production process and the set of covariates accounted for. For benchmarking, it may be desirable to exclude the decision variables of the unit of interest in order to assess its position just based on given characteristics. It does not have to be the case that 
the same functional form assumptions apply for DEA or SFA when a restricted set of covariates is used (Worthington, 2001). Second, DEA and SFA are sensitive to outliers, possibly caused by measurement error. It is therefore difficult to estimate the frontier which reflects the maximum (DEA) or the upper tail (SFA) of the empirical distribution of outcomes conditional on the covariates considered. Third, DEA is a flexible but purely deterministic method. SFA allows for random variation in outcomes but it is typically implemented in a way that assumes a constant parametric distribution of inefficiency in absolute terms relative to the frontier. Such a parametric model may not be flexible enough to account for the variation in outcomes and inefficiencies across units. Fourth, correspondingly, frontier efficiency measurement typically does not provide a benchmark for the dispersion of outcomes which varies with the covariates. Fifth, applications of DEA and SFA to our knowledge rarely account for spillover effects across units in a close geographic neighborhood. Using SFA this could be done by applying techniques from spatial econometrics. DEA could possibly use covariates from adjacent regions as additional inputs. Sixth, DEA and SFA only provide little guidance as to how to find the most comparable benchmark for a unit of interest. This is a challenging issue in small data sets when a large number of covariates has to be considered, these covariates vary strongly across units, and spatial spillover effects have to be accounted for.

While frontier efficiency measurement techniques attempt to estimate the efficiency relative to a fully specified production process, a benchmarking method may simply require a comparison level based on similar regions. Such an approach requires to identify similar regions based on exogenous labor market characteristics, i.e. the benchmarking method should provide some counterfactual estimate for the level of the outcome variable based on these similar regions. When decision variables are not used to define similarity of regions, the benchmarking method allows to investigate whether differences in decision variables account for the difference between the actual outcome and the estimated counterfactual outcome. In an influential study for the benchmarking practice for labor market regions in Germany, Blien et al. (2010) use a cluster analysis to identify clusters of similar labor market regions in Germany based on exogenous labor market characteristics. The study uses a matching function framework to identify the key labor market characteristics and estimate the clusters solely based on these observed characteristics of regions. The outcomes within a cluster provide a benchmark. Because of the similarity of observed characteristics the estimated clusters often involve various regions which are not too far apart. The clusters do not allow for heterogeneity in the region specific (local) 
definition of a suitable comparison group of regions.

This paper develops a new non-parametric approach to benchmark labor market regions based on kernel matching, accounting both for observed labor market characteristics and geographic distance. ${ }^{1}$ We implement different similarity measures capturing the heterogeneity in local labor market conditions and propose two different ways to model spatial proximity - geographical distance and relative commuting flows. Accounting for spillover effects from neighborhood is important since in a regional context, the labor market situation in neighboring regions is likely to affect the performance of the analyzed employment office area. Our suggested approach is illustrated based on quarterly data for 176 labor market regions in Germany during the time period of 2006 to 2008. Our outcome variable of interest is, similar to Blien et al. (2010), the rate of hirings into regular employment among the unemployed. We suggest a leave-one-out cross-validation procedure regarding the prediction of the outcome variable in order to find an optimal weighting scheme between spatial proximity and similarity in labor market characteristics. In a detailed sensitivity analysis, we investigate different specifications of the kernel functions and choose the preferred specification based on our cross-validation procedure. The implied weighting scheme provides a specific comparison group for each labor market region, which can be used to estimate the counterfactual distribution of outcomes and which we display graphically by means of maps for each region considered. The regions can be ranked regarding their actual outcome level based on the estimated counterfactual distribution. Our approach allows the dispersion of outcomes to vary by observed labor market characteristics. In addition, we provide region specific estimates of the absolute differences in counterfactual outcomes by quantile and the actual outcome in a region. An advantage of our approach is that it produces results on the matching quality indicating the extent to which a reliable benchmark for a specific region can be determined. For some regions, this does not seem feasible due to lack of common support. We provide a detailed sensitivity analysis regarding the specification of the matching approach. Overall, our application shows that the suggested approach can be implemented in a satisfactory way.

The remainder of the paper proceeds as follows. Section 2 reviews the literature on benchmarking analysis of labor market regions. Section 3 develops our benchmarking

\footnotetext{
${ }^{1}$ We use the terms 'performance', 'ranking', and 'benchmarking' of regions interchangeably. Doing so, we refer to relative or absolute differences in the outcome variable measured after controlling for exogenous labor market characteristics and spatial proximity. The benchmarking results (strictly speaking) only apply if we control for all the relevant exogenous labor market characteristics.
} 
approach. The panel data on labor market regions in Germany are described in section 4. Section 5 discusses the empirical results. Section 6 concludes. The appendix provides further detailed empirical results.

\section{Literature}

A benchmarking analysis of labor market regions is required to assess the performance of regional employment offices, which act as local agents for a central government agency. Typically, the policy goal is to maximize the hiring (job finding) rate among the unemployed. A number of studies investigate the performance of regional employment offices regarding this goal based on a matching function for the local labor market. Analogous to a production process, the matching function explains hirings in a period as a function of the number of job seekers and the number of job openings (Blanchard and Diamond, 1989; Pissarides, 1990; Petrongolo and Pissarides, 2001). The benchmarking approach must take account of the fact that the level of hirings does not only depend upon the input factors mentioned above, but also on the prevailing conditions (frictions) within local labor markets.

The empirical literature mainly relies on two approaches for frontier efficiency measurement, namely the Stochastic Frontier Approach [SFA] (Battese and Coelli, 1995) and the Data Envelopment Analysis [DEA] (Gong and Sickles, 1992). Applications to measure the performance of regional employment offices build on a matching function and interpret the deviations from the estimated frontier as the degree of inefficiency. The two approaches differ with respect to the specification of the production technology and the measurement of technical efficiency. Furthermore, studies using SFA typically focus on a benchmarking analysis of local labor markets, whereas studies using DEA concentrate on measuring the efficiency of regional employment offices.

SFA uses a parametric Maximum Likelihood (ML) approach to estimate the production frontier model and to measure the implied inefficiency. Assumptions regarding the matching function and the specification of the inefficiency term are required. Typically, the matching function is assumed to follow a Cobb-Douglas function. The disturbance term is a mixture of two components. One component is assumed to be a random error term with expectation zero. The second component follows a strictly nonnegative distribution and represents the inefficiency relative to the implied production frontier, which is obtained by setting both error terms to zero. The first error term accounts for random 
variation of the outcome variable which is unrelated to the production frontier.

Several studies use SFA to estimate the matching efficiency of labor market regions, see for instance Ibourk et al. (2003) for France, Ilmakunnas and Pesola (2003) for Finland, Fahr and Sunde (2006) for West Germany, and Ramirez and Vassiliev (2007) for Switzerland. Based on regional panel data, all these studies aim to exploit variation in matching efficiency across regions and over time. The inefficiency term is specified as a function of the local labor market characteristics, such as the composition of the regional labor force with respect to age and education, GDP per capita, proportion of long-term unemployment spells, and others. Ilmakunnas and Pesola (2003) find evidence for spillover effects across regions when controlling for averages of unemployment and vacancy rates from neighboring regions. Fahr and Sunde (2006) also investigate the link between matching efficiency and spatial dependencies in the hiring rate. Their results suggest that the estimated spatial patterns are mostly stable over time, but exhibit strong spatial heterogeneity. Ramirez and Vassiliev (2007) analyze the public placement system in Switzerland. Unlike the studies cited so far, this study estimates explicitly the technical efficiency of local labor market authorities (employment offices). Technical efficiency involves two components: exogenous factors, which are not under the control of the employment office, and managerial inefficiency. The matching function also includes the number of job counselors as an input factor. The literature often treats this as a discretionary (endogenous) variable, which reflects the activity of the employment office (Sheldon, 2003), which makes it difficult to compare the efficiency across employment offices. Ramirez and Vassiliev (2007) find evidence for a strong impact of exogenous regional characteristics on technical efficiency. At the same time, there is considerable scope for improving the managerial efficiency of employment offices. The study does not account for spillover effects across adjacent regions.

DEA is a non-parametric method using linear programming techniques to detect best practices and to measure technical efficiency. DEA does not impose any restrictions on the functional form with respect to the frontier technology and the efficiency term, which is of particular importance when analyzing the performance of 'non-profit' organizations for which a well defined microeconomic objective function may not exist (Worthington, 2001). DEA only requires the output possibility set to be convex and monotone (Gong and Sickles (1992)). Comparing SFA and DEA, Gong and Sickles (1992) find that the performance of SFA depends crucially on the functional form assumptions regarding the underlying technology and that in case of a severe functional form misspecification, DEA 
is outperforming SFA. Furthermore, DEA allows the estimation of production frontier functions based on multiple outcomes in the case that the units of observation have multidimensional objectives. In DEA, efficiency of one unit is determined relative to the efficiency of all the other units in the sample. Efficient units lie on the production frontier and receive a score of one when there is no convex linear combination of other units that produce more output with the same amount of input factors. Units below the frontier function are regarded as technically inefficient and receive a score less than one. An important point emphasized by Sheldon (2003) is that efficient units in DEA may lack comparable units ('peers') and may therefore not serve as role models. The linear programming technique might then produce efficient units simply because of their uniqueness in the sample, possibly being oversensitive to outliers (Worthington, 2001). Addressing some of these problems, Sheldon (2003) eliminates the efficient unit from the reference group and computes a further score for efficient units based on 'second-best performers'. Another disadvantage of DEA is that it is a purely deterministic method.

Sheldon (2003) and Vassiliev et al. (2006) employ DEA to analyze the efficiency of regional employment offices for Switzerland. The two studies differ strongly in the specification of the frontier function. This refers mainly to the exogenous factors, like local environmental determinants, and to endogenous input factors such as the number of job counselors per employment office. Sheldon (2003) uses a two-step procedure. First, the relative matching efficiency of Swiss placement offices is measured using DEA, focusing solely on 'non-discretionary' factors (besides stocks of unemployed and vacancies, shares of unemployment composition with respect to age, gender, education etc.). Second, the estimated relative efficiency is regressed on 'discretionary' factors that are under the control of the employment office (e.g. number of job counselors, administrators, sanctioning actions per unemployed). The results suggest that Swiss regional employment offices reach only two thirds of their efficiency potential and that counseling is more effective to increase matching efficiency relative to other active labor market policies. Vassiliev et al. (2006) also use a two-step procedure, but proceed in a different way. The authors distinguish between two types of inputs - outcome variables that have to be optimized and resources of the employment office. First, only input factors that are under the control of the employment office are included. Second, the estimated efficiency scores are regressed on exogenous variables characterizing the local labor market situation. The estimated residuals from this regression are interpreted as residual efficiency scores measuring managerial performance. The study finds that regional labor market characteristics are 
significant determinants of the hiring rate and that there is significant scope for improving matching efficiency. However, neither of the studies account for possible spillover effects across regions.

While DEA and SFA attempt to estimate the efficiency relative to a fully specified production process, Blien et al. (2010) pursue a more modest goal. The study implements a cluster analysis of labor market regions, thus providing a benchmark based on similar regions. Specifically, the authors identify different types of labor market regions in Germany, where the spatial entities are represented by administrative units of the Federal Employment Service. Blien et al. (2010) use a two-step procedure, which results in a fixed predetermined number of groups (clusters) of regions. First, a regression estimating a matching function identifies significant exogenous determinants of the hiring rate and, subsequently, these determinants are weighted by their corresponding t-statistics. Second, the different groups of the labor market regions are identified by means of a clustering algorithm. This is based on the Euclidean distance in the weighted labor market characteristics which has been identified in the first step. The goal is to identify groups of regions with a high degree of homogeneity in exogenous labor market characteristics within the group. Blien et al. (2010) present results for 12 and 5 clusters, respectively, the so-called Comparison and Strategy types. The study does not provide a region specific comparison level, but a comparison to the mean outcome within the cluster is possible. The outcomes within a cluster provide an important benchmark in the controlling practice of the Federal Labor Agency (Bundesagentur für Arbeit) in Germany. Despite its usefulness, the approach has some disadvantages. First, Blien et al. (2010) determine the number of clusters a priori. Second, the outcome variable plays no role for the cluster analysis in the second step. Only the first step provides the link to the outcome variable when identifying the variables used in the cluster analysis. Third, Blien et al. (2010) do not take account of possible spillover effects across regions. Nevertheless, the estimated clusters often involve adjacent regions because of the similarity in observed characteristics.

\section{New Benchmarking Approach}

\subsection{Conceptual Idea}

Our benchmarking approach builds upon the matching function

$$
H=A(w) \cdot f(U, V, \tilde{x}),
$$


where hirings (outflows) from unemployment into regular employment $H$ are a function of the stock of unemployed $(U)$, the stock of vacancies $(V)$, and the efficiency parameter $(A(w))$. Furthermore, the matching function depends upon observables $\tilde{x}$ and unobservables $w$. The variables $\tilde{x}$ are intended to capture differences in regional and labor market characteristics like changes in the labor force composition or changes in the local economic structure. The variables $\tilde{x}$ also capture spillover effects from adjacent regions (e.g. working through the values of $U$ or $V$ in adjacent regions). We define the vector of labor market characteristics $x \equiv(U, V, \tilde{x})$ as the vector of all covariates considered in equation (1). $x$ may involve lagged values of some variables. Analogous to Sheldon (2003) or Blien et al. (2010), we make the assumption that regions share a common matching technology but we remain agnostic regarding the precise functional form. Our benchmarking concept estimates the residual efficiency $A(w)$ in each region after controlling for interregional differences in observed characteristics. It should be noted that the residual efficiency term depends on the unobservable variables $w$ and on random noise. The variables $w$ might reflect the endogenous activities of the local labor agencies as well as unobserved determinants. In our benchmarking analysis, the outcome variable of interest is the hiring rate among the unemployed $(Y=H / U)$, see section 4 for the data.

The conceptual idea of our benchmarking approach is to estimate in a flexible, nonparametric way the counterfactual distribution of outcomes $Y_{r t}$ in region $r$ at time $t$ based on data for all other regions. The approach accounts both for similarity in exogenous labor market characteristics and for geographic proximity in order to identify comparable regions which serve as benchmark for region $r$. We argue that it is important to account both for labor market characteristics and geographic proximity because labor markets with similar characteristics are likely to show similar outcomes. Results in the existing literature also suggest that regions in closer geographical proximity share similar regional characteristics (Blien et al. (2010)). Thus, the geographical distance may serve as a proxy for unobserved labor market determinants. Furthermore, interregional dependencies (e.g. in form of interactions between different local institutions) and spillover effects may be limited by geographical distance, and they are expected to be much stronger for adjacent areas. More importantly, an unemployed person will be more likely to find a job in a region that is in the neighborhood to his/her region of residence, simply because of lower mobility and opportunity costs arising from spatial proximity. In contrast to the approach by Blien et al. (2010), who classify regions into a small number of groups, our benchmarking estimates are smooth functions in the variables considered, thus implying 
a region specific group of comparable (not necessarily equally weighted) regions.

The estimation of the conditional distribution of $Y$ based on comparable regions - we denote this by conditioning on covariates $x_{r t}$ - allows to measure the conditional quantile position for each region $r$ at time $t, Q P\left(y_{r t} \mid \mathbf{x}_{r t}\right)$, based on the actual performance $y_{r t}$. This measure ranks each region based on the counterfactual distribution of labor market outcomes, thus providing a relative performance indicator and reflecting the relative scope for improvement. When $Q P\left(y_{r t} \mid \mathbf{x}_{r t}\right)$ is equal to $50 \%$, the region is a median performer, i.e. half of the comparable regions show a better performance and half of them show a worse performance. Regions with a quantile position at the top of the distribution, $Q P\left(y_{r t} \mid \mathbf{x}_{r t}\right)>>50 \%$, considerably outperform the reference group, whereas quantile positions at the bottom, $Q P\left(y_{r t} \mid \mathbf{x}_{r t}\right)<<50 \%$, show a clear underperformance. Our benchmarking approach allows for a ranking of regions regarding their relative performance. Our final results display regions with low ranks and others with high ranks. In addition to the rank measures, we could use the conditional expectation or conditional quantiles of the counterfactual distribution to provide reference points for an absolute performance indicator.

\subsection{Formal Description}

Assume that $N$ is the number of regions in the sample with $r=1, \ldots, N$ and $j \in N_{-r} \equiv$ $\{1, \ldots, N\} \backslash r$, i.e. $N_{-r}$ refers to the set of the first natural numbers up to $N$ without $r$. Let $Y_{r t}$ be the random outcome variable and $y_{r t}$ the actual observed value in region $r$ at time $t$, with $t=1, \ldots, T$. The estimation of the expected conditional quantile position of region $r$ at time $t$ is based on a Nadaraya-Watson kernel regression of a dummy variable $I\left(y_{j t} \leq y_{r t}\right)$ on the vector of labor market characteristics $\mathbf{x}_{r t}$ and spatial proximity of regions, for all $j \neq r$. The conditional quantile position is estimated by

$$
\widehat{Q P\left(y_{r t} \mid \mathbf{x}_{r t}\right)}=\sum_{j \in N_{-r}} w(j, r, t) I\left(y_{j t} \leq y_{r t}\right)
$$

where $I(\cdot)$ denotes the indicator function taking the value of 1 , if $y_{j t} \leq y_{r t}$, and 0 otherwise. $w(j, r, t)$ represents the weight function measuring the similarity of region $j \in N_{-r}$ to region $r$. Analogous to a kernel-based matching approach in the program evaluation literature (Imbens, 2004), the weights are defined based on the kernel function $K(\cdot)$ as

(3) $\quad w(j, r, t)=\frac{K(j, r, t)}{\sum_{j \in N_{-r}} K(j, r, t)}$. 
The weights $w(j, r, t)$ account for the similarity of regions with respect to labor market characteristics and spatial proximity. The two dimensions are captured by a twodimensional product kernel $K(\cdot)$. Using a leave-one-out estimation approach, we exclude region $r$ from the estimation of the counterfactual. The definition in equation (3) ensures that the weights $w(\cdot)$ sum up to one when region $r$ is omitted.

We implement the following two alternative definitions of the kernel function regarding spatial proximity:

(4a) $K(j, r, t)=\exp \left[-\frac{D_{\mathbf{x}}}{h_{m}^{2}}\right] \cdot \exp \left[-\left(\frac{d_{j, r}}{h_{d}}\right)^{2}\right]$ and

$$
K(j, r, t)=\exp \left[-\frac{D_{\mathbf{x}}}{h_{m}^{2}}\right] \cdot\left[1+\left(\frac{r p_{j, r}}{h_{d}}\right)^{2}\right] .
$$

In both cases, the first dimension containing $D_{\mathbf{x}}$ captures regional differences in labor market characteristics. The second dimension reflects the spatial proximity. In equation (4a), spatial proximity is measured by the geographical distance $d_{j, r}$ and a Gaussian kernel function is used to downweight regions with a large spatial distance. Equation (4b) uses relative commuting flows $r p_{j, r}$ from region $j$ to region $r$. When commuting flows are zero $\left(r p_{j, r}=0\right)$, the specification in equation $(4 \mathrm{~b})$ implies that regions are only compared with regard to $D_{\mathbf{x}}$.

To account for differences in observable labor market characteristics, we implement in equations $(5 \mathrm{a})-(5 \mathrm{~d})$ four different distance measures $D_{\mathbf{x}}$ proposed in the literature (Imbens, 2004).

$$
D_{M, \mathbf{x}}=\left(\mathbf{x}_{j t}-\mathbf{x}_{r t}\right)^{\prime} \widehat{V}_{\mathbf{x}}^{-1}\left(\mathbf{x}_{j t}-\mathbf{x}_{r t}\right)
$$

$$
D_{A I, \mathbf{x}}=\left(\mathbf{x}_{j t}-\mathbf{x}_{r t}\right)^{\prime} \operatorname{diag}\left(\widehat{V}_{\mathbf{x}}^{-1}\right) \cdot\left(\mathbf{x}_{j t}-\mathbf{x}_{r t}\right)
$$

$$
D_{Z, \mathbf{x}}=\sum_{k=1}^{K}\left(x_{k j t}-x_{k r t}\right)^{2} \cdot \hat{\beta}_{k}^{2}
$$

$$
D_{I, \mathbf{x}}=\left(\mathbf{x}_{j t}-\mathbf{x}_{r t}\right)^{\prime}\left(\hat{\beta}_{\mathbf{x}} \hat{\beta}_{\mathbf{x}}^{\prime}+\sigma_{R}^{2} \widehat{V}_{\mathbf{x}}^{-1} / N\right)\left(\mathbf{x}_{j t}-\mathbf{x}_{r t}\right)
$$

Equation (5a) defines the Mahalanobis distance to measure the similarity in labor market characteristics. The widely used Mahalanobis distance uses the inverse of the variance-covariance matrix in the $\mathrm{x}$-vector, $\widehat{V}^{-1}$, to standardize the differences in the 
covariates. Imbens (2004) points out that the Mahalanobis distance can produce bad matches when the correlation between the $\mathbf{x}$-variables in the sample is high. To overcome this problem, Abadie and Imbens (2006) propose to use merely the diagonal matrix of the inverse of the variances of the covariates to standardize regional differences, as displayed in equation (5b) and henceforth denoted as AI-distance.

Both the Mahalanobis distance and the AI-distance have the drawback that all covariates receive the same weight, irrespective of their importance for predicting the outcome variable. This point is addressed by Zhao (2004), who focuses on the useful information contained in the covariate with regard to the explaining outcome variable. Zhao proposes to minimize the sum of the absolute deviations in the $\mathbf{x}$-variables, weighted by their coefficient in the regression of the outcome variable on $x$. As a modified version of Zhao's distance measure, equation (5c) involves the squared deviations weighted by the squared coefficients - this modification simplifies the cross-validation procedure described below. Imbens (2004) suggests that the optimal distance measure involves a combination of the sample variance-covariance matrix and the outer product of regression coefficients obtained from the outcome regression. This is the fourth alternative considered in equation (5d), where $\sigma_{R}^{2}$ denotes the squared standard error from the outcome regression. As a caveat, note that the third and the fourth alternative result in biased estimates of the counterfactual outcomes, in the case that the outcome regression is misspecified (Imbens, 2004).

The weight function $w(\cdot)$ depends on two unknown bandwidth parameters $h_{m}$ and $h_{d}$. $h_{m}$ concerns the similarity of regions regarding labor market characteristics and $h_{d}$ concerns the spatial proximity. A small value for a bandwidth implies that only a small number of close neighbors in the corresponding dimension can be used as the comparison group, while a large value implies that also distant regions are in the comparison groups. We suggest to choose optimal bandwidths based on a "leave-one-out cross validation" approach, which minimizes the squared prediction error in the outcome variable $y_{r t}$. Formally, we suggest to minimize

$$
\left[\hat{h}_{m}, \hat{h}_{d}\right]=\underset{h_{m}, h_{d}}{\arg \min } C V\left(h_{m}, h_{d}\right)=\frac{1}{N \cdot T} \sum_{r=1}^{N} \sum_{t=1}^{T}\left(y_{r t}-\hat{y}_{-r t}\left(\mathbf{x}_{r t}\right)\right)^{2}
$$

with respect to $h_{m}$ and $h_{d}$. Here, $\hat{y}_{-r t}\left(\mathbf{x}_{r t}\right)$ denotes the Nadaraya-Watson estimator of $y_{r t}$ when region $r$ is omitted. Our implementation chooses the same optimal smoothing parameters for the entire sample period $t=1, \ldots, T$. The objective function measures the mean squared error (MSE) of the prediction based on the comparable regions and the 
optimal smoothing parameters are chosen such that the benchmark regions, defined by the implied weighting scheme (equations $4 \mathrm{a}$ and $4 \mathrm{~b}$ ), allow for an optimal prediction of the outcome variable. Subsequently, we use the same bandwidths to estimate the conditional quantile position for each region.

The entire estimation approach is carried out using the econometric software package TSP Version 5.0. The optimal bandwidth parameters are determined by numerical optimization. First, we undertake a fine grid search to determine good starting values. Then, we use gradient based iteration methods (using the ML procedure in TSP). The robustness of the bandwidth choice is examined by means of alternative starting values. We only report the estimation results based on the optimal bandwidths.

\section{Data and Descriptive Statistics}

The German Federal Employment Agency (FEA) involves 178 regional employment offices (Arbeitsagenturen). These are the lowest regional units in the FEA organization with local policy authority and executive functions. The labor market reforms during the years 2002 to 2005 changed the organizational structure of the FEA (Jacobi and Kluve, 2007). These changes involved some decentralization of the decision-making process and a re-organization of the regional employment offices. The goals of the reforms were to improve the effectiveness of placement services and to increase the efficiency of the FEA. Furthermore, the reforms attempted to increase the transparency through the introduction of results-based accountability and controlling measures.

Our study uses panel data for 176 regional employment offices, as our labor market regions, during the time period from 2006 to 2008. Because of large commuting flows and the reorganization over time, we merge the three employment offices in Berlin into one region. The data set consists of quarterly averages, involving a total of $2112(\equiv 176 \times 12)$ observations. The data are provided by the Institute for Employment Research (IAB) in Nuremberg.

The outcome variable of interest is the six-months rate of hirings into non-subsidized employment. It is defined as the number of unemployed people entering into a nonsubsidized employment for more than six months relative to the stock of unemployed in the SGB III. ${ }^{2}$ The hiring rate among the unemployed is a useful outcome variable in light

\footnotetext{
${ }^{2}$ Unemployed who receive benefits or services based on the Book III of the Social Code in Germany. These are typically individuals who have been unemployed for at most 12 months (or a period of at most
} 
of the aforementioned matching function approach. In addition, increasing the hiring rate is generally considered to be a key goal of employment offices (Sheldon, 2003) and labor market policy in general (Blien et al., 2010). Increasing the hiring rate can be considered as one of the most direct ways for an employment agency to reduce unemployment and to shorten the average duration of unemployment spells (Vassiliev et al., 2006).

To account for spatial proximity, we use data on the geographical distance between the labor market regions (measured in $\mathrm{km}$ ) and on rates of commuting flows calculated relative to the stock of employees at the place of work. The commuting flow data are available on an annual basis for the years 2006, 2007, and 2008. Both alternatives lead to the construction of a symmetric spatial weighting $176 \times 176$ matrix with zeroes on the main diagonal.

Labor market regions differ strongly regarding their labor market characteristics, which provides the setting under which employment offices operate. These labor market characteristics are therefore likely to affect the regional hiring rate. We take account of labor market characteristics that are, at least in the short run, exogenous for the activities of the regional employment office. The variables considered include the unemployment rate in the region, the labor force composition with respect to gender, education, and industry, degree of tertiarization, average wages, seasonal span (maximal seasonal difference) of unemployment, and population density. In addition, the share of non-subsidized vacancies relative to the number of unemployed in the corresponding region is used as a proxy for the regional labor market tightness. Moreover, the average regional separation rate is approximated by using the proportion of individuals entering unemployment for a given period of time. Unfortunately, we can not distinguish whether the unemployed enter from former employment or from out-of-labor-force.

Table 1 (Appendix A) reports descriptive statistics of the outcome variable and the labor market characteristics used in the analysis. Over the entire period (2006-2008), the average hiring rate among the unemployed is $11.9 \%(12.1 \%$ in West and $11.1 \%$ in East Germany, respectively). The lowest value is found for Sangerhausen (5.2\% in 4th quarter 2006 ) and the highest value for Passau (44.8\% in 2nd quarter 2006). On average, the hiring rate amounts to $10.8 \%$ in $2006,12.3 \%$ in 2007 , and $12.5 \%$ in 2008 . In addition, there are noticeable cyclical fluctuations in the outcome variable with the maximum value always observed for the 2nd quarter of a year.

24 months for older unemployed). 


\section{Results}

\subsection{Regression Analysis}

The first step of our benchmarking approach determines the regional labor market characteristics which are relevant for the outcome variable of interest. The specification of the regression follows a matching function approach. We pool all 2112 region-period observations and regress our outcome variable, the hiring rate, on a number of labor market characteristics. Furthermore, the specification involves quarterly dummies to control for seasonality. For the subsequent analysis, we calculate the performance measures for the quarterly data, but then only report annual averages. We consider two alternative model specifications: regression (1) represents the local economic and industry structure by employee shares, whereas regression (2) uses the degree of tertiarization described by the fraction of employees in the service sector. Our regressions are descriptive and they do not necessarily estimate causal effects. Their purpose is to identify labor market characteristics, which we think are exogenous (at least in the short run) and which have predictive power for the outcome variable of interest.

Table 2 (Appendix A) reports the results from pooled OLS regressions. It turns out that the estimated coefficients have the expected sign, in accordance with the results in Blien et al. (2010). For example, the unemployment rate, the proportion of females among the unemployed and employed, respectively, the relative unemployment inflow, and the log average wages show a negative association with the hiring rate. A positive association is found for the relative vacancy rate and the seasonal span of unemployment. Based on Wald tests for joint significance, we conclude from regression (1) that the labor force composition with respect to education and industry is significantly associated with the hiring rate. However, regression (2) does not yield significant results for education. We therefore exlude education in the subsequent matching analysis. Two further covariates prove to be insignificant - the East-West dummy and the population density. Despite these results, we consider the two variables to be important labor market characteristics and therefore we include them in the subsequent matching analysis.

\subsection{Comparison of Regions and Bandwidth Choice}

Based on matching with respect to the relevant labor market characteristics, we now determine the optimal bandwidth parameters which are need for the specification of the weight function. The cross-validation procedure is implemented both for the variables 
from regression (1) and regression (2).

Table 3 (Appendix A) reports the results from the cross-validation procedure for various specifications of the weighting function and summarizes the optimal bandwidths, the corresponding MSE, and the number of iterations required for convergence. To scrutinize the bandwidth choice by means of a detailed sensitivity analysis, we implement the following four specifications:

a) Regions are compared with each other only in terms of labor market characteristics (second term in equations (4a) and (4b) is omitted),

b) in addition to a), spatial proximity is taken into account and is measured by geographical distance,

c) in addition to a), spatial proximity is taken into account and is measured by the logarithm of geographical distance, and

d) in addition to a), spatial proximity is taken into account and is measured by relative commuting flows.

The results in Table 3 suggest that the specifications with the log geographical distance produce the lowest MSE, irrespective of the selected set of labor market characteristics ( $\mathbf{x}$-variables) and the distance measure for $\mathbf{x}$ used. Table 3 also shows that the specification that ignores spatial proximity and compares regions only in terms of labor market characteristics is associated with a higher MSE compared to the other alternatives. This means that spatial proximity is important when matching regions - however, this only holds for geographical distance but not for commuting flows. With regard to the distance measures capturing differences in the labor market characteristics, a considerable improvement in the MSE criterion is achieved using the modified Zhao distance. Small differences are typically found between regression (1) and regression (2). Except for the results based on the Mahalanobis distance, the MSE is always lower for regression (1) than for regression (2).

The results in Table 3 show that the smallest MSE is obtained for the modified Zhao (2004) distance using the variables in regression (1) and the log geographic distance (this case is printed in bold face). For this specification, the cross-validation procedure determines the following bandwidths: $\widehat{h_{m}}=0.0088495$ and $\widehat{h_{d}}=2.59543$, with MSE $=$ $1.6536 \cdot 10^{-4}$. Unless stated otherwise, the results discussed in the following are based on this specification and the two associated optimal bandwidth parameters. 
To investigate further whether the selected bandwidth parameters represent the global minimum within the plausible range of values, we plot the MSE for different bandwidth values in both dimensions (see Figure 1, Appendix B). ${ }^{3}$ The graph to the left (to the right) in Figure 1 shows the shape of the cross-validation function for varying bandwidths of the spatial (statistical) distance for a given optimal value of the other bandwidth, i.e. $\widehat{h_{m}}=0.0088495$ and $\widehat{h_{d}}=2.59543$, respectively. In both dimensions, the MSE function proves to be strictly convex. This suggests that the proposed two-dimensional crossvalidation procedure in fact detects the global optimum.

\subsection{Spatial Distribution of Benchmark Weights}

Our analysis estimates a benchmark of similar regions at any given point in time, where the benchmark is defined by means of the implied weighting scheme. Now, we address the following two questions: First, how does the spatial distribution of benchmark weights look like? Second, is the composition benchmark group composition stable or does it change over time? Figures 2.1 to 2.176 in Online Appendix C provide evidence to address these two questions. ${ }^{4}$ Each figure refers to one region $r$ and shows the implied weighting for the three years 2006, 2007, and 2008. Each map represents the spatial distribution of the average normalized weights $w(j, r, t)$ for regions $j \neq r$ in one year. The normalized weights define the comparison group and correspond to the weight of a region $j$ in the benchmark for region $r$. The size of the weights is expressed by different shades of colors. Region $r$, for which the benchmark is estimated for, is represented by a right-angled grid. Regions with the highest weights are filled up with straight lines, while regions not in the benchmark group or with very low weight values are colored in white. Regions with a weight lower than 0.9 are marked by different shades of colors, with the color getting lighter the lower the weight.

The evidence in Online Appendix $\mathrm{C}$ yields the following general findings:

- For almost all regions in Germany, the benchmark with the highest weight lies in close proximity (see e.g. the central part of Lower-Saxony, the Ruhr area, and some part of Southern Germany). This is evidence for the existence of spillover effects

\footnotetext{
${ }^{3}$ The plausible range of values excludes small bandwidth values for whom underflow problems arise when calculating the weighting function.

${ }^{4}$ Because of the large file size, the Online Appendix $\mathrm{C}$ only presents results for selected regions http:// www.empiwifo.uni-freiburg.de/discussion-papers-1. Results for the omitted regions are available upon request.
} 
between adjacent regions. However, the maps also show that the weights are also driven by the similarity in labor market characteristics. The last point is particularly important in the case of large cities or metropolitan areas like Hamburg, Bremen, Hannover, Düsseldorf, Frankfurt, Cologne, and Munich. This suggests that large cities should be compared with large cities only (though the small weights suggest that the comparability of the benchmark regions is often small in thess cases) and not with adjacent rural regions. The latter finding is in accordance with the results in Blien et al. (2010).

- Regarding the importance of labor market characteristics, our results are driven by the distance measure used. To confirm this, Online Appendix $\mathrm{D}^{5}$ shows the regional distribution of weights based on different distance measures for selected cases. It turns out that the modified Zhao distance and the AI-distance lead to similar results. The weights estimated with the Mahalanobis distance and the Imbens (2004) measure, however, are more strongly driven by geographic proximity.

- The maps suggest that a stable benchmark group can be found for most of the regions because we observe only slight changes of the weights over time. Furthermore, most of the changes in weights refer to benchmark regions with a weight lower than 0.1 .

- The region-specific benchmarks differ regarding two aspects, namely the number of regions in the benchmark group (group size) and the strength of the benchmark weights. We both find cases with a small benchmark group size and relatively large weights (one weight larger than 0.5 ) and cases with a large benchmark group size and relatively small weights (less than 0.1 )

- With the exception of Dresden and Potsdam, East German regions are benchmarked by East German regions. Furthermore, for West German regions at the border to East Germany, there are no comparable regions in East Germany. This result mainly reflects differences in the prevailing labor market characteristics.

In addition to the spatial distribution of benchmark weights, Tables 4 to 6 (Appendix A) show the ranking of the five nearest neighbors (as defined by the statistical distance measure) and their corresponding normalized weights. The last column reports the share of weights among the five nearest neighbors in the benchmark group - these are the five

\footnotetext{
${ }^{5}$ See http://www.empiwifo.uni-freiburg.de/discussion-papers-1.
} 
most comparable regions. We find that this share varies considerably from one region to another region and that it mostly takes values larger than $50 \%$. These results suggest that a small benchmark group of regions can be identified for most cases.

The results so far indicate that the benchmark groups differ considerably with respect to size and similarity of the benchmark group. We analyze this further by calculating for each region $r$ the average of the total absolute values of the kernel function of equation (4a) over the entire period of 12 quarters $\left(1 / 12 \sum_{t=1}^{12} \sum_{j \in N_{-r}} K(j, r, t)\right)$. We use this as an absolute measure of similarity of the benchmark group. Figure 3 (Appendix B) shows that regions with a relatively low similarity of the benchmark group are located in the North-East and the South-East of Germany. In addition, regions in Bavaria as well as large cities and metropolitan areas are also only partially comparable with other regions. On the other hand, the total sum of absolute weights proves to be substantially higher in West and Northwest Germany, in particular in the Ruhr area.

\subsection{Quantile Position as a Relative Performance Indicator}

Based on the optimal specification of the weighting function, we now estimate the conditional quantile position for each region and determine subsequently its performance relative to its benchmark group. The variance of estimated quantile positions is calculated in a first approximation based on the Bernoulli distribution and is given by

$$
\left.\operatorname{Var}\left(Q \widehat{P\left(y_{r t} \mid \mathbf{x}_{r t}\right.}\right)\right)=\sum_{j \in N_{-r}} w^{2}(j, r, t) \cdot \hat{F}_{j}\left(y_{r t}\right) \cdot\left(1-\hat{F}_{j}\left(y_{r t}\right)\right)
$$

where $\hat{F}_{j}\left(y_{r t}\right)$ is the estimated cumulative distribution function of the outcome in region $j$ based on the outcome in region $r .{ }^{6}$ This variance estimate only reflects the uncertainty in estimating the quantile position based on the counterfactual outcome distribution for given weights (note that the weights are normalized to sum up to one). It would be computationally infeasible to account for the estimation error in the weights.

We present the estimated quantile positions and their standard errors as annual averages. For each region, we report the estimated quantile positions and their standard errors, in Table 7 for 2006, in Table 8 for 2007, and in Table 9 for 2008 (Appendix A). In addition, Figure 4 (Appendix B) sorts the 176 regions according to their quantile position. The dotted lines represent the $90 \%$ confidence bands and demonstrate the reliability of

\footnotetext{
${ }^{6}$ More formally, $\hat{F}_{j}\left(y_{r t}\right)=\frac{\sum_{j, l \in N_{-r}} K(j, l, t) \cdot I\left(y_{l t} \leq y_{r t}\right)}{\sum_{j, l \in N_{-r}} K(j, l, t)}$. It means that 175 values are calculated for each region $r$ reflecting a total of 30,800 estimates.
} 
the estimator. Quantile positions of less than 20\% indicate a rather poor performance, i.e. these regions perform worse than $80 \%$ of their corresponding benchmark group. Correspondingly, the regions with a quantile position of more than $80 \%$ can be viewed as 'best-practice' regions. The performance of these regions in terms of the hiring rate lies above the performance of $80 \%$ of the comparable regions.

Figure 5 (Appendix B) shows the spatial distribution of the quantile positions. The quantile positions are classified into four groups and marked by different shades of colors. The 'best-practice' regions are grey, whereas the weakest performers are colored white. Blue refers to a relatively good and green to a relatively weak performance, respectively. Figure 5 shows the following general findings: (1) Regions in the upper and lower part of the outcome distribution are located mostly at state borders (Bundeslandsgrenze). (2) Based on the four classified groups, $56.8 \%$ of the regions do not change the group over time. Stability of the group is mainly observed for regions in East Germany, major parts of Bavaria, and in regions at the national border. (3) For 34 regions (19.3\%), we observe an improvement in the quantile position by one group from 2006 to 2008, whereas a deterioration by one group is found for 36 regions (20.5\%). These are primarily regions within Baden-Württemberg, Saarland, Rheinland-Pfalz, and Hesse. Recall that such changes often reflect changes relative to geographically adjacent regions.

\subsection{Matching Quality}

The benchmark group should be comparable with the region to be benchmarked regarding the labor market characteristics considered. We now investigate the quality of the matching of the labor market characteristics (x-variables) based on normalized absolute differences

$$
\operatorname{diff} s_{x_{r}}=\frac{1}{T} \sum_{t=1}^{T}\left|\frac{x_{r t}-\hat{x}_{-r t}}{\sigma_{x_{t}}}\right| \quad \text { with } \quad \hat{x}_{-r t}=\frac{\sum_{j \in N_{-r}} K(j, r, t) \cdot x_{j t}}{\sum_{j \in N_{-r}} K(j, r, t)},
$$

where $\sigma_{x_{t}}$ denotes the sample standard deviation of explanatory variable $x$ at time $t$. $\operatorname{diff} s_{x_{r}}$ is calculated for each region $r$ as a sample average over the entire sample period and shows the standardized absolute difference between observed and estimated values based on the benchmark group. Analogous to equation (6), $\hat{x}_{-r t}$ is the Nadaraya-Watson estimator of $x_{r t}$, where region $r$ is not taken into account when $x_{r t}$ is estimated for that region. We use the rule of thumb, that a mismatch in variable $x$ for region $r$ still exists after matching when $\operatorname{diff} s_{x_{r}} \geq 1.645$, i.e. when the average standardized difference between 
observed and estimated value in variable $x$ for that region exceeds the $90 \%$ critical value of the standard normal distribution.

Table 10 (Appendix A) presents descriptive statistics of the standardized differences of the set of covariates used in regression (1). The distribution of this mismatch indicator turns out to be strongly skewed to the right. In addition, the upper decile (90\%-percentile) always takes values less than 1.645, i.e., a mismatch in one labor market determinant is observed only for at most $10 \%$ of all regions. In fact, the number of regions with a mismatch in labor market characteristics is much smaller and varies between 1 (e.g. population density) and 10 (share of employees in the mining sector). No mismatch was found for a total of 7 explanatory variables - unemployment rate, average wages, and seasonal span of unemployment among others. Based on these results, we conclude that the $\mathbf{x}$-variables are well balanced by our nonparametric matching approach, i.e. the implied benchmark groups are highly comparable with the region to be benchmarked.

\subsection{Absolute Performance}

As the final part of our analysis, we estimate the absolute performance of a region relative to its benchmark group. This allows us to assess the possible absolute scope for improvement and deterioration in the outcome variable. ${ }^{7}$ For region $r$, the absolute performance is estimated as a difference between the observed outcome in that region and a reference point from the counterfactual outcome distribution. As our reference point, we use the median, which is estimated nonparametrically by means of a leave-one-out weighted median regression. Then, the absolute performance is given by

$$
A \widehat{P\left(y_{r t} \mid \mathbf{x}_{r t}\right)}=y_{r t}-Q_{\hat{Y}_{-r t}}\left(1 / 2 \mid \mathbf{x}_{r t}\right)
$$

where $Q_{\hat{Y}_{-r t}}\left(1 / 2 \mid \mathbf{x}_{r t}\right)$ represents the $50 \%$ quantile of the conditional outcome distribution. We apply the same weighted scheme as used for the calculation of conditional quantile positions. Consequently, the absolute performance indicator measures the deviations of the actually observed outcome of the labor agency in region $r$ at time $t$ from the estimated median outcome based on similarity in labor market characteristics and spatial proximity. Negative values indicate an underperformance, whereas positive values reveal overperformance. Analogous to the quantile positions, we estimate absolute performance for each quarter separately, but report only annual averages (see Table 11 (Appendix A)).

\footnotetext{
${ }^{7}$ We thank Joachim Möller for his suggestion to measure absolute performance as part of our analysis.
} 
Figure 6 (Appendix B) shows the spatial distribution of absolute performance for the years 2006 to 2008 . The indicator is grouped into five classes depicted by different shades of colors, with the color getting darker the better the performance. Compared to the results based on the quantile positions, the absolute performance measure shows a rather moderate change over time and stronger spatial dependency. Figure 7 reveals that almost half of the regions have an absolute performance of up to +/- half a percentage point (ppoint), i.e. the observed outcome differs by at most half a ppoint from the median of the counterfactual outcome distribution. In addition, the maps show that the extreme values in the conditional outcome distribution mostly reflect strong negative spatial dependencies. Basically, regions with a strong overperformance (a hiring rate of more than one ppoint above the estimated median) are located at the national border - and these regions are probably affected by regions across the border. Considering the development of the spatial distribution of absolute performance over time, we observe an improvement for a number of East German regions. In contrast, we find a deterioration of absolute performance in some other parts of Germany, e.g. in the Ruhr area.

\section{Conclusions}

This study proposes a new benchmarking approach to assess the labor market performance of a region. The approach uses nonparametric matching techniques without having to specify the entire production process. We suggest to estimate the conditional quantile position of a region as a relative performance measure based on the counterfactual conditional distribution of outcomes for a group of comparable regions. The similarity of regions is measured both in terms of exogenous labor market characteristics and spatial proximity. We implement different similarity measures capturing the heterogeneity in labor market characteristics, and we use two alternative definitions for spatial proximity. The new benchmarking approach is applied to 176 labor market regions in Germany for the period of 2006 to 2008. Our outcome variable of interest is the hiring rate among the unemployed. We implement a leave-one-out cross-validation procedure to choose the values of the bandwidth parameters. The results show that controlling for the labor market characteristics as well as for spatial proximity is quite important. The implied benchmark groups of similar regions and the estimated relative and absolute performance measure remain quite stable over time. The examination of the matching quality shows only a negligible number of cases with a mismatch in some of the labor market characteristics 
considered.

Benchmarking labor market regions is a useful tool for identifying 'best practices' as well as low matching efficiency in the labor market. The proposed approach satisfies this purpose by ranking each labor market region relative to the counterfactual distribution of outcomes based on comparable regions. However, our approach does not assess the reasons for the estimated performance measure. Thus, the approach presented here can be seen as a first step in evaluating the matching efficiency of labor market regions. Similar to Sheldon (2003), a next step could be to regress the estimated performance measure (relative or absolute) on factors that are under the control of the decision makers in the region (e.g. the employment office). This would shed more light on the determinants of the ranking of regions.

\section{References}

Abadie, A. and G. W. Imbens (2006). Large Sample Properties of Matching Estimators for Average Treatment Effects. Econometrica 74(1), 235-267.

Battese, G. and T. Coelli (1995). A Model for Technical Inneficiency Effects in a Stochastic Frontier Production Function for Panel Data. Empirical Economics 20, 325-332.

Blanchard, O. J. and P. Diamond (1989). The Beveridge Curve. Brookings Papers in Economic Activity 1 1, 1-76.

Blien, U., F. Hirschenauer, and P. Van (2010). Classification of regional labour markets for purposes of labour market policy. Papers in Regional Science 89(4), 859-880.

Fahr, R. and U. Sunde (2006). Regional Dependencies in Job Creation: An Efficiency Analysis for Western Germany. Applied Economics 38(10), 1193-1206.

Gong, B.-H. and R. C. Sickles (1992). Finite sample evidence on the performance of stochastic frontiers and data envelopment analysis using panel data. Journal of Econometrics 51, 259-284.

Ibourk, A., B. Maillard, S. Perelman, and H. R. Sneessens (2003). Aggregate Matching Efficiency: A Stochastic Production Frontier Estimation, France 1990-1995. Empirica 31(1), 1-25. 
Ilmakunnas, P. and H. Pesola (2003). Regional Labour Market Matching Functions and Efficiency Analysis. Labour 17(3), 413-437.

Imbens, G. W. (2004). Nonparametric Estimation of Average Treatment Effects under Exogeneity: A Review. The Review of Economics and Statistics 86(1), 4-29.

Jacobi, L. and J. Kluve (2007). Before and After the Hartz Reforms: The Performance of Active Labor Market Policy in Germany. Journal for Labor Market Research 40(1), 45-64.

Moretti, E. (2010). Local Labor Markets. Handbook of Labor Economics 4, Part B, $1237-1313$.

OECD (2000). Disparities in Regional Labor Markets. OECD Employment Outlook Paris, $31-79$.

Petrongolo, B. and C. A. Pissarides (2001). Looking into the Black Box: A Survey of the Matching Function. Journal of Economic Literature 39(2), 390-431.

Pissarides, C. A. (1990). Equilibrium Unemployment Theory. Oxford: Oxford University Press.

Ramirez, J. and A. Vassiliev (2007). An Efficiency Comparison of Regional Employment Offices Operating under Different Exogenous Conditions. Swiss Journal of Economic and Statistics 143(1), 31-48.

Sheldon, G. M. (2003). The Efficiency of Public Employment Services: A Nonparametric Matching Function Analysis for Switzerland. Journal of Productivity Analysis 20, 4970.

Vassiliev, A., G. F. Luzzi, Y. Flückiger, and J. V. Ramirez (2006). Unemployment and employment effices' efficiency: What can be done? Socio-Economic Planning Science 40(3), 169-186.

Worthington, A. (2001). An Empirical Survey of Frontier Efficiency Measurement Techniques in Education. Education Economics 9(3), 245-268.

Zhao, Z. (2004). Using Matching to Estimate Treatment Effects: Data Requirements, Matching Metrics, and Monte Carlo Evidence. The Review of Economics and Statistics 86(1), 91-107. 
Appendix A

Tables 
Table 1: Descriptive statistics (2006-2008)

\begin{tabular}{|c|c|c|c|c|c|}
\hline Variable & Mean & St.dev & Median & Min & Max \\
\hline Rate of integration & 0.1188 & 0.0437 & 0.1082 & 0.0524 & 0.4478 \\
\hline East-West dummy & 0.1989 & 0.3992 & 0.0000 & 0.0000 & 1.0000 \\
\hline Unemployment rate & 0.0992 & 0.0457 & 0.0896 & 0.0235 & 0.2789 \\
\hline \multicolumn{6}{|l|}{ Share of registered unemployed (SGB III) by age } \\
\hline $15-24$ years old & 0.1491 & 0.0296 & 0.1460 & 0.0698 & 0.2641 \\
\hline $25-54$ years old & 0.6739 & 0.0349 & 0.6775 & 0.5283 & 0.7640 \\
\hline $55-64$ years old & 0.1770 & 0.0282 & 0.1759 & 0.1003 & 0.2873 \\
\hline Share of registered female unemployed (SGB III) & 0.5279 & 0.0536 & 0.5272 & 0.3131 & 0.6916 \\
\hline Share of female employed & 0.4517 & 0.0326 & 0.4510 & 0.3628 & 0.5438 \\
\hline \multicolumn{6}{|l|}{ Share of employees by education } \\
\hline Elementary and secondary school (without VT) & 0.1419 & 0.0398 & 0.1463 & 0.0635 & 0.2511 \\
\hline High school without VT & 0.0153 & 0.0078 & 0.0132 & 0.0049 & 0.0449 \\
\hline Elementary school with VT & 0.5811 & 0.0642 & 0.5855 & 0.3836 & 0.7174 \\
\hline High school with VT & 0.0394 & 0.0142 & 0.0360 & 0.0150 & 0.0925 \\
\hline Technical college & 0.0324 & 0.0095 & 0.0307 & 0.0151 & 0.0764 \\
\hline University & 0.0493 & 0.0237 & 0.0427 & 0.0195 & 0.1475 \\
\hline Education unknown & 0.1405 & 0.0403 & 0.1327 & 0.0625 & 0.2756 \\
\hline \multicolumn{6}{|l|}{ Share of employees by sectors (NACE 2003) } \\
\hline Agriculture, hunting and forestry & 0.0140 & 0.0112 & 0.0094 & 0.0021 & 0.0635 \\
\hline Fishing & 0.0001 & 0.0004 & 0.0000 & 0.0000 & 0.0039 \\
\hline Mining and quarrying & 0.0049 & 0.0086 & 0.0020 & 0.0000 & 0.0649 \\
\hline Manufacturing & 0.2714 & 0.0932 & 0.2660 & 0.0873 & 0.5449 \\
\hline Electricity, gas and water supply & 0.0092 & 0.0046 & 0.0081 & 0.0024 & 0.0290 \\
\hline Construction & 0.0634 & 0.0175 & 0.0617 & 0.0281 & 0.1244 \\
\hline Wholesale and retail trade & 0.1485 & 0.0230 & 0.1465 & 0.0939 & 0.2365 \\
\hline Hotels and restaurants & 0.0278 & 0.0120 & 0.0242 & 0.0124 & 0.1108 \\
\hline Transport, storage and communication & 0.0528 & 0.0228 & 0.0473 & 0.0210 & 0.2409 \\
\hline Financial intermediation & 0.0295 & 0.0149 & 0.0259 & 0.0118 & 0.1238 \\
\hline Real estate, renting and business activity & 0.1104 & 0.0411 & 0.0998 & 0.0398 & 0.2571 \\
\hline Public administration and defense & 0.0632 & 0.0193 & 0.0583 & 0.0296 & 0.1552 \\
\hline Education & 0.0370 & 0.0171 & 0.0310 & 0.0123 & 0.0948 \\
\hline Health and social work & 0.1252 & 0.0244 & 0.1236 & 0.0716 & 0.2111 \\
\hline Other community and service activities & 0.0397 & 0.0137 & 0.0378 & 0.0170 & 0.1071 \\
\hline Private households with employed persons & 0.0013 & 0.0006 & 0.0013 & 0.0001 & 0.0054 \\
\hline Others & 0.0008 & 0.0024 & 0.0002 & 0.0000 & 0.0303 \\
\hline Degree of tertiarization & 0.6367 & 0.0890 & 0.6359 & 0.3908 & 0.8525 \\
\hline Flow into unemployment (relative to employed) & 0.0304 & 0.0136 & 0.0269 & 0.0098 & 0.1311 \\
\hline Non-subsidized vacancies (relative to unemployed SGB III) & 0.3315 & 0.2004 & 0.2912 & 0.0209 & 1.7934 \\
\hline Average wages & 80.2236 & 10.1086 & 80.8213 & 56.5464 & 109.8218 \\
\hline Seasonal span of unemployment & 0.1672 & 0.0973 & 0.1434 & 0.0312 & 0.7300 \\
\hline Density of population & 418.72 & 580.66 & 195.28 & 46.0911 & 3849.1543 \\
\hline
\end{tabular}

Notes: Number of observations: 2112; number of regions: 176 . 
Table 2. Results of pooled OLS regression on degree of integration (2006-2008)

\begin{tabular}{|c|c|c|c|c|}
\hline \multirow[b]{2}{*}{ Variable } & \multicolumn{2}{|c|}{ Regression (1) } & \multicolumn{2}{|c|}{ Regression (2) } \\
\hline & Coefficient & St.error & Coefficient & St.error \\
\hline Constant & $0.6697^{* * *}$ & $(0.09249)$ & $0.6747^{* * *}$ & $(0.08773)$ \\
\hline East-West dummy & 0.0058 & $(0.00553)$ & 0.0064 & $(0.00488)$ \\
\hline Unemployment rate & $-0.2527^{* * *}$ & $(0.03294)$ & $-0.1497^{* * *}$ & $(0.03161)$ \\
\hline \multicolumn{5}{|l|}{ Share of registered unemployed (SGB III) by age } \\
\hline 15-24 years old & $-0.2099^{* * *}$ & $(0.03898)$ & $-0.1455^{* * *}$ & $(0.03501)$ \\
\hline $55-64$ years old & $-0.1693^{* * *}$ & $(0.02899)$ & $-0.1439^{* * *}$ & $(0.02528)$ \\
\hline Share of registered female unemployed (SGB III) & $-0.0468^{* *}$ & $(0.01872)$ & $-0.0514^{* * *}$ & $(0.01818)$ \\
\hline Share of female employed & $-0.1272^{* * *}$ & $(0.04676)$ & $-0.0931^{* *}$ & $(0.03710)$ \\
\hline \multicolumn{5}{|l|}{ Share of employees by education $\dagger$} \\
\hline Elementary and secondary school (without VT)) & -0.0560 & $(0.03545)$ & -0.0533 & $(0.03363)$ \\
\hline High school without VT & 0.1956 & $(0.31145)$ & 0.1231 & $(0.33517)$ \\
\hline High school with VT & -0.2355 & $(0.16146)$ & -0.2346 & $(0.17289)$ \\
\hline Technical college & $-0.2075^{*}$ & $(0.11047)$ & -0.1399 & $(0.10474)$ \\
\hline University & -0.0683 & $(0.06046)$ & -0.0344 & $(0.05690)$ \\
\hline Education unknown & 0.0192 & $(0.02962)$ & 0.0085 & $(0.02509)$ \\
\hline \multicolumn{5}{|l|}{ Shares of employees by sectors (NACE 2003) } \\
\hline Agriculture, hunting and forestry & 0.0047 & $(0.11353)$ & & \\
\hline Fishing & $7.1978^{* * *}$ & $(1.58827)$ & & \\
\hline Mining and quarrying & -0.0498 & $(0.06234)$ & & \\
\hline Electricity, gas and water supply & $0.2948^{* *}$ & $(0.14587)$ & & \\
\hline Construction & $0.2768^{* * *}$ & $(0.07179)$ & & \\
\hline Wholesale and retail trade & $-0.0795^{* *}$ & $(0.03632)$ & & \\
\hline Hotels and restaurants & $0.2023^{* * *}$ & $(0.06804)$ & & \\
\hline Transport, storage and communication & $-0.0487^{*}$ & $(0.02566)$ & & \\
\hline Financial intermediation & $0.1016^{*}$ & $(0.05747)$ & & \\
\hline Real estate, renting and business activity & 0.0299 & $(0.03361)$ & & \\
\hline Public administration and defense & $0.0695^{*}$ & $(0.03634)$ & & \\
\hline Education & $0.1278^{*}$ & $(0.07106)$ & & \\
\hline Health and social work & 0.0415 & $(0.04612)$ & & \\
\hline Other community and service activities & 0.0298 & $(0.05960)$ & & \\
\hline Private households with employed persons & -1.7154 & $(1.40630)$ & & \\
\hline Others & 0.1321 & $(0.25572)$ & & \\
\hline Degree of tertiarization & & & $0.0360^{* *}$ & $(0.01613)$ \\
\hline Flow into unemployment (Share; Employed) & $-0.9488^{* * *}$ & $(0.10721)$ & $-1.0081^{* * *}$ & $(0.10606)$ \\
\hline Non-subsidized vacancies (Share; Unemployed SGB III) & $0.0326^{* * *}$ & $(0.00565)$ & $0.0334^{* * *}$ & $(0.00574)$ \\
\hline Average wages (in logarithm) & $-0.0859^{* * *}$ & $(0.01880)$ & $-0.0901^{* * *}$ & $(0.01869)$ \\
\hline Seasonal span of unemployment & $0.1223^{* * *}$ & $(0.00933)$ & $0.1405^{* * *}$ & $(0.00889)$ \\
\hline Density of population (in logarithm) & -0.0019 & $(0.00142)$ & -0.0053 & $(0.00125)$ \\
\hline Quarter dummies & yes & & yes & \\
\hline $\bar{R}^{2}$ & 0.6724 & & 0.6609 & \\
\hline Observations/Number of regions & $2112 / 176$ & & $2112 / 176$ & \\
\hline
\end{tabular}

Notes: †Reference category: Elementary and secondary school (with VT); $\ddagger$ Reference category: Manufacturing Clustered standard errors in parentheses. ${ }^{* * *},{ }^{* *},{ }^{*}$ significant at the $1 \%, 5 \%$, and $10 \%$ level 


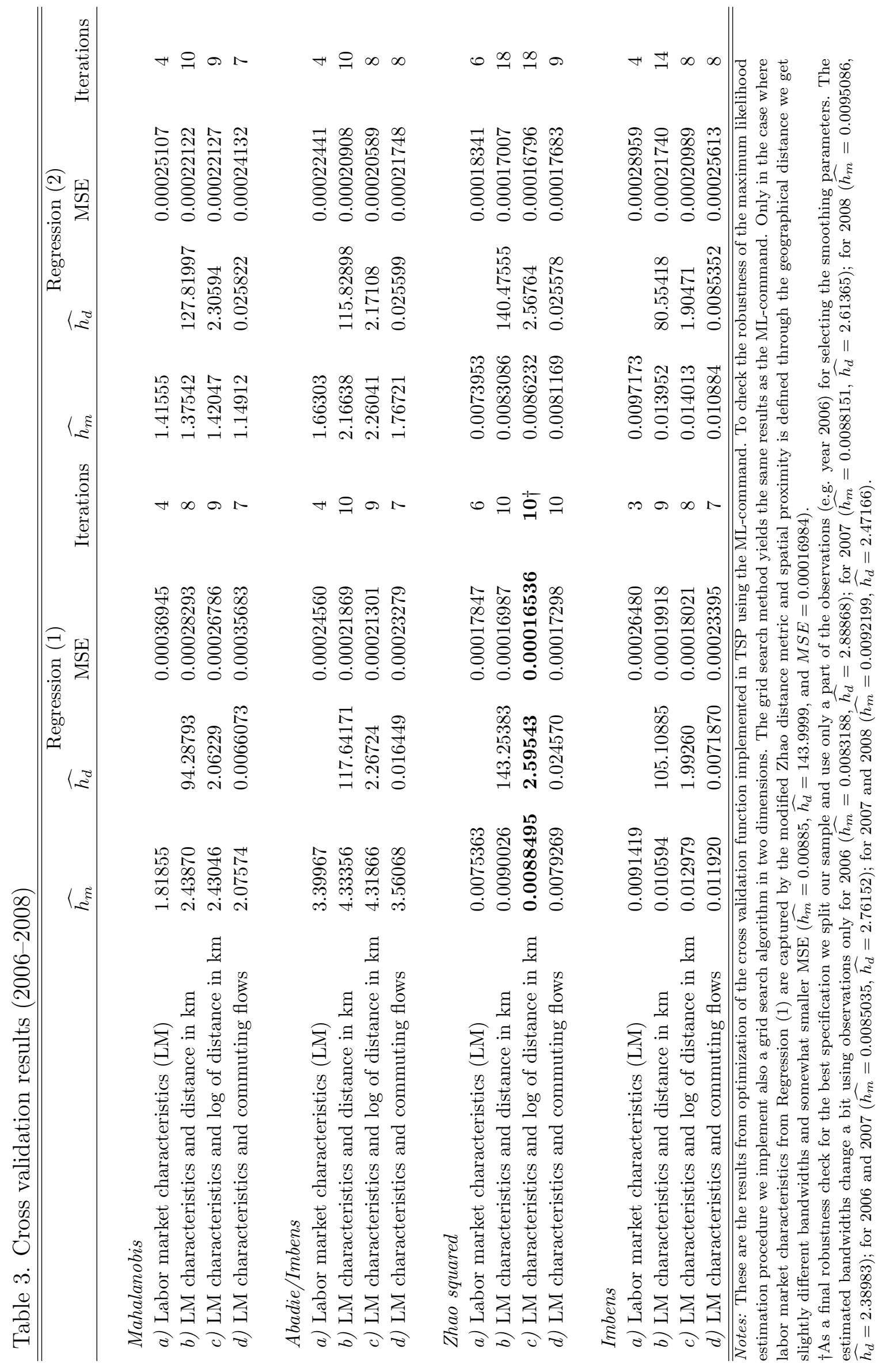




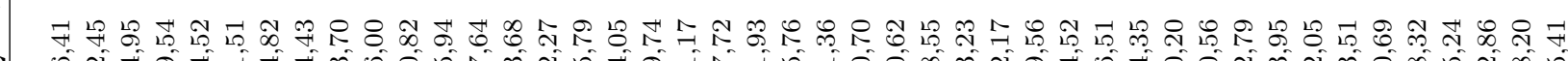

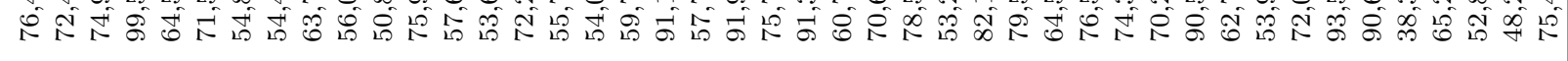

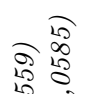

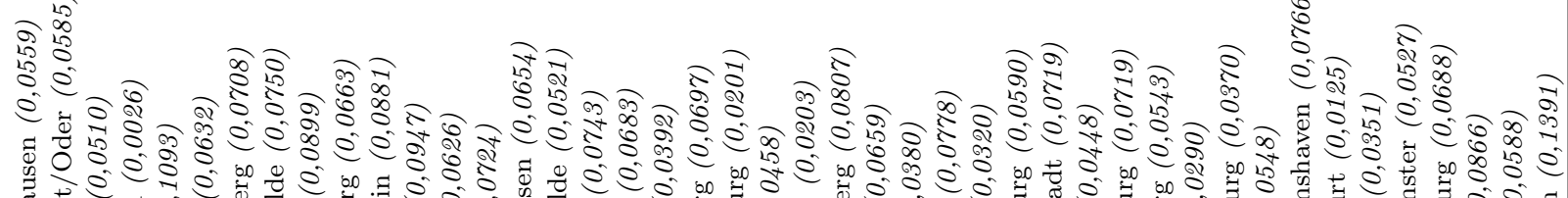

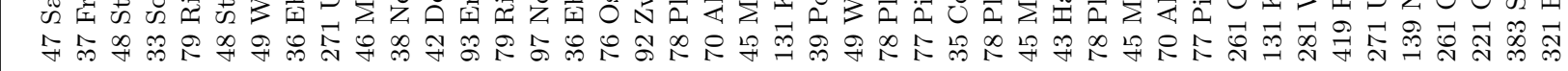

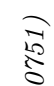

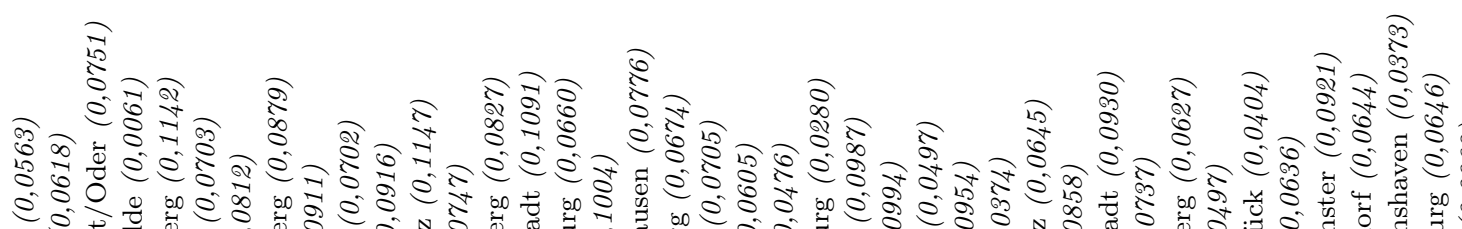

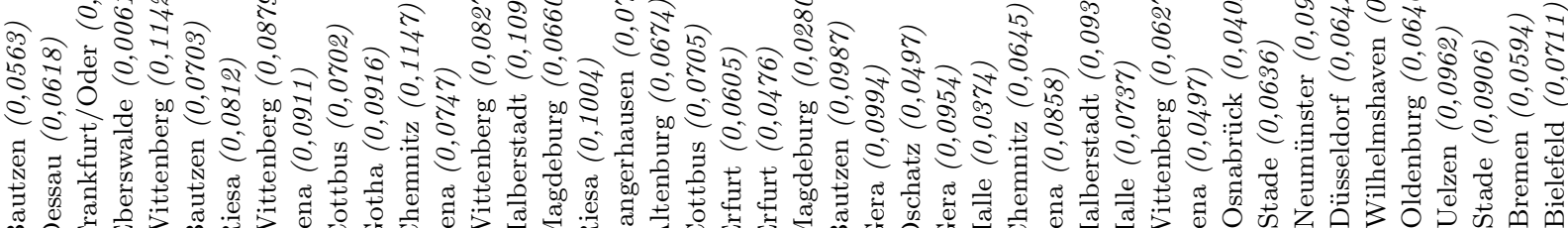

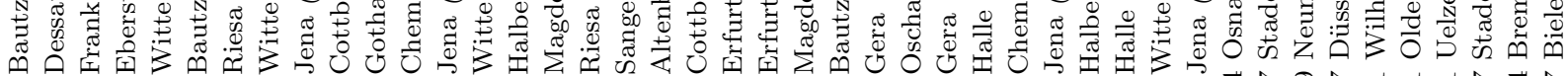

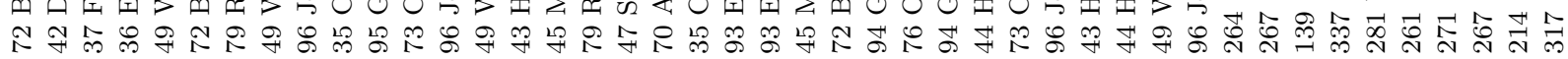
के

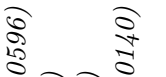

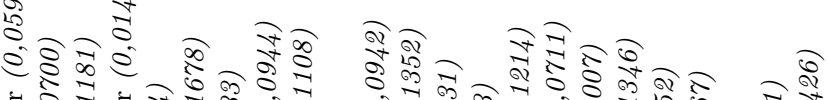

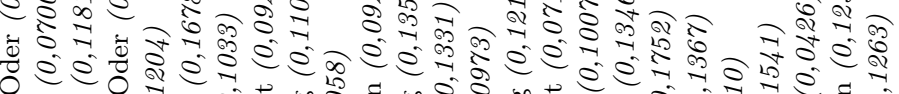

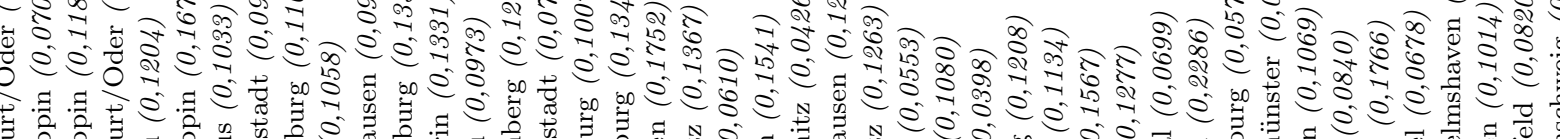

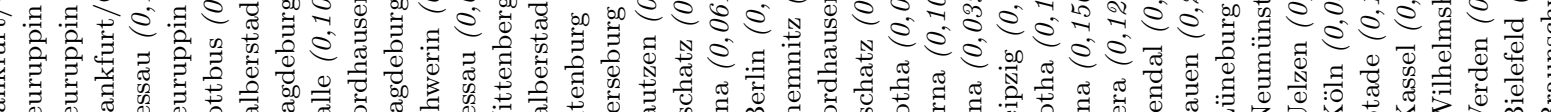

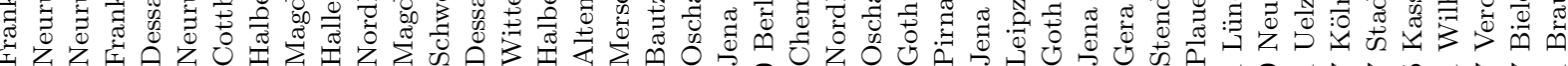

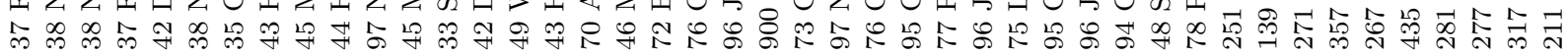

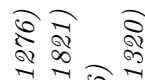

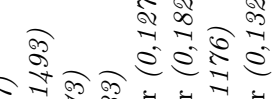

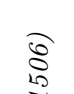

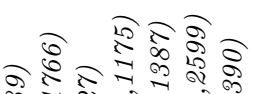

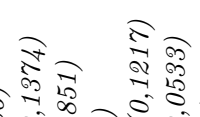

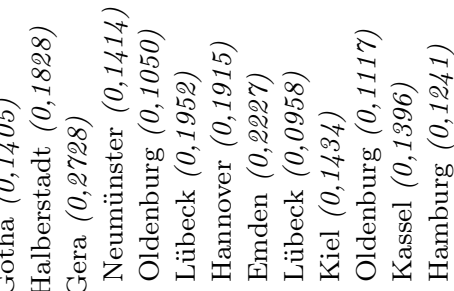

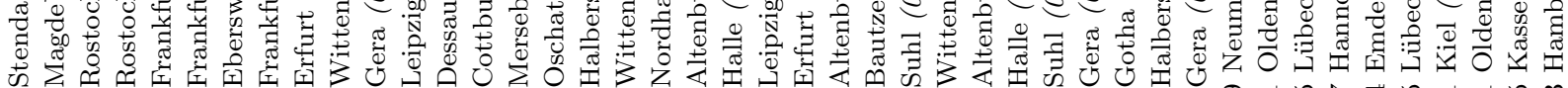

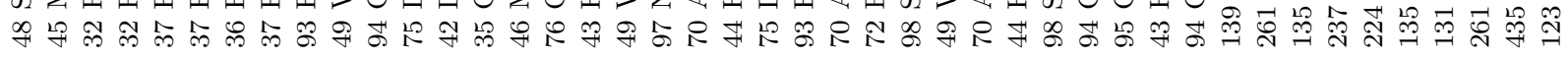<smiles>C=C[C@H]1C=C[C@@H]1C</smiles>

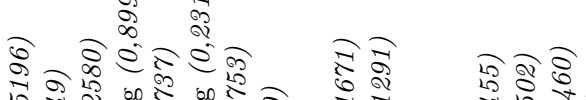

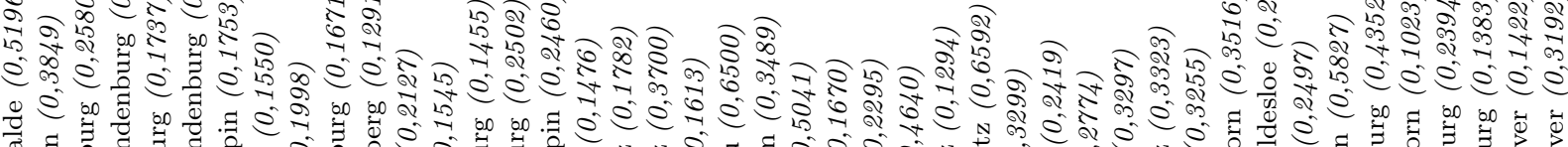

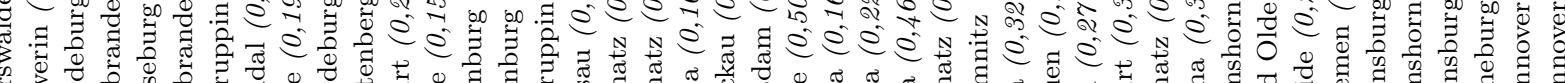

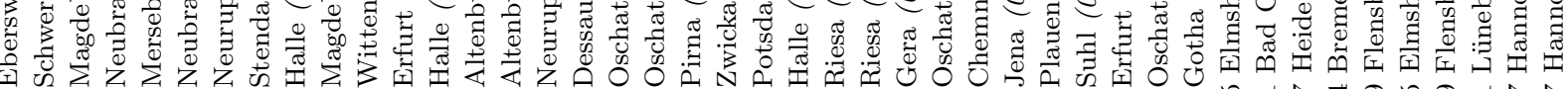

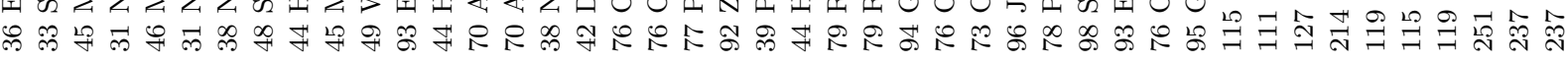

$\infty$

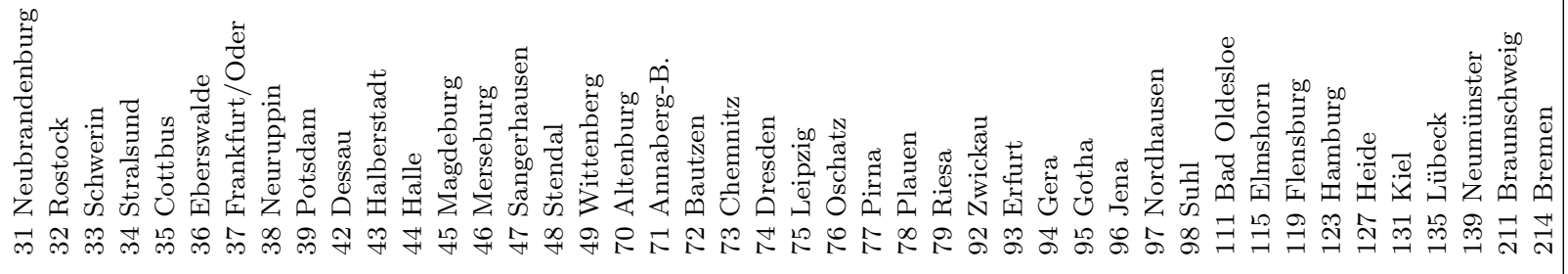




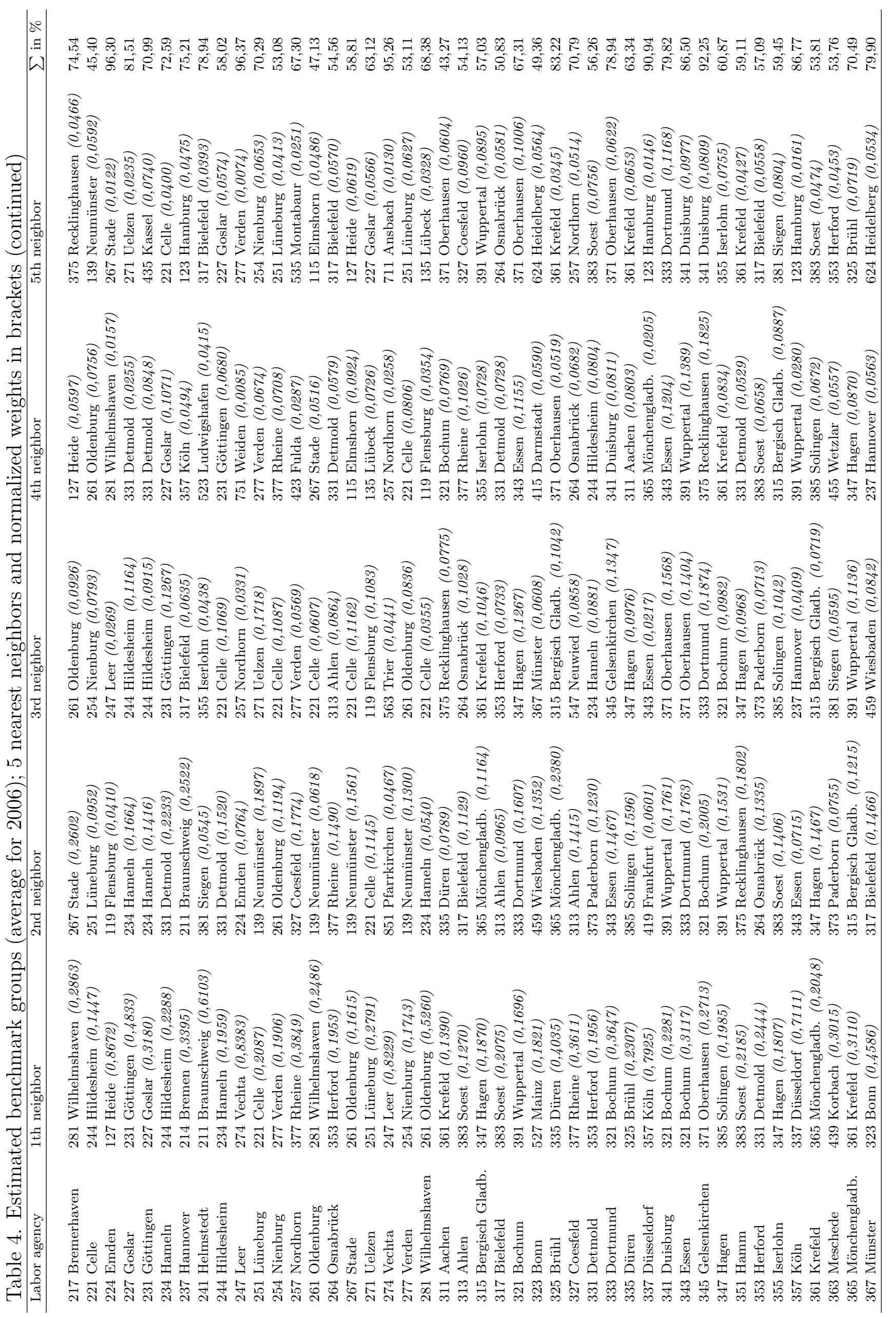




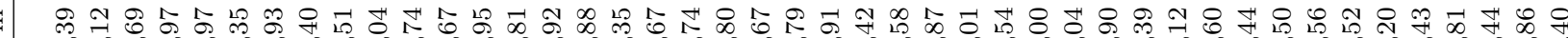

W ชิ

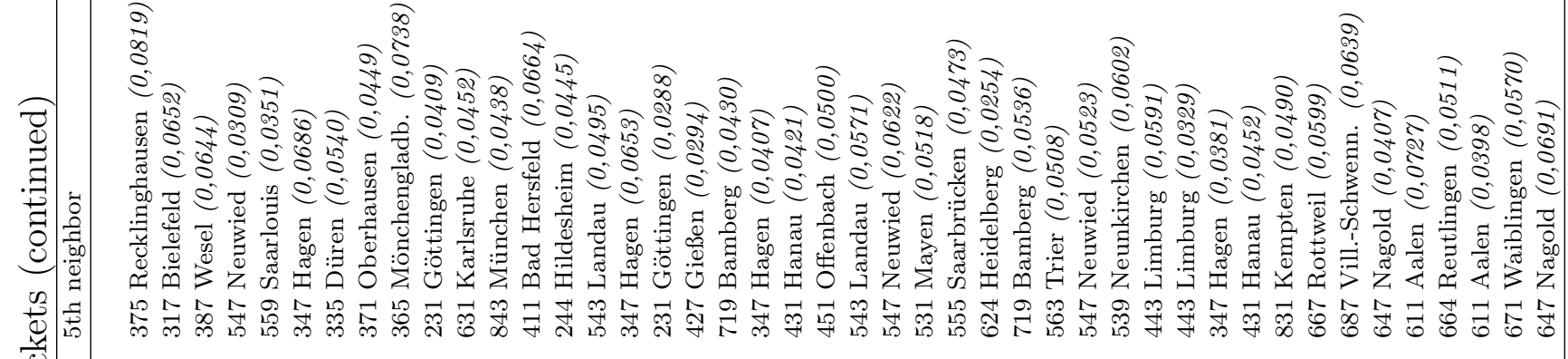

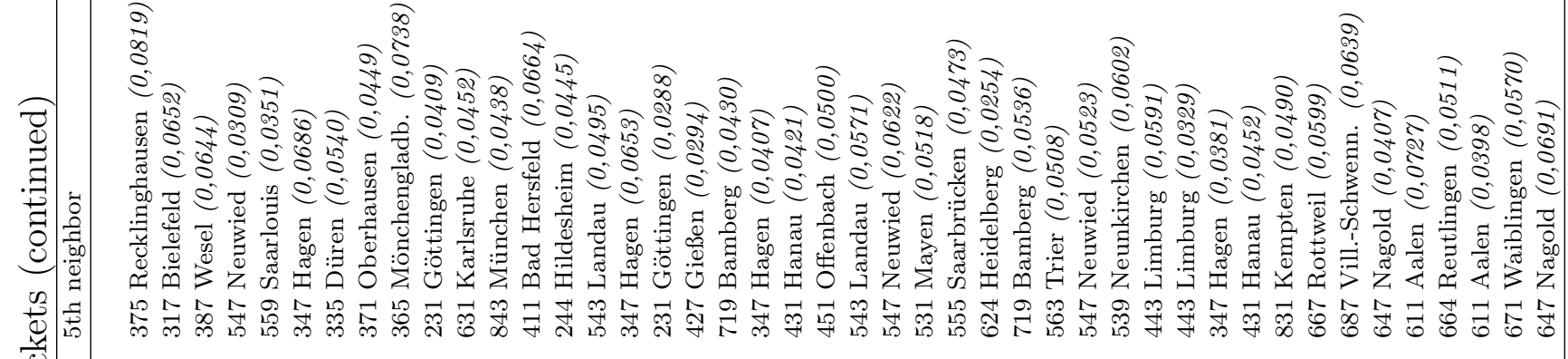

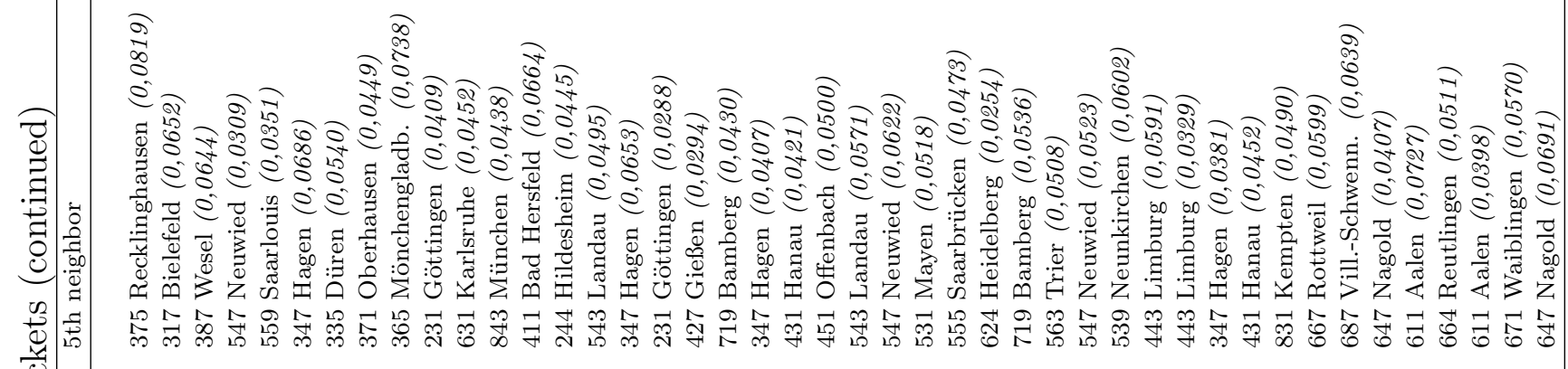

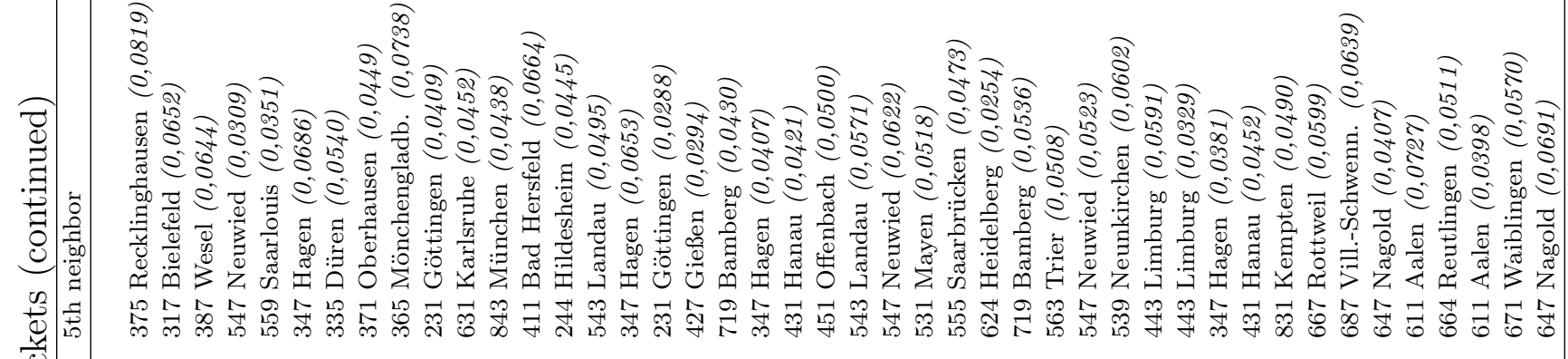

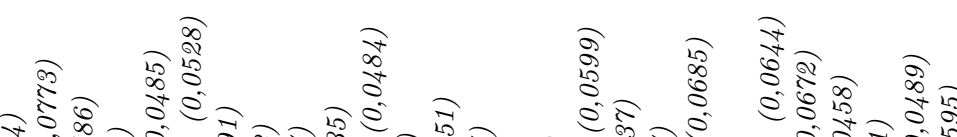

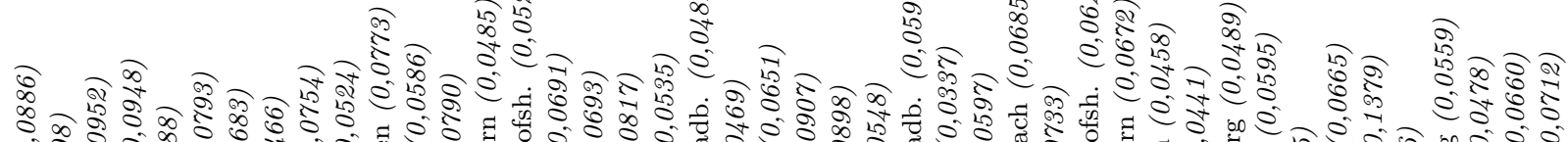

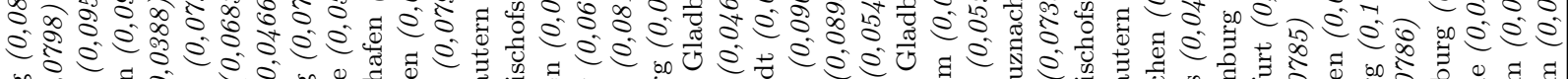

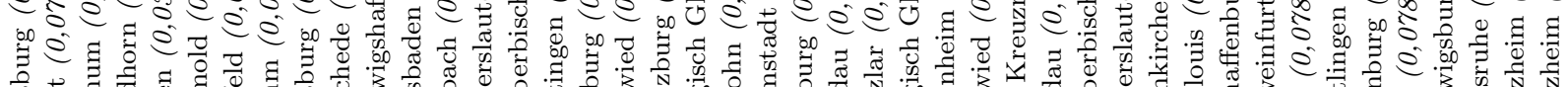

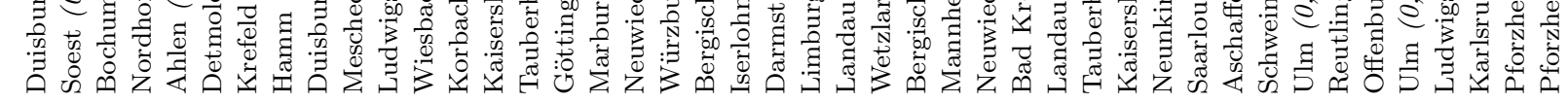

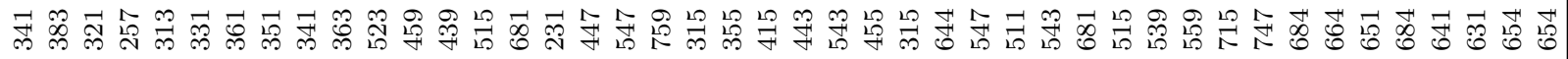

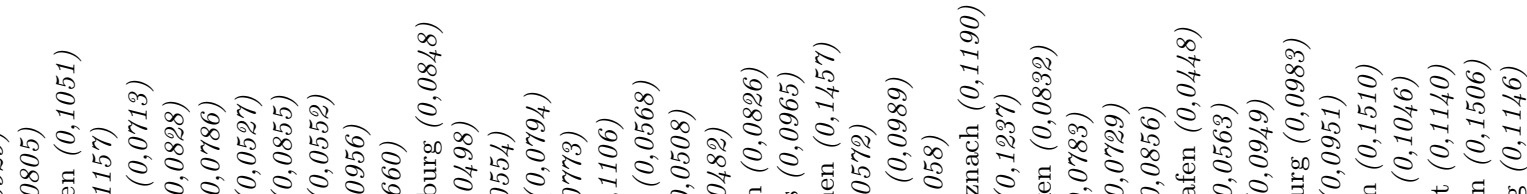
$8 \%$.

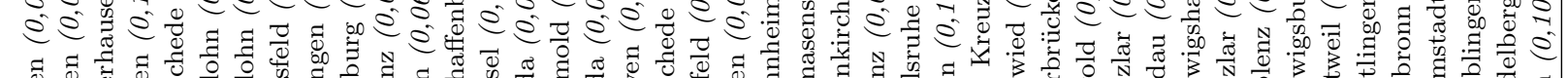

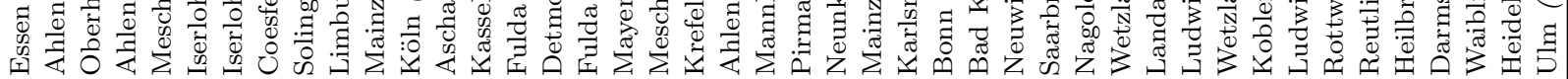

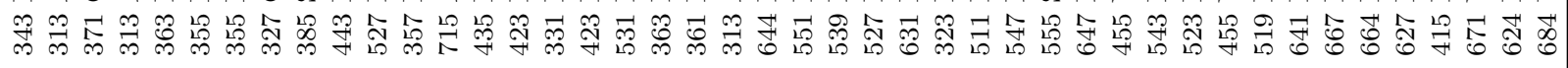

总

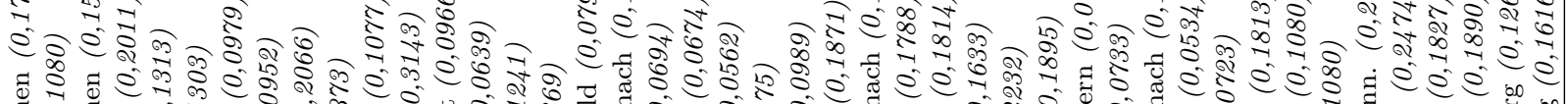

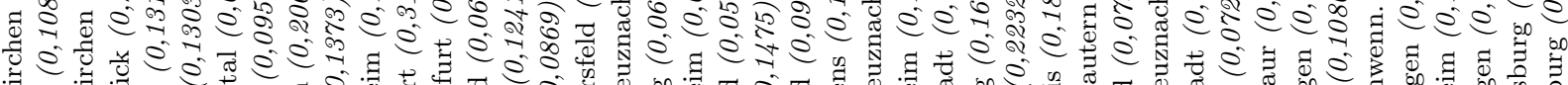

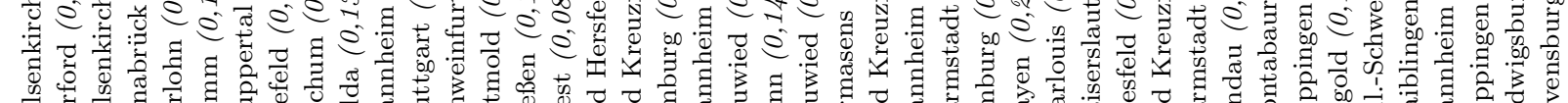

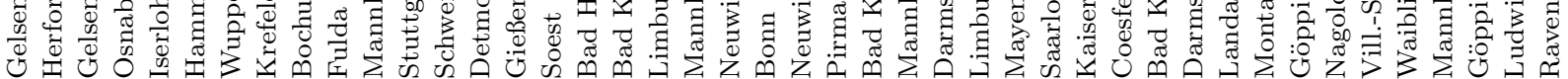

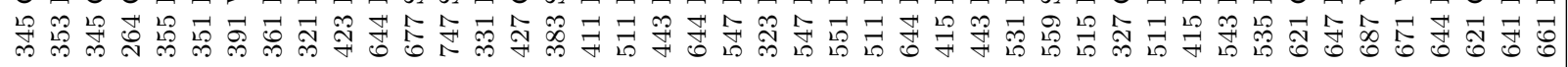

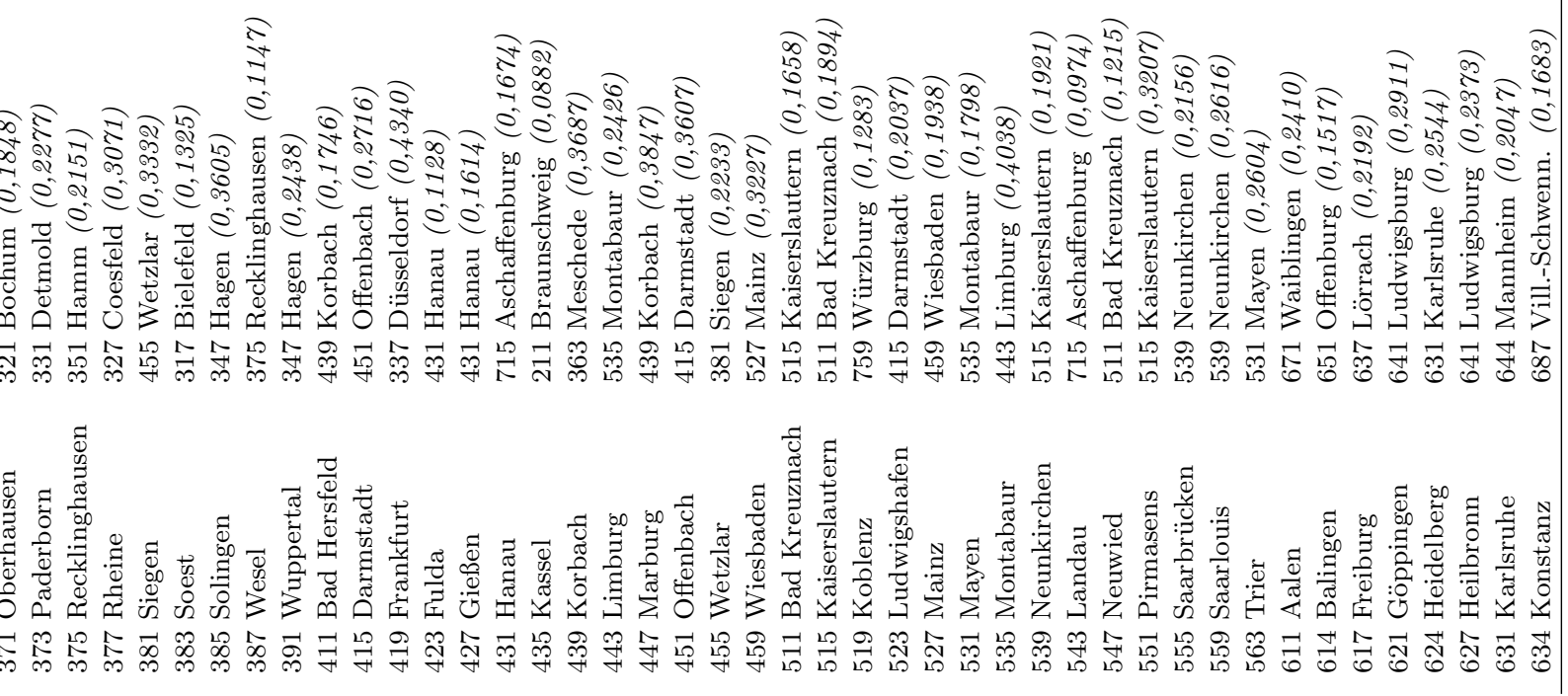


皮

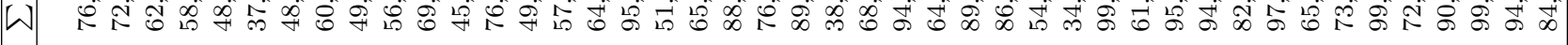

8े

10

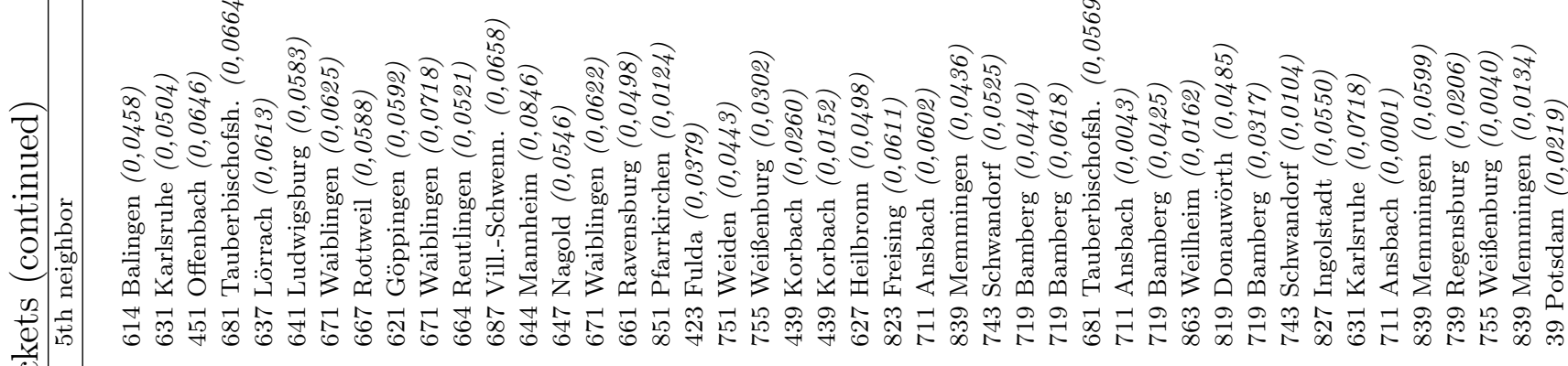

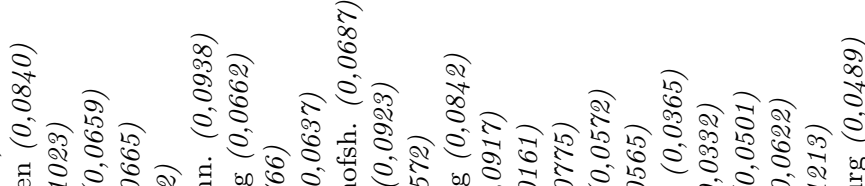

को 0 के

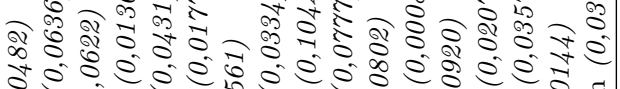

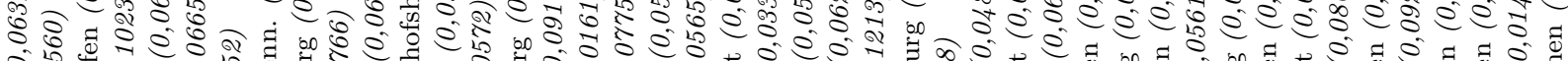

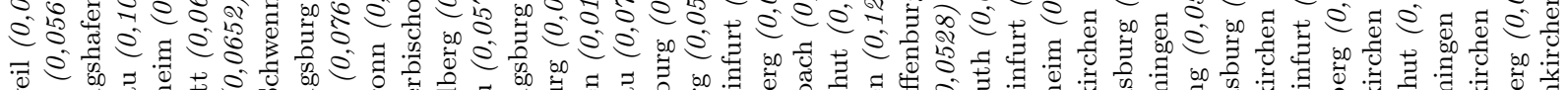

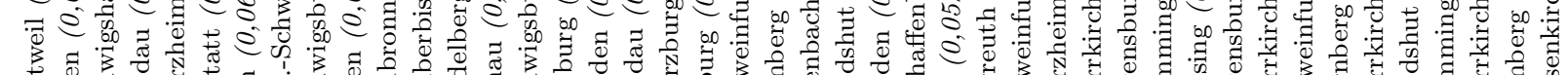

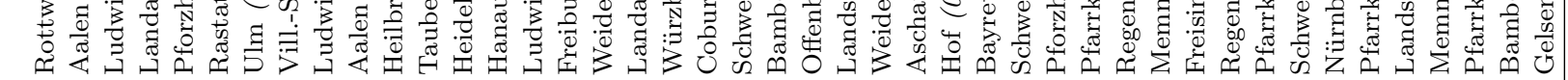

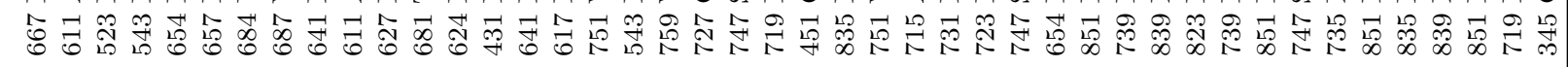

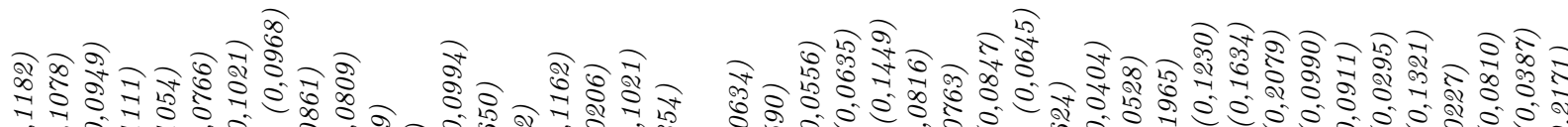

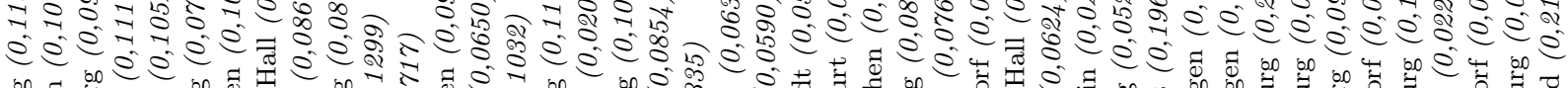
so 000

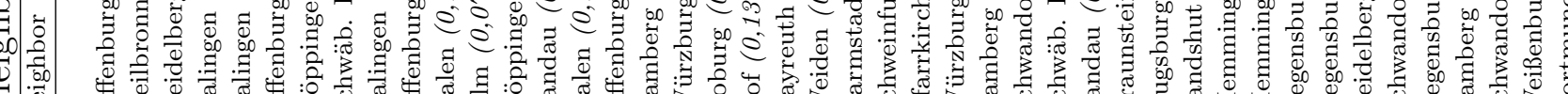

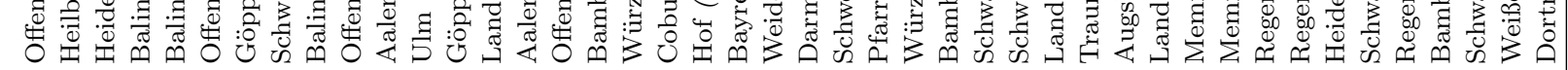

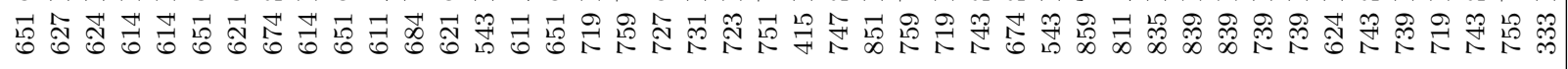

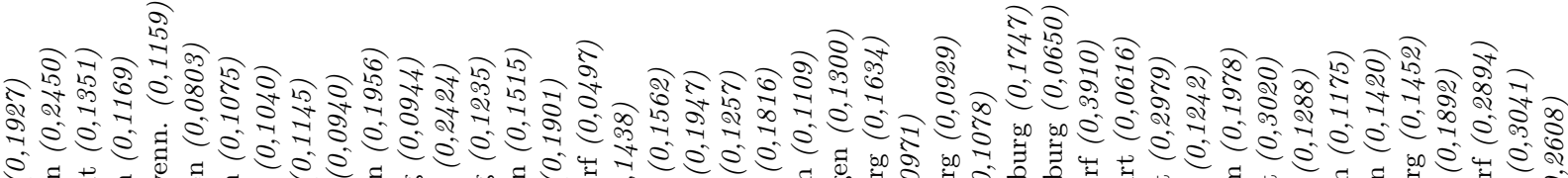
6000.

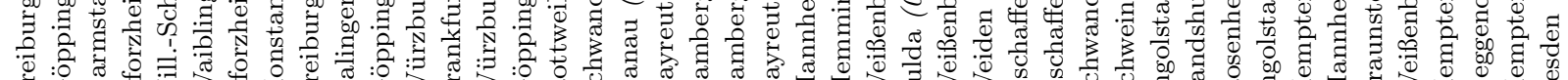

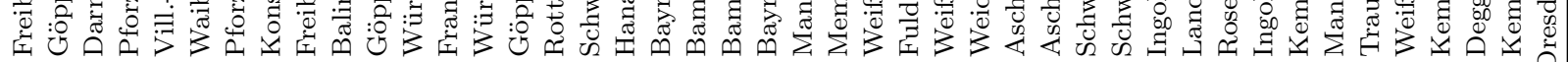

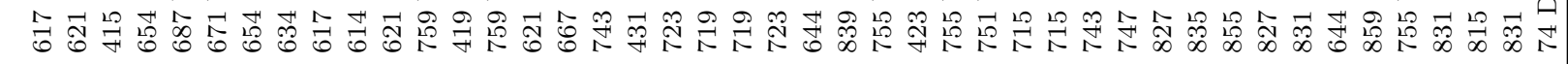

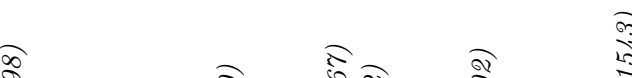<smiles>[CH]1C=C[CH+]1</smiles>

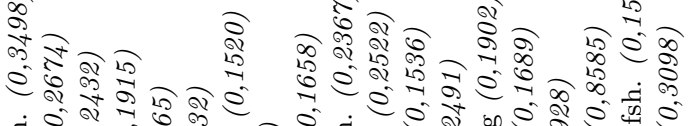

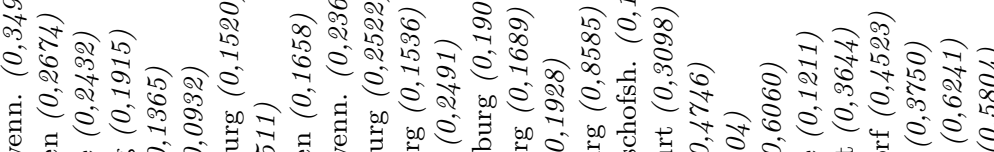

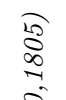

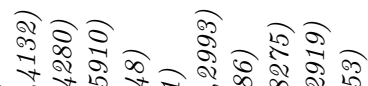

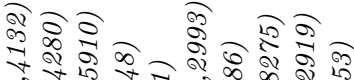
$\stackrel{\infty}{\stackrel{8}{2}}$

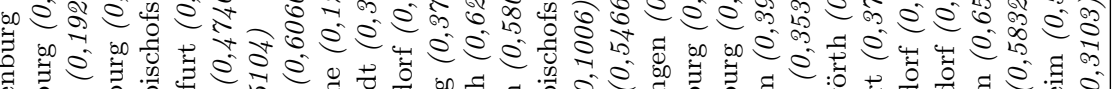

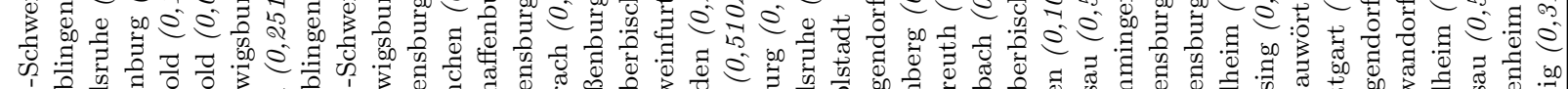

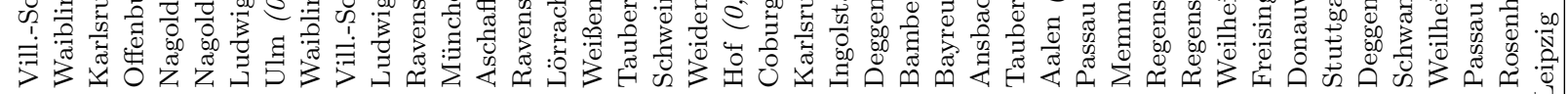

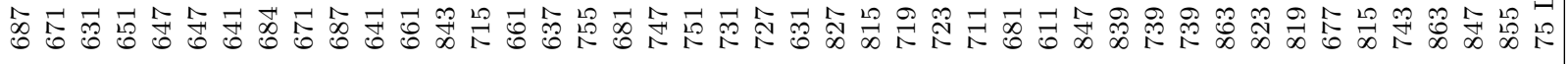

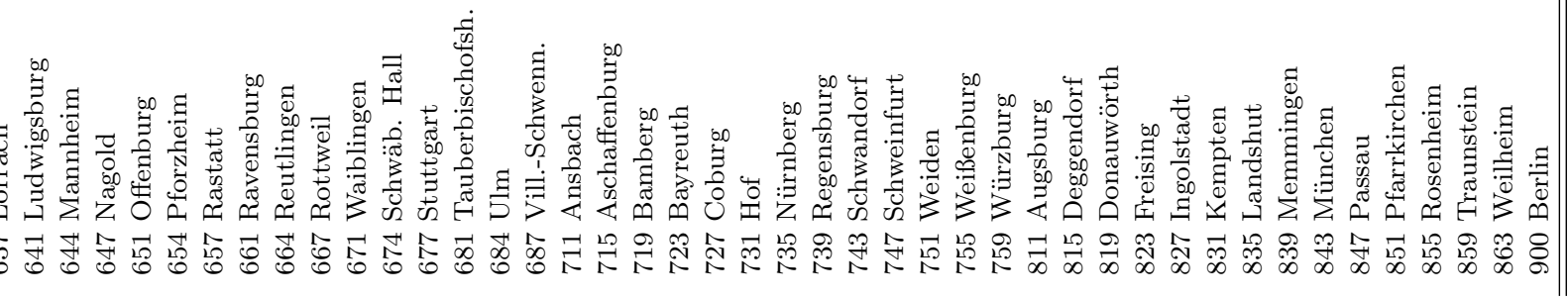




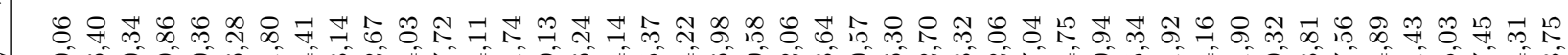

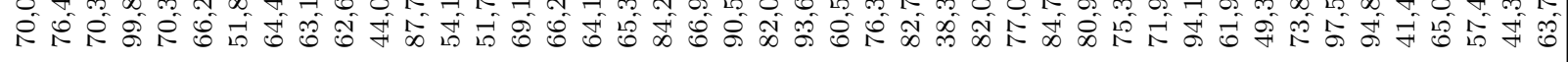

20
$\infty$
$\infty$
0
0

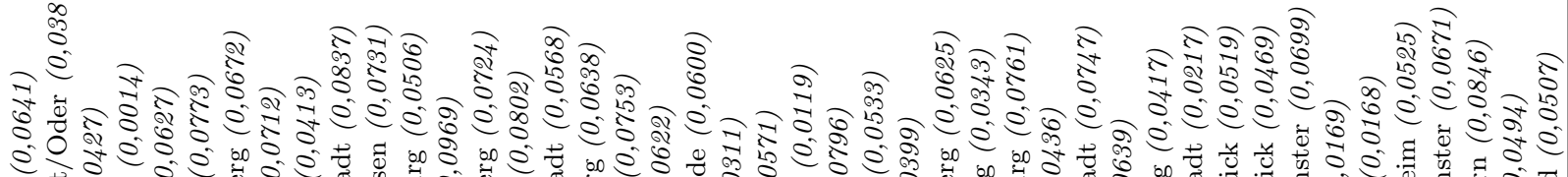

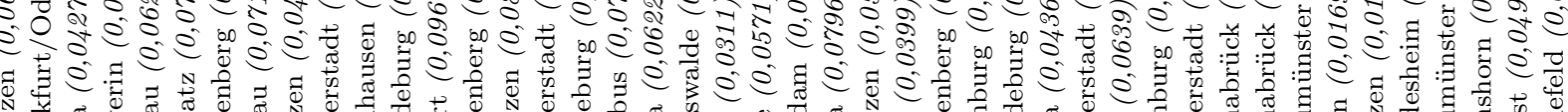

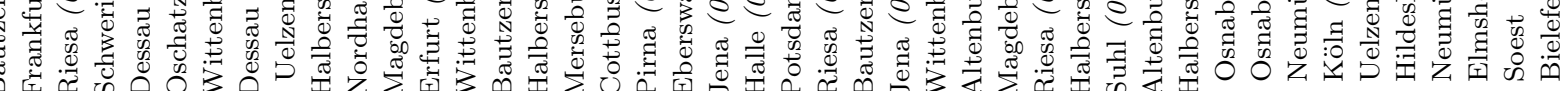

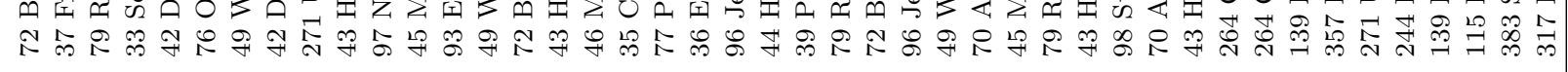

की

\section{(1)}

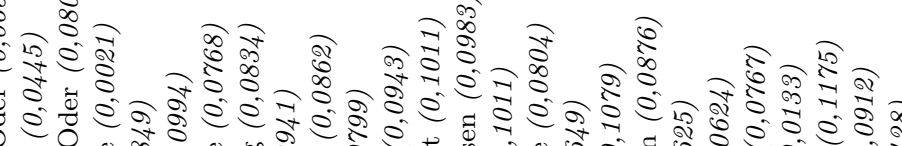

बै

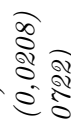

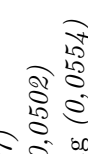

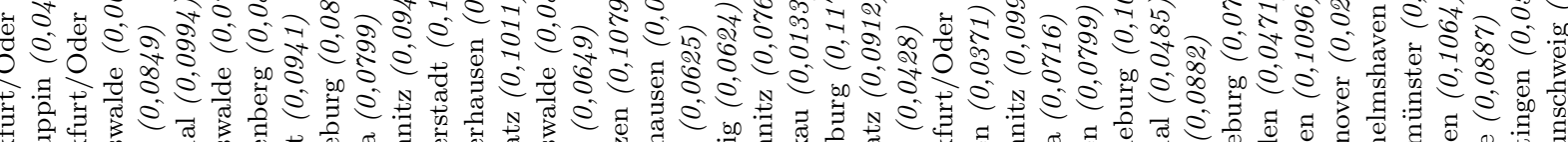

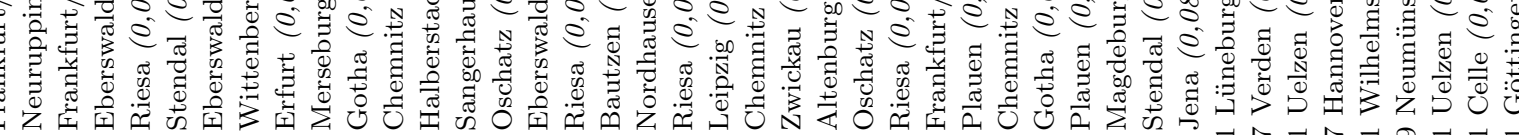

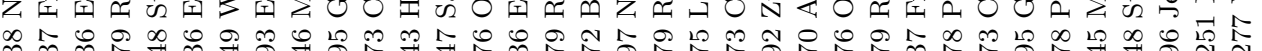

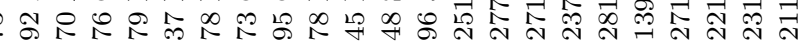

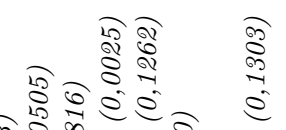

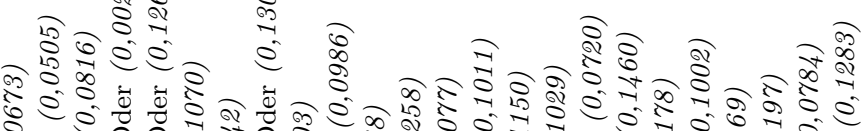

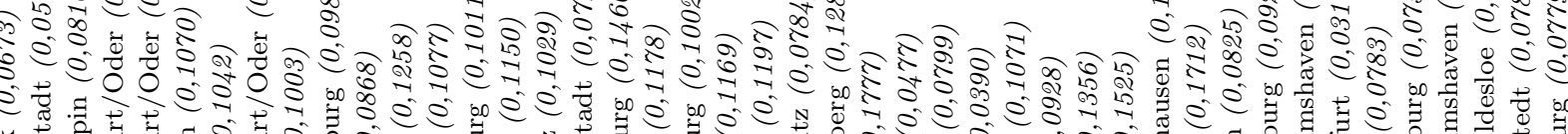

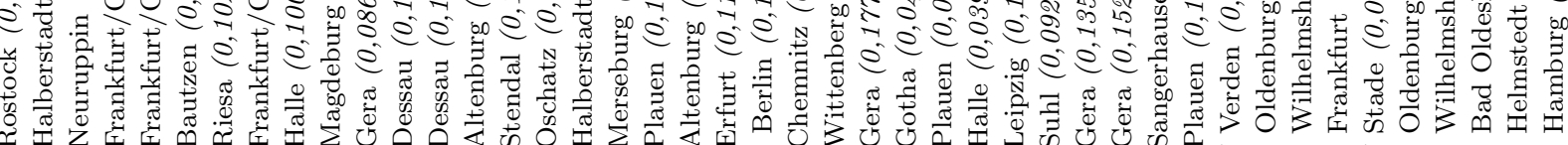

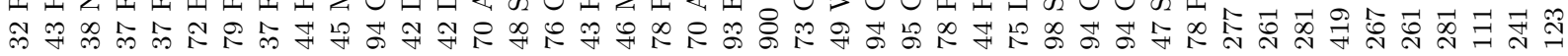
20<smiles></smiles>

ब.

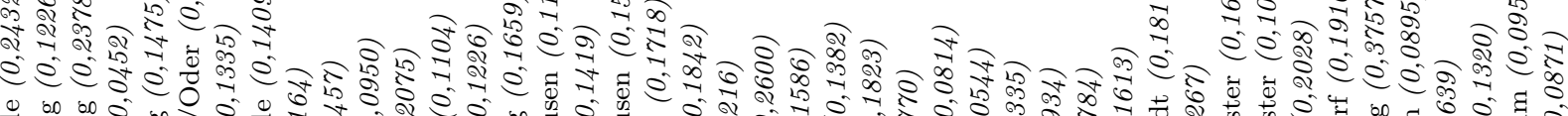

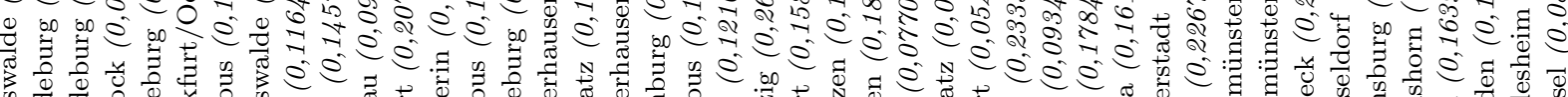

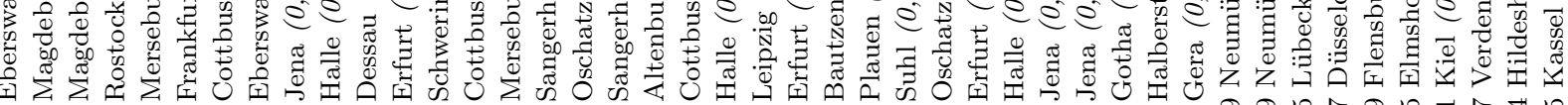

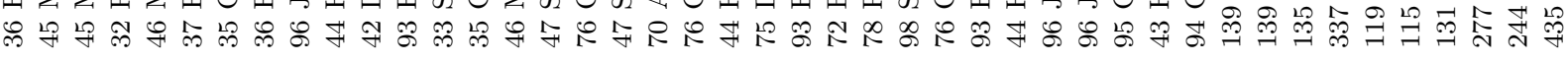

so

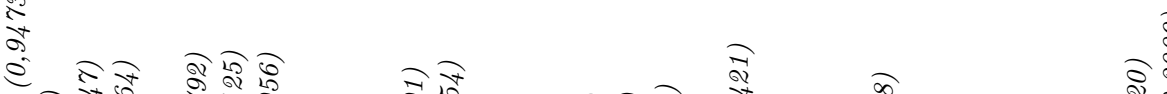

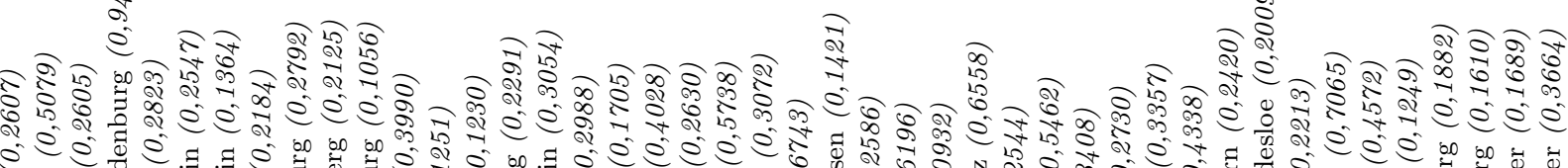

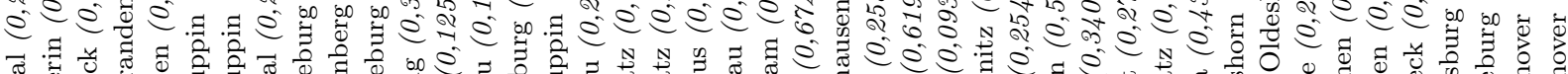

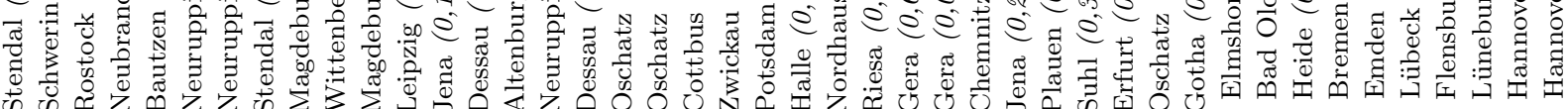

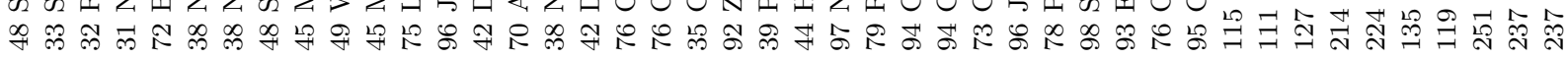

$\stackrel{\operatorname{son}}{\circ}$

\section{.}

竞

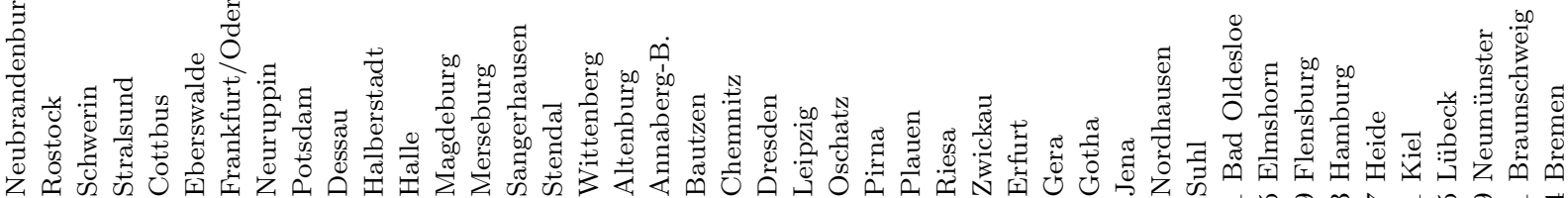
จะ⿻三丨 


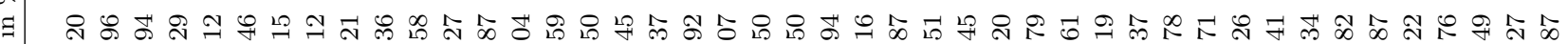

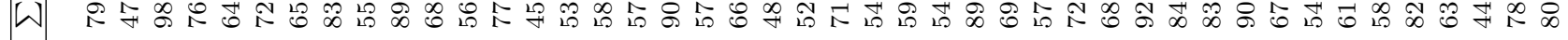

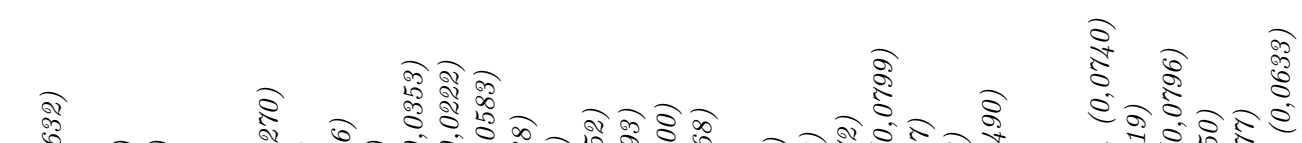

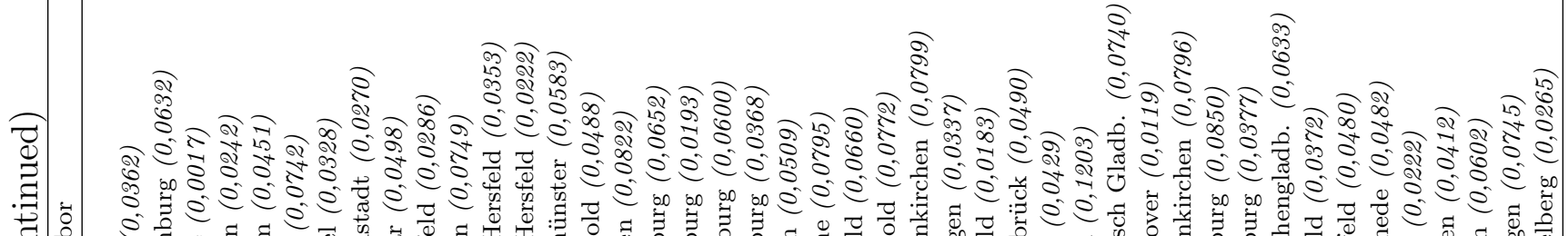

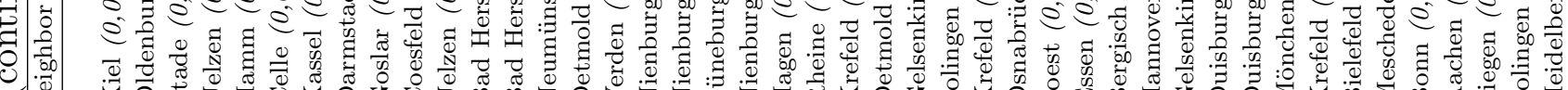

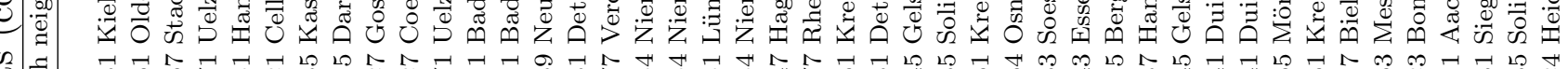

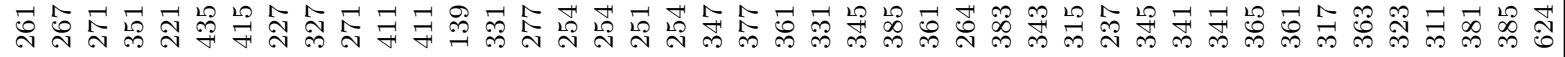

is 8

is $e^{-1}$

तิ

(1)

$\stackrel{\infty}{\stackrel{\Upsilon}{*}}$

:

7

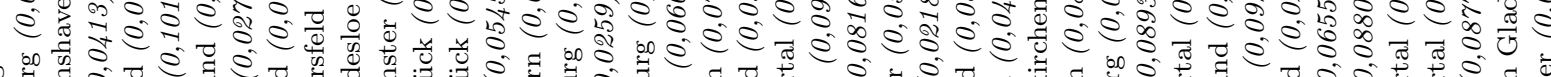
z

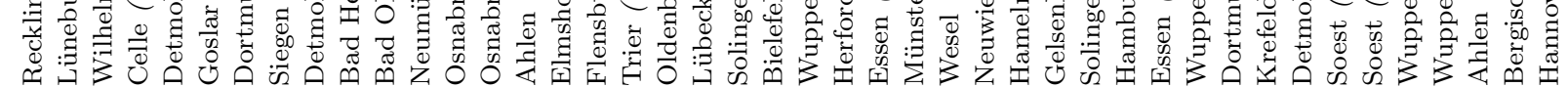

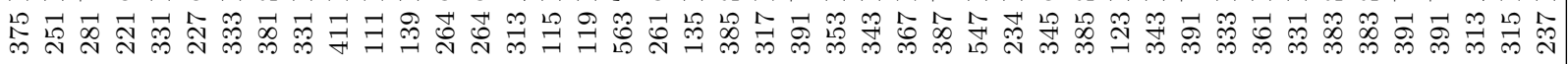

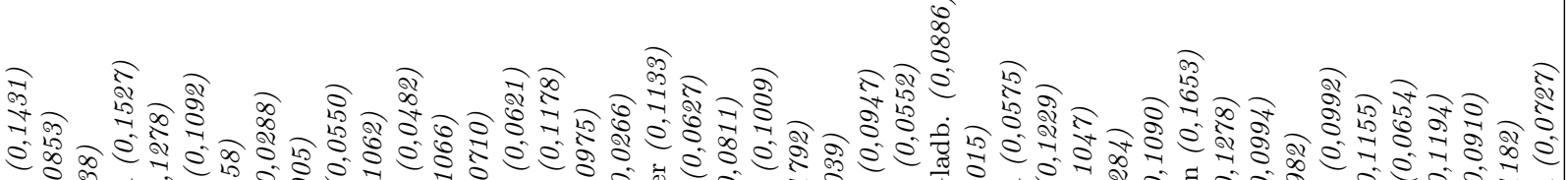

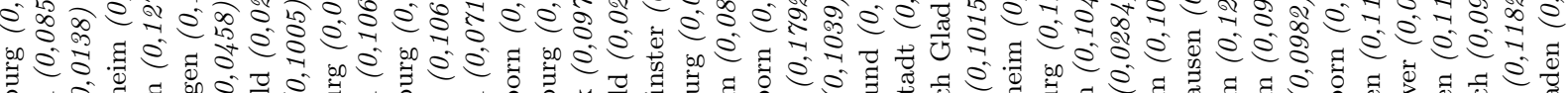

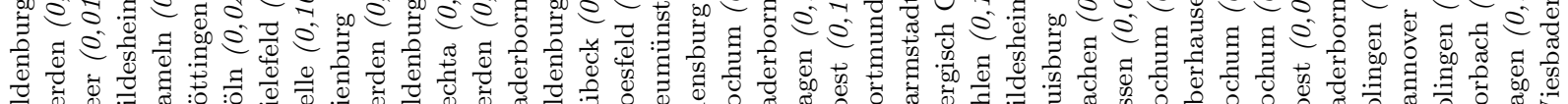

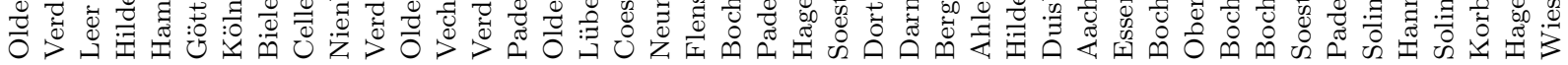

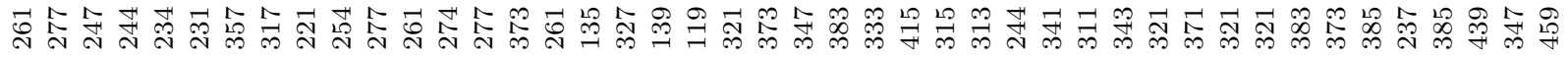

造

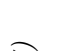

ชิ

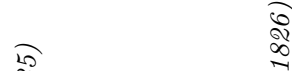

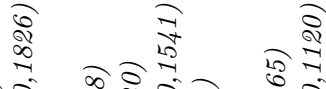

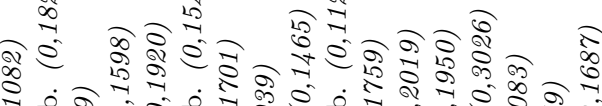

ญิ จิ

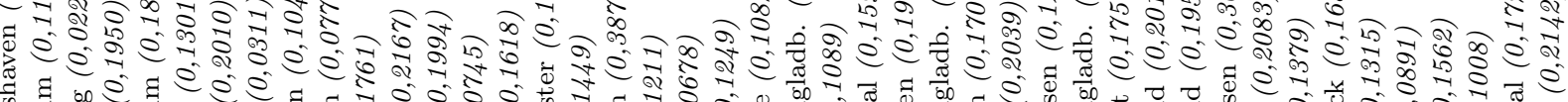

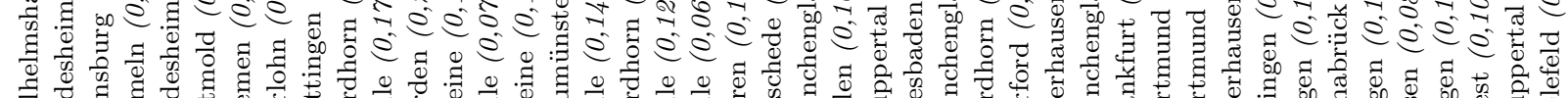

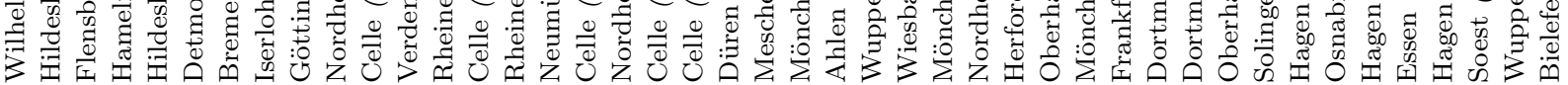

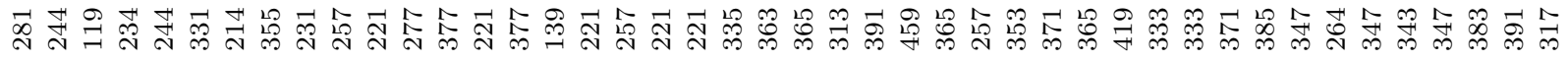

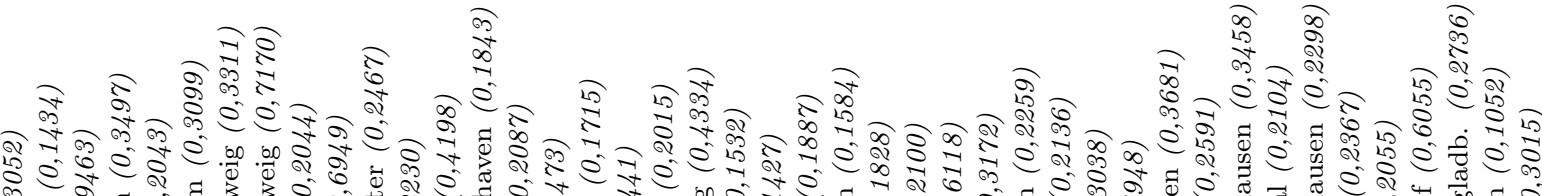

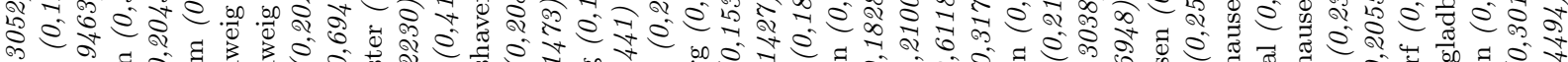
é

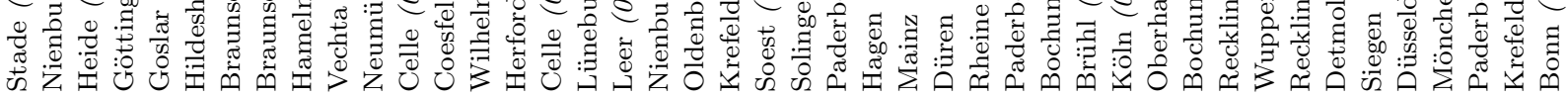

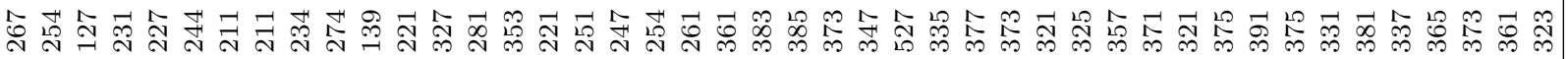

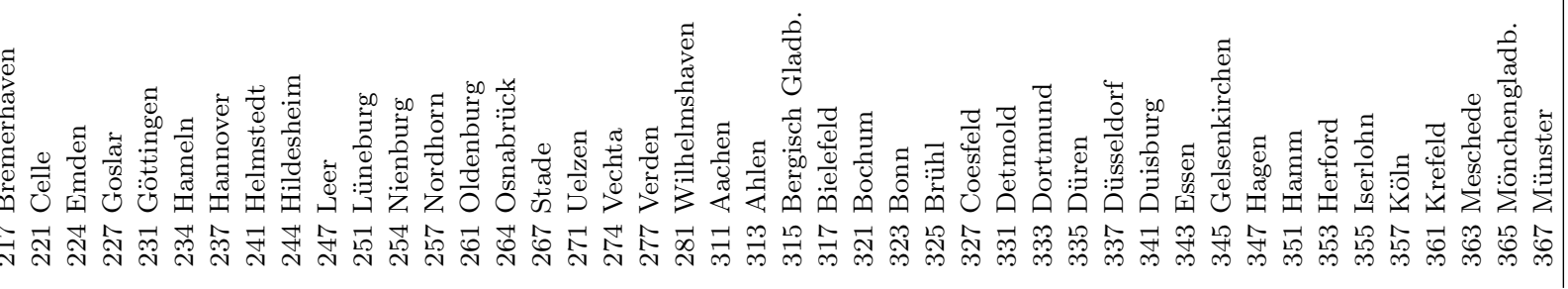




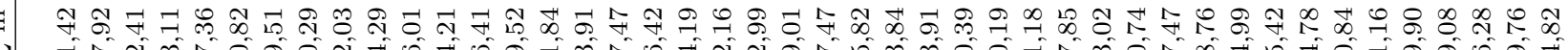

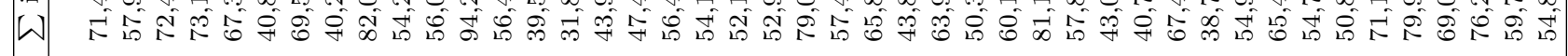

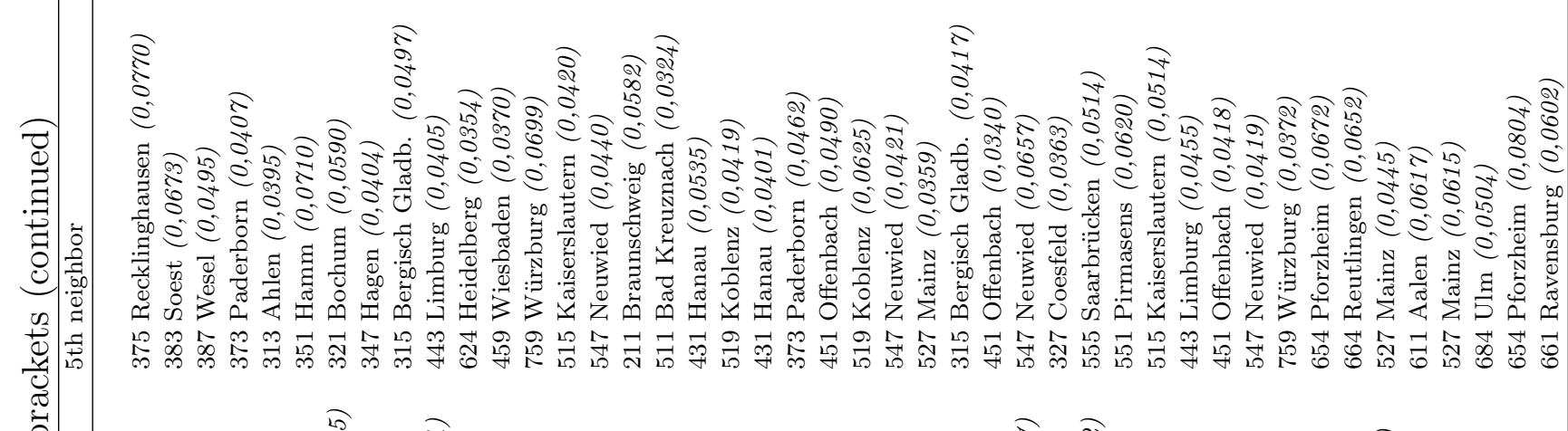

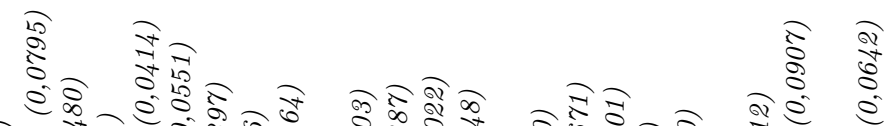

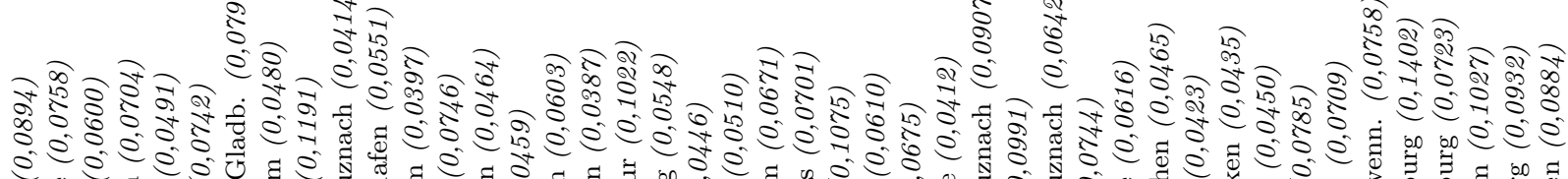

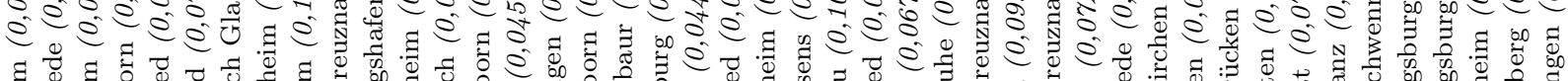

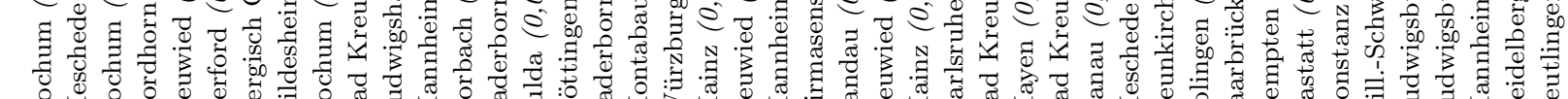

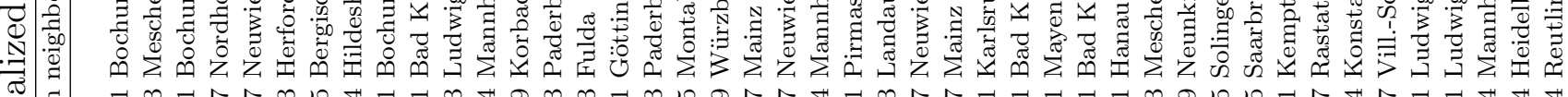

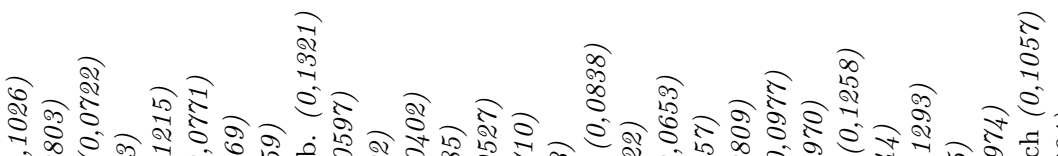

盛

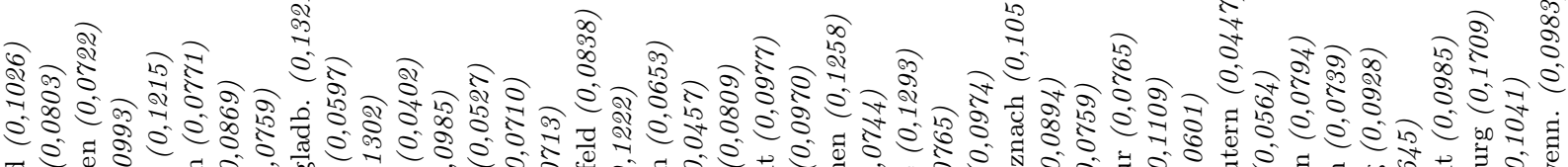

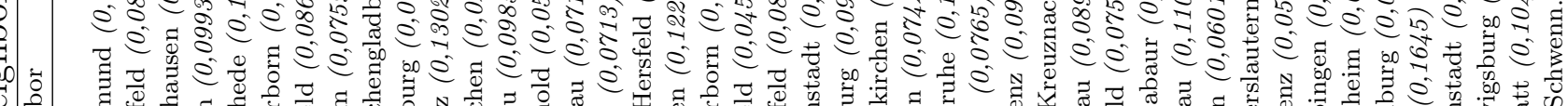

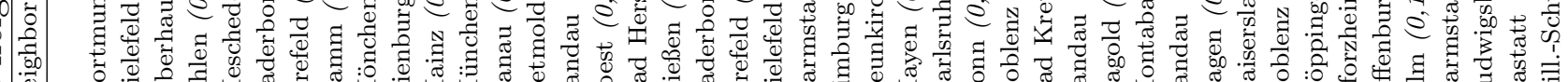

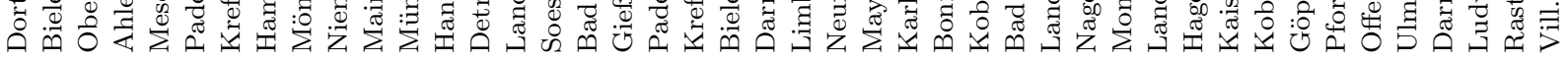

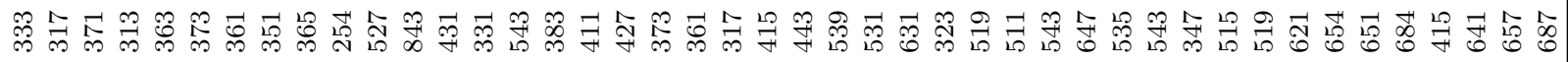

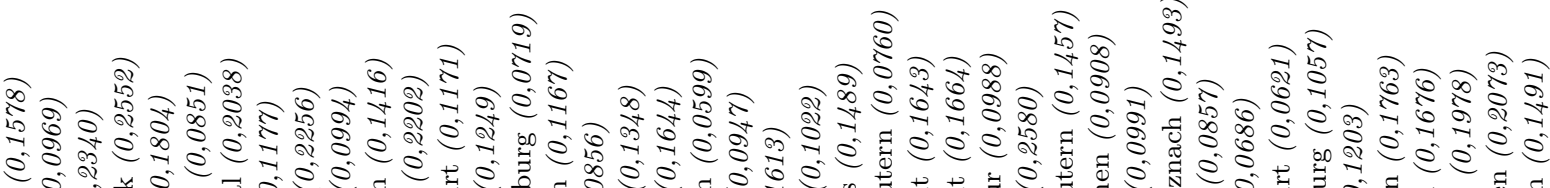

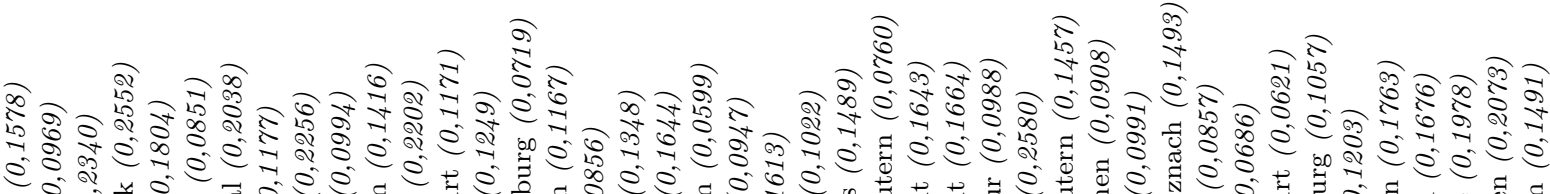

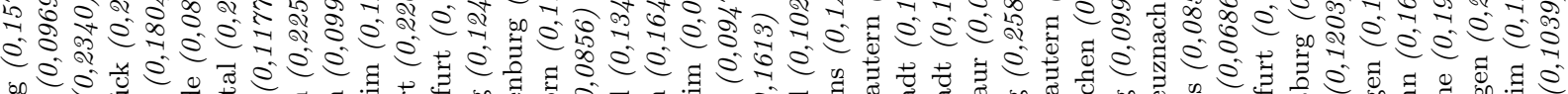

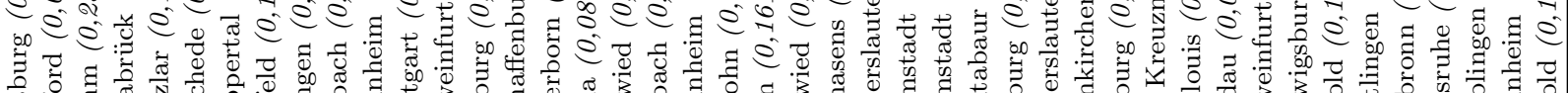

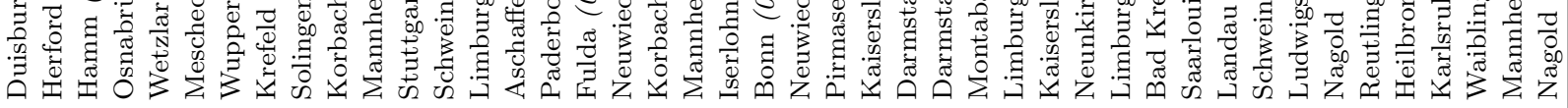

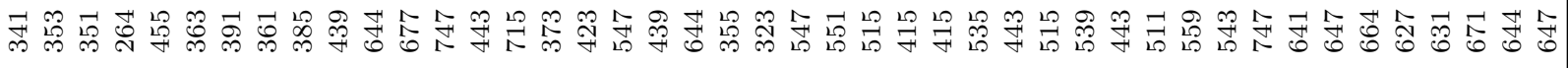

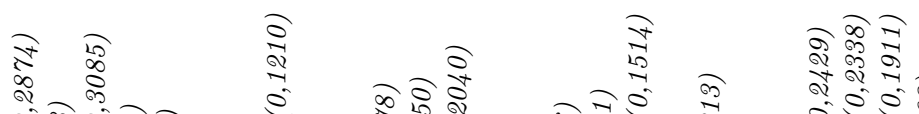

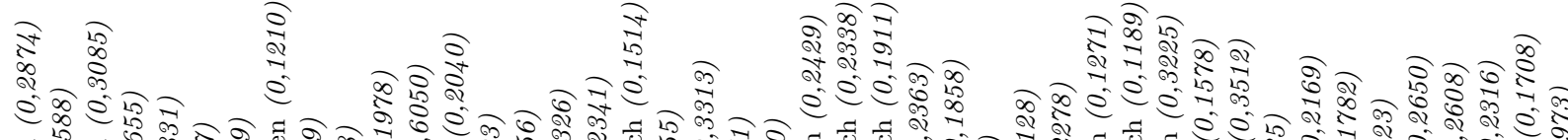

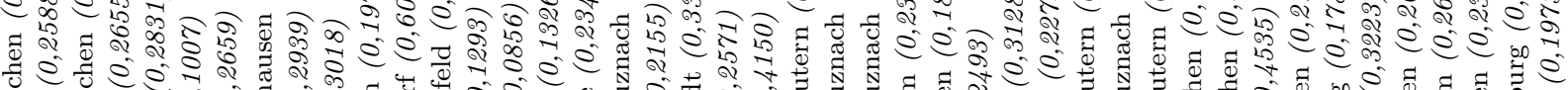

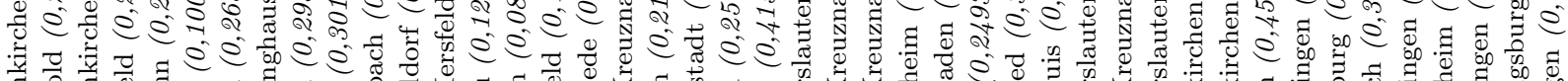

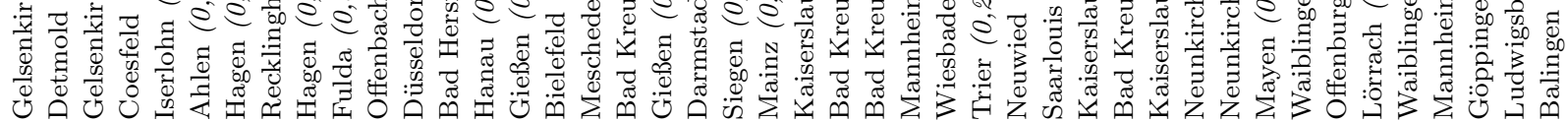

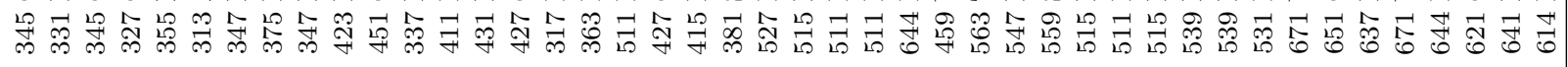

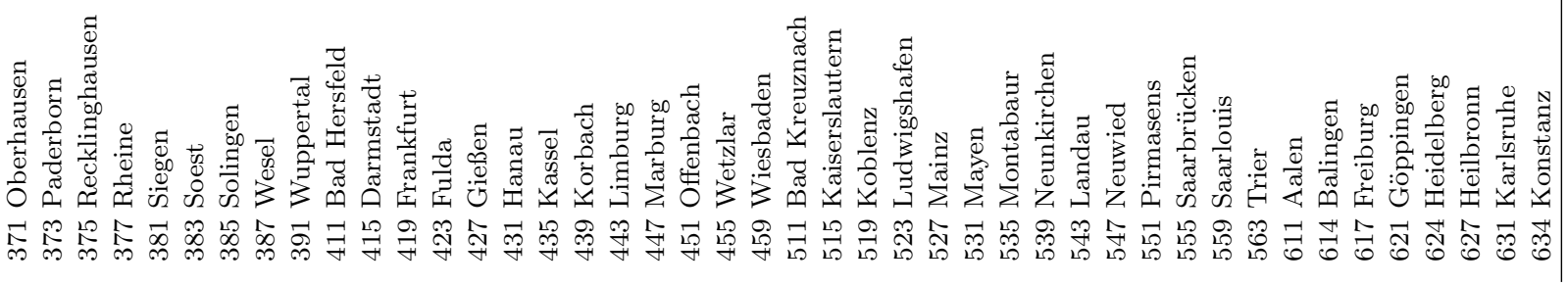




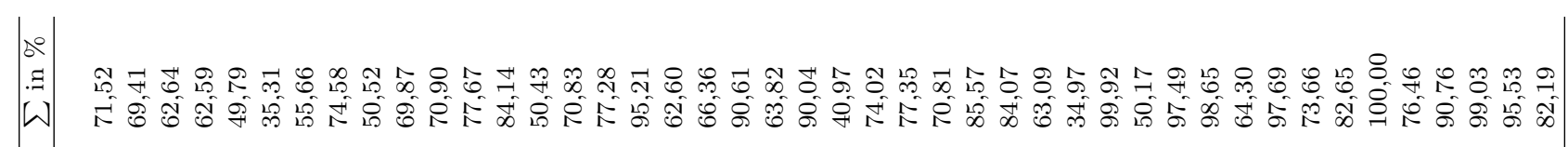

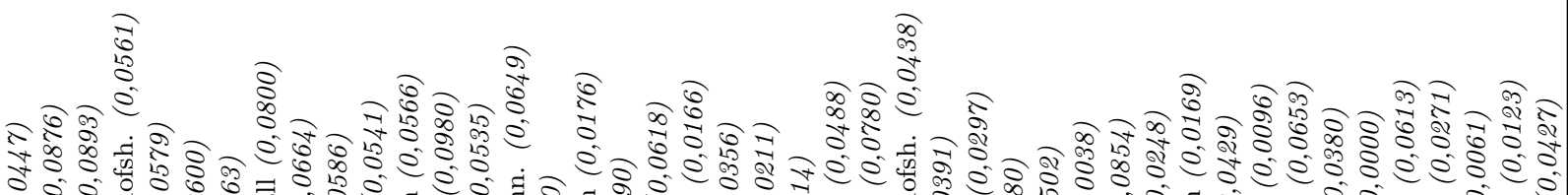

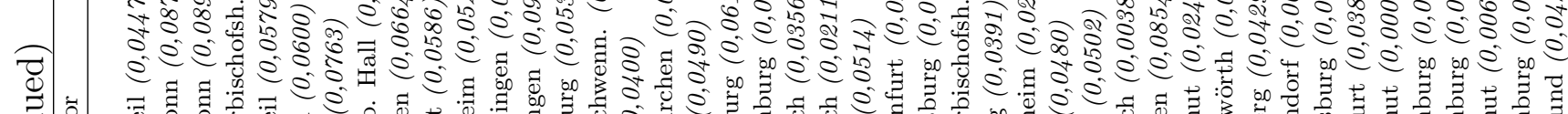

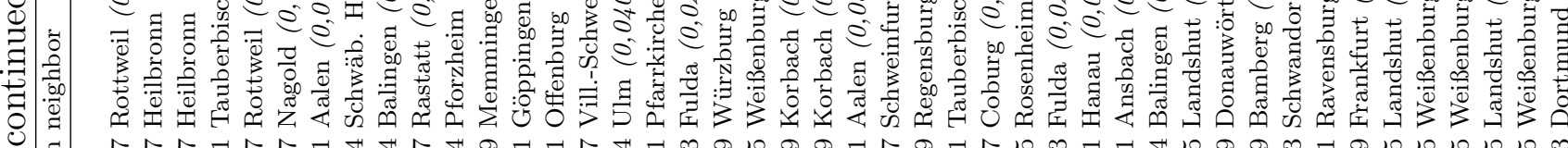

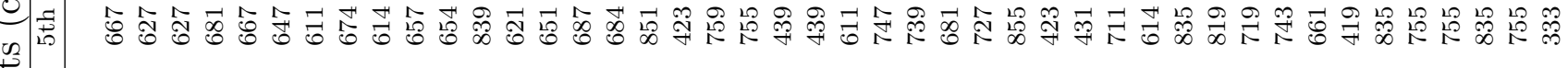

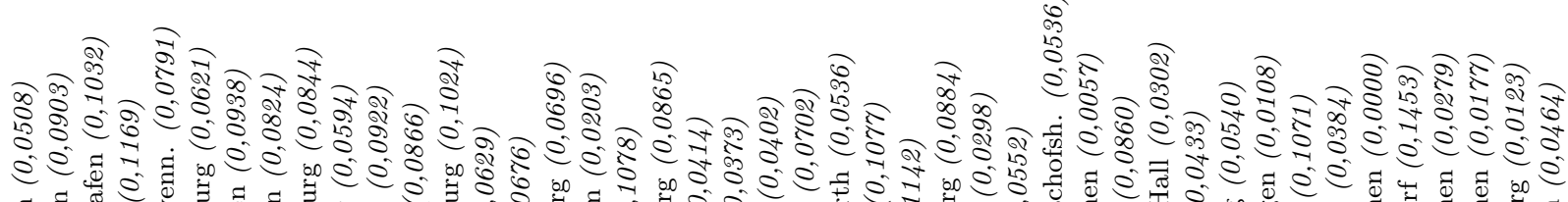

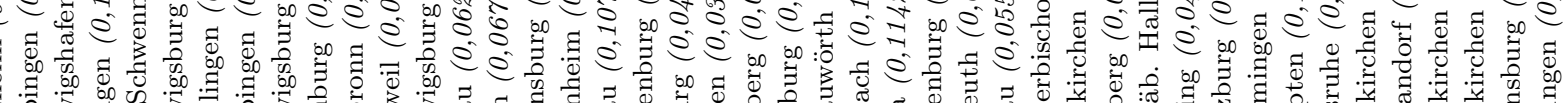

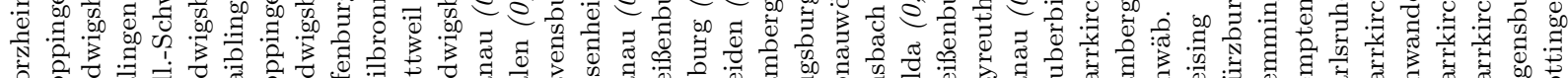

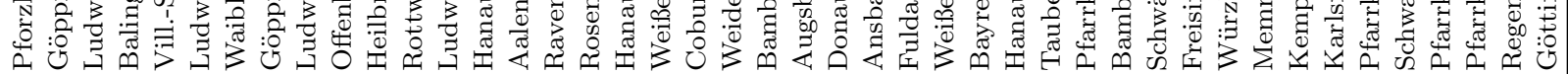

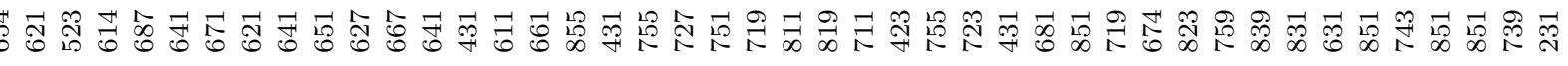

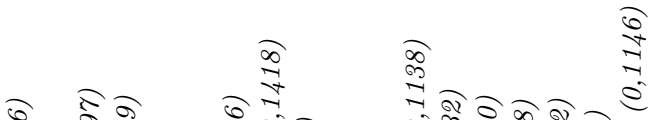

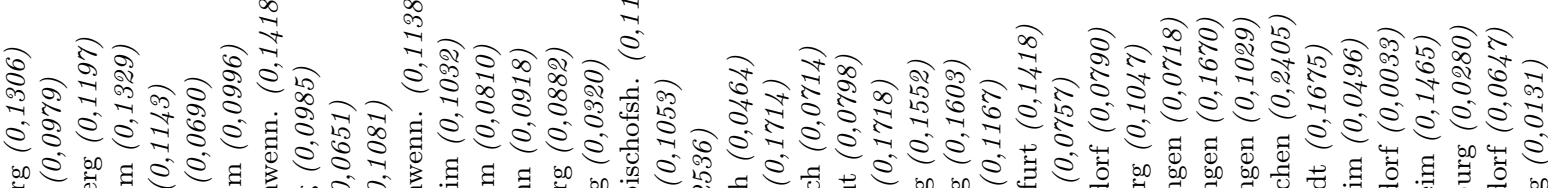
be

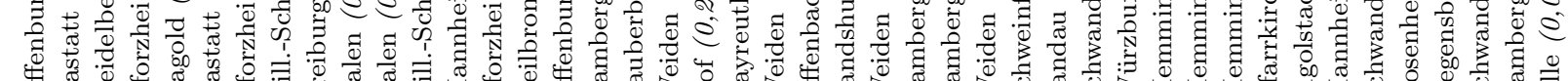

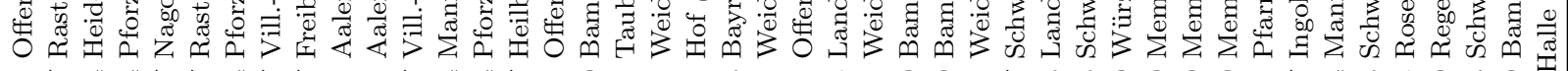

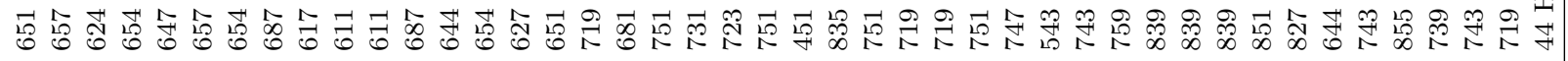

$\stackrel{2}{8}$

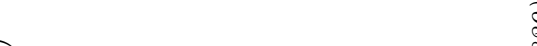

के

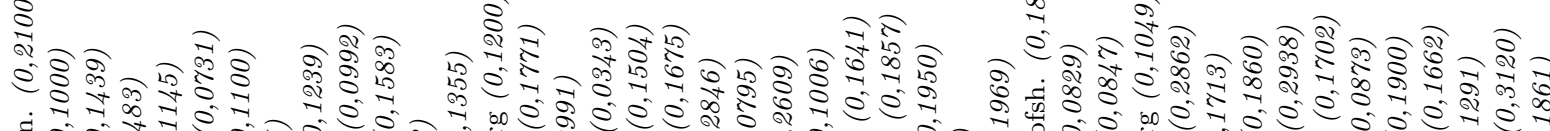

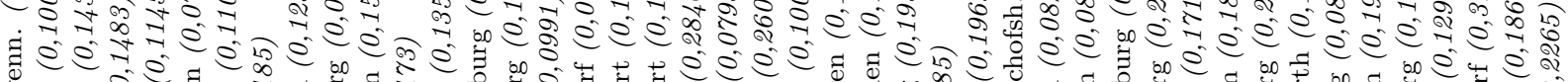
离。

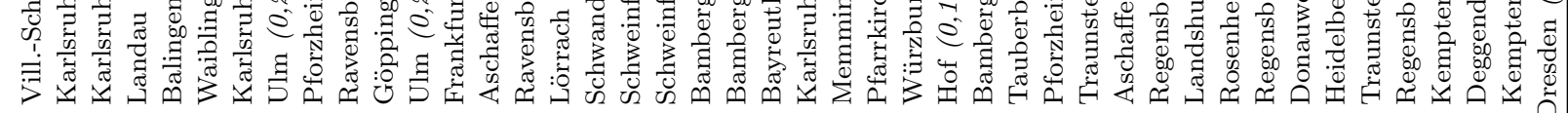

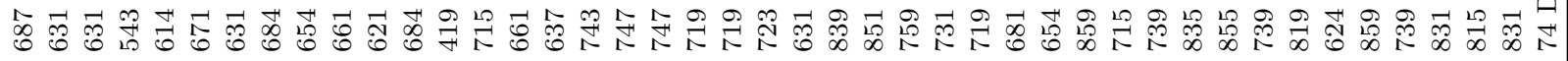

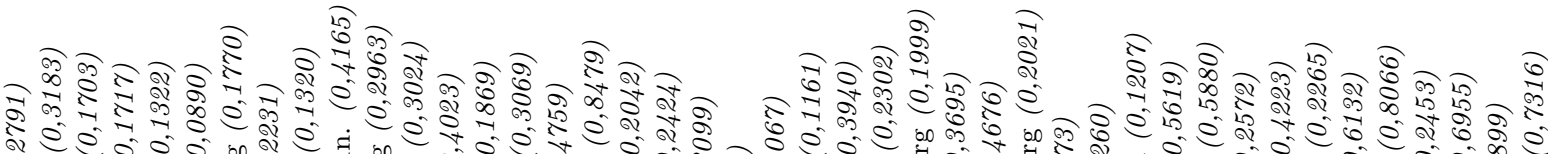

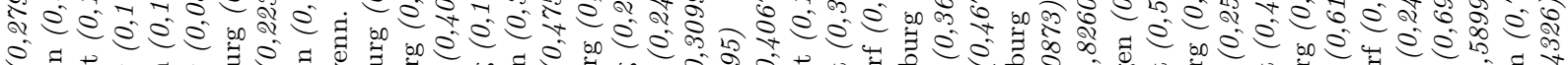
so

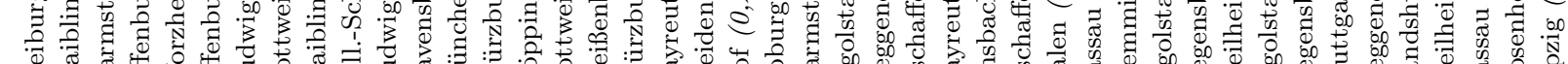

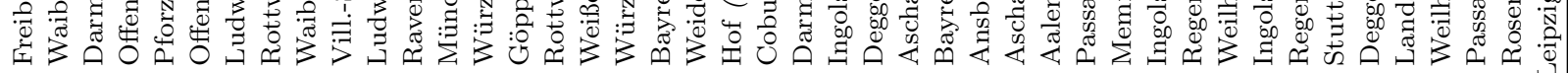

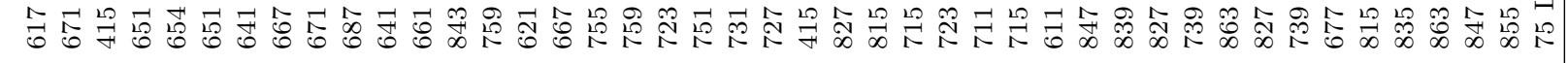

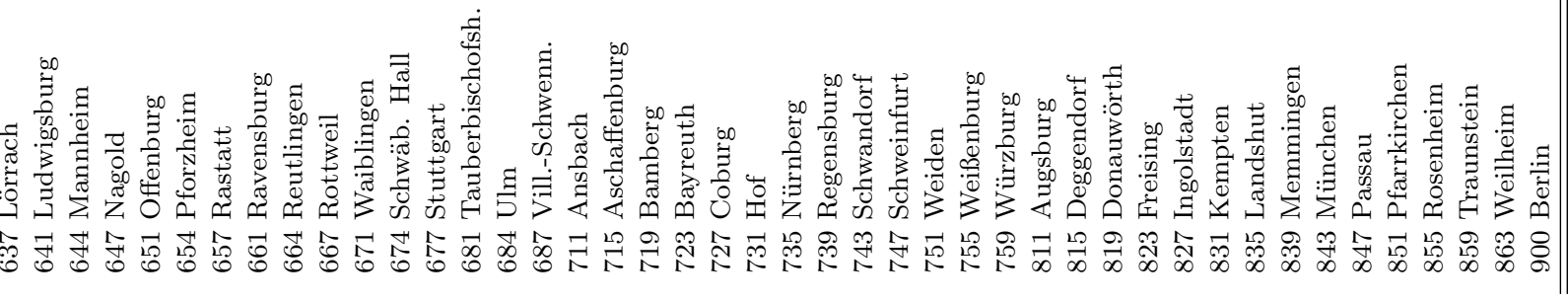




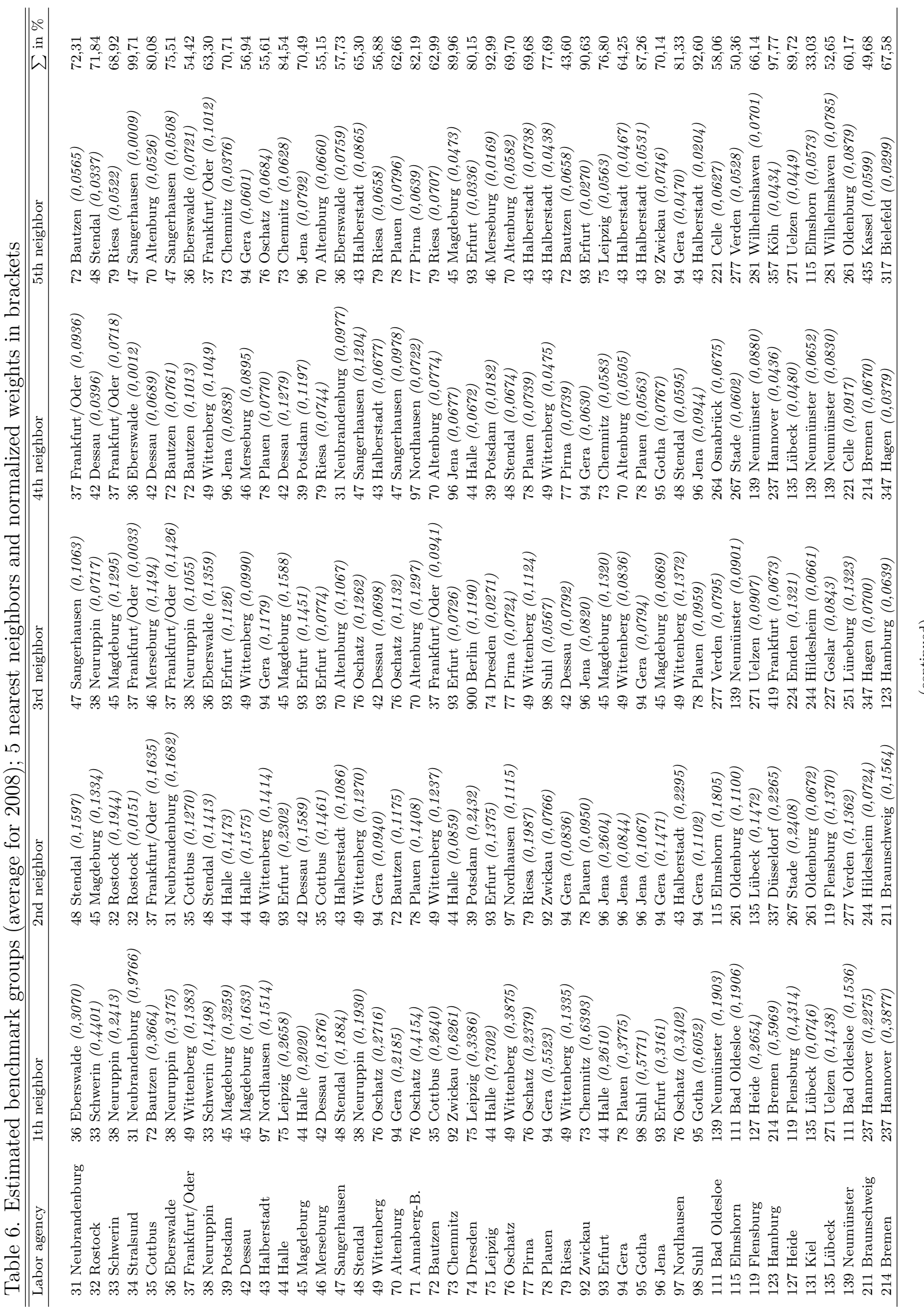




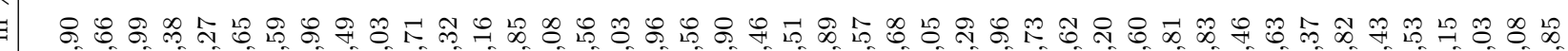

W

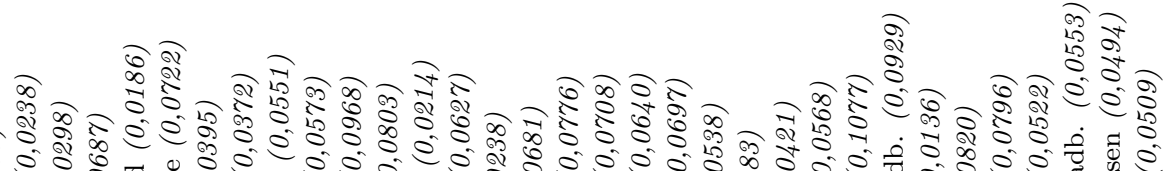

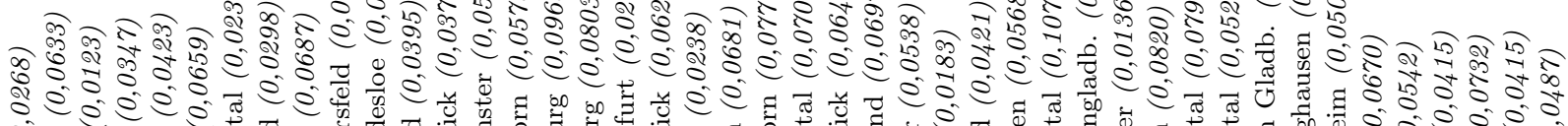

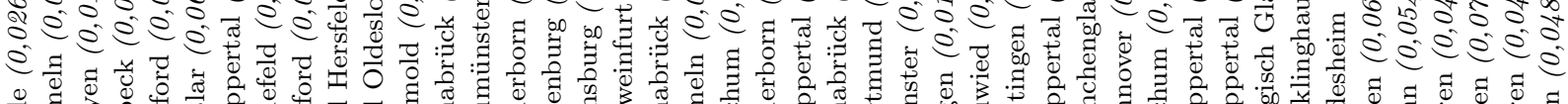

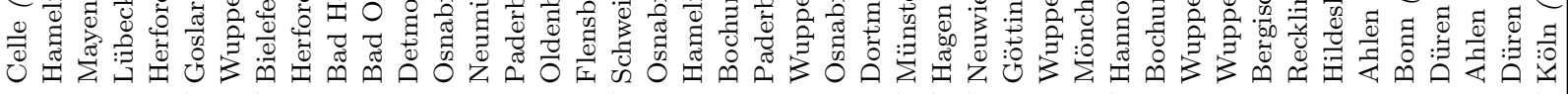

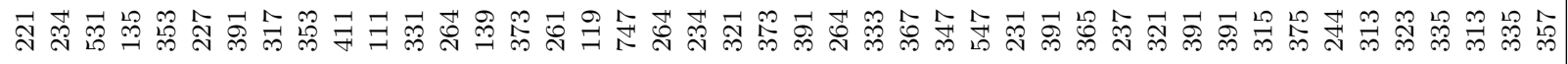

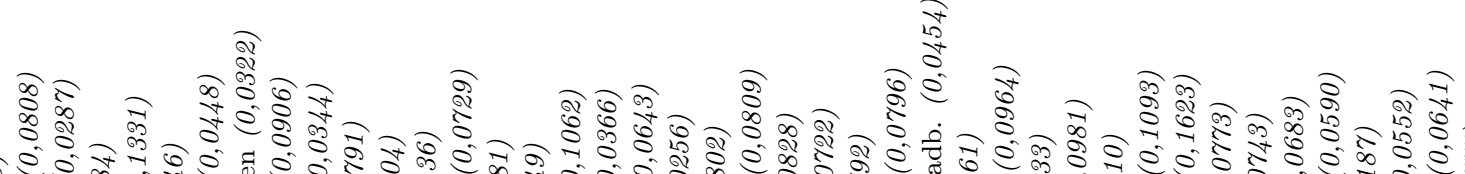

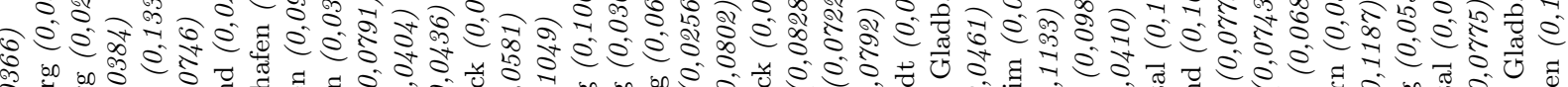

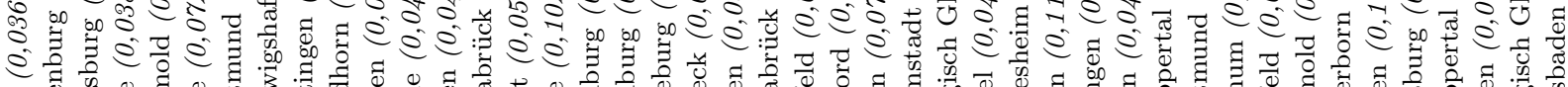

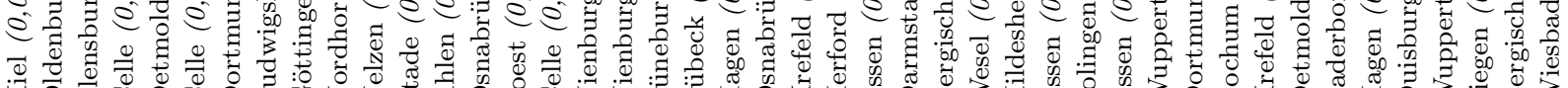

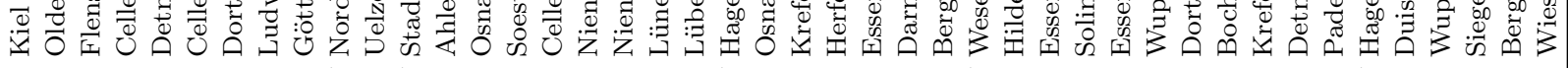

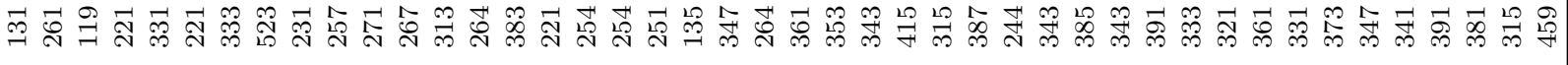

$\overbrace{}^{\infty}$

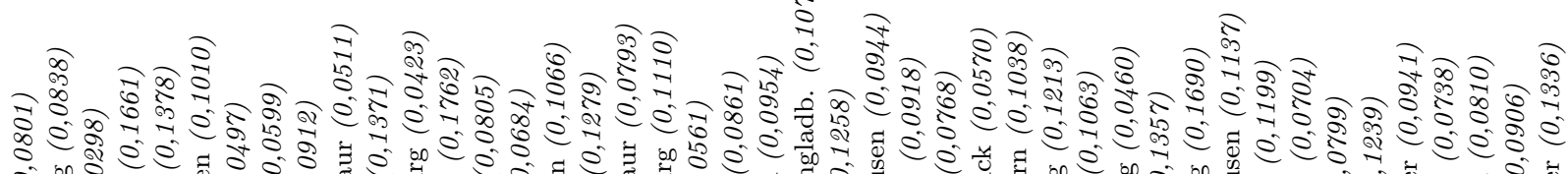
éla

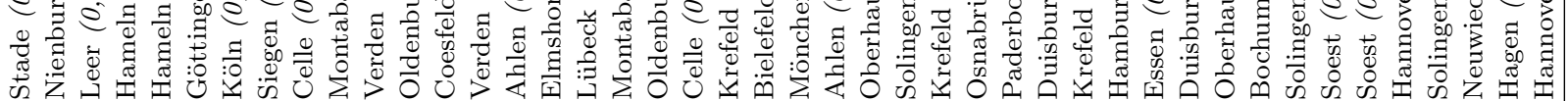

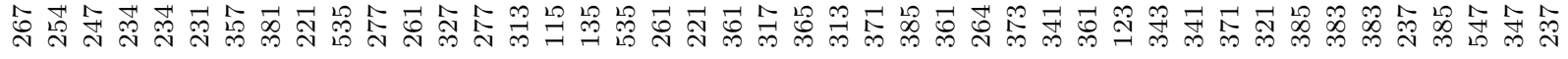

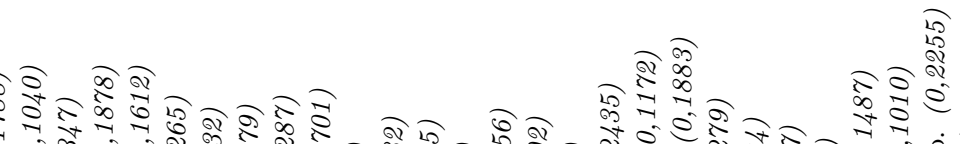

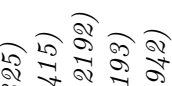

ㅇำ

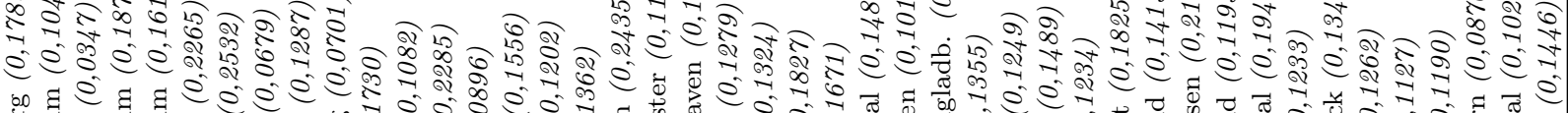

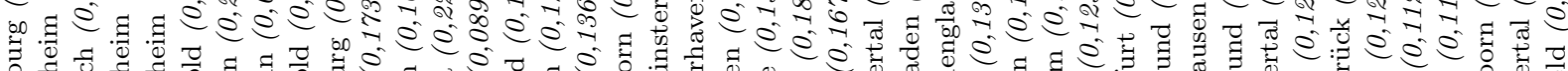

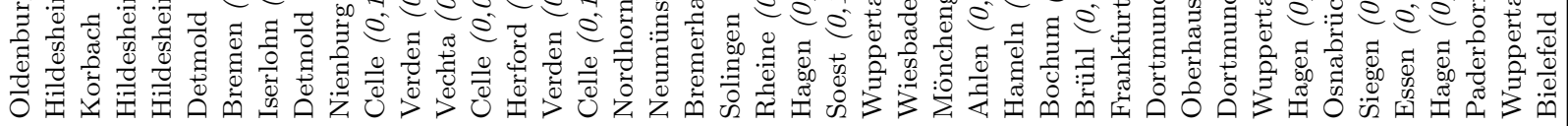

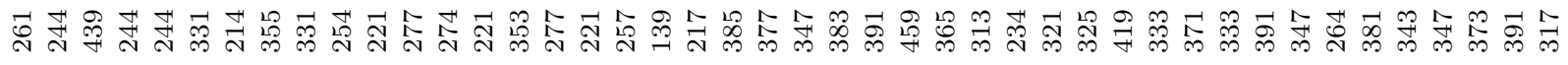

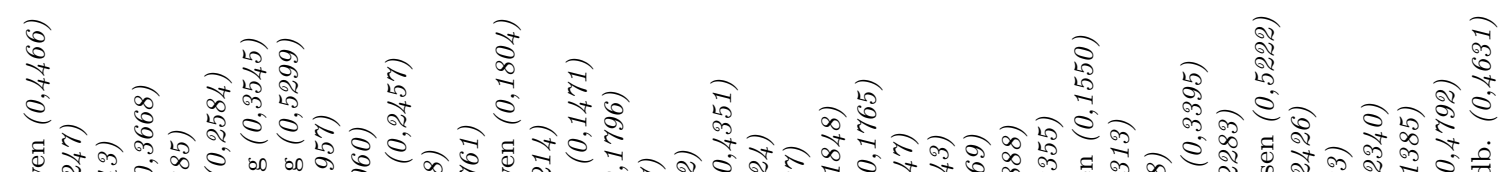

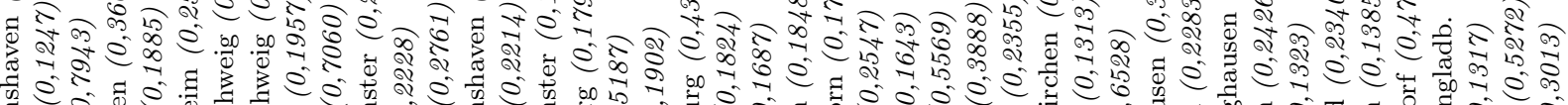

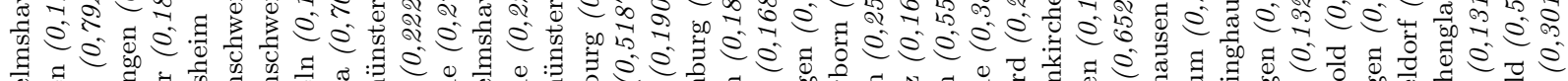

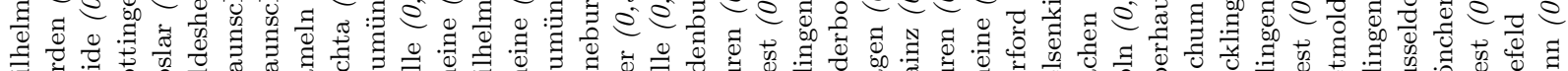

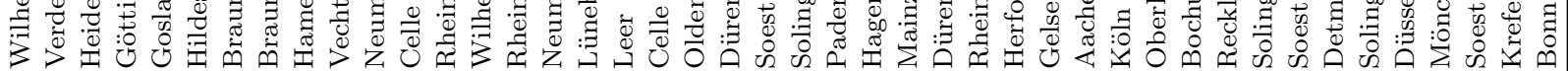

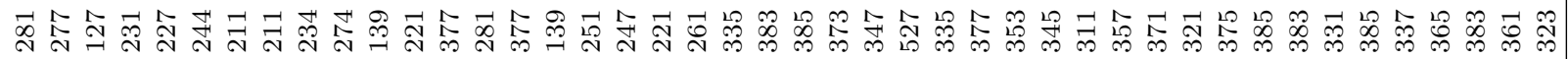

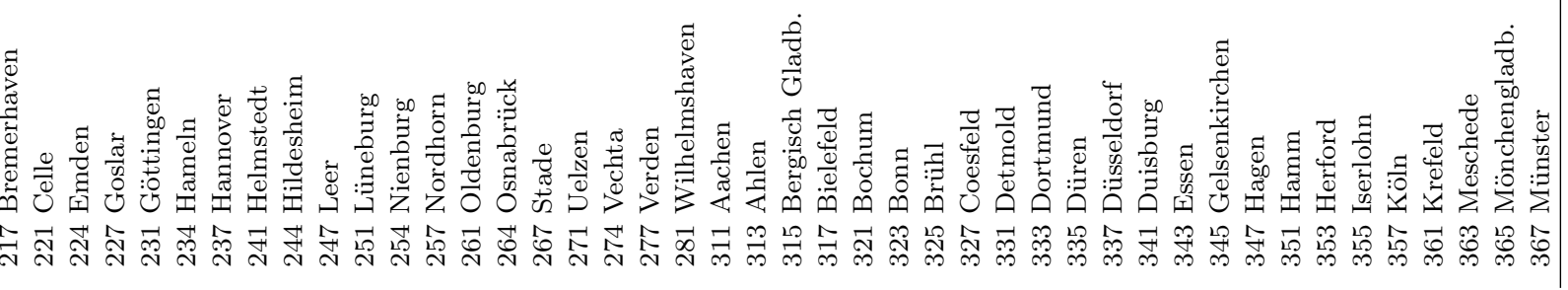


卌

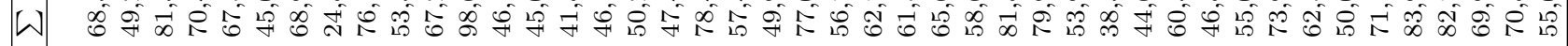

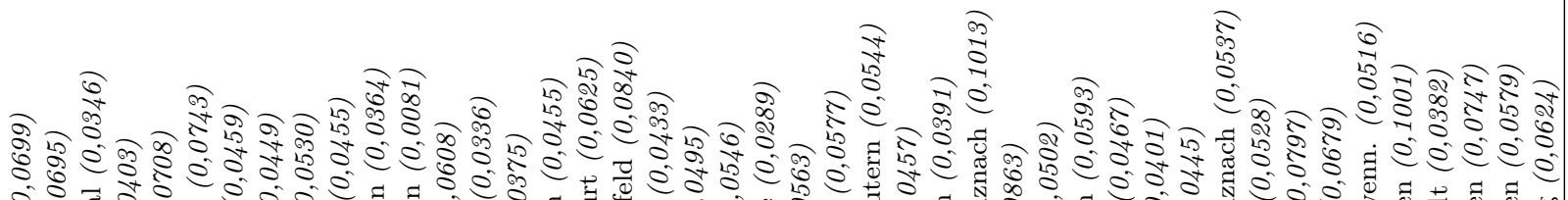

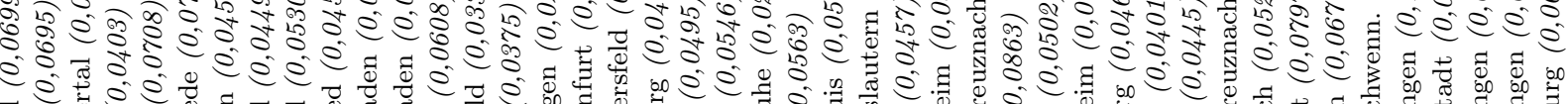

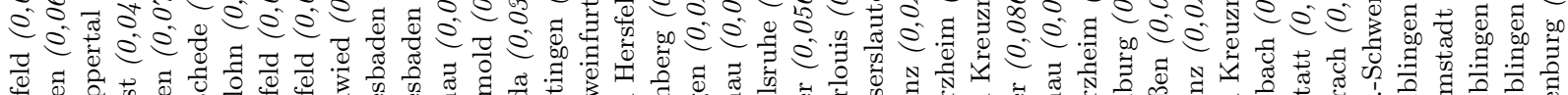

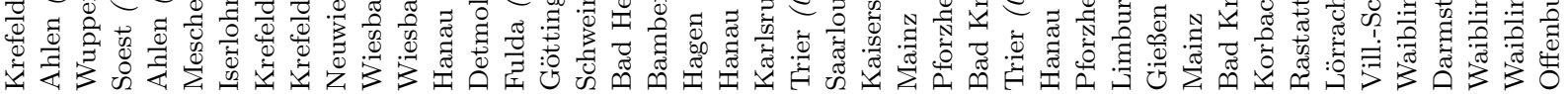

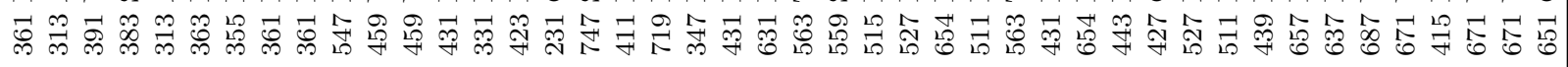

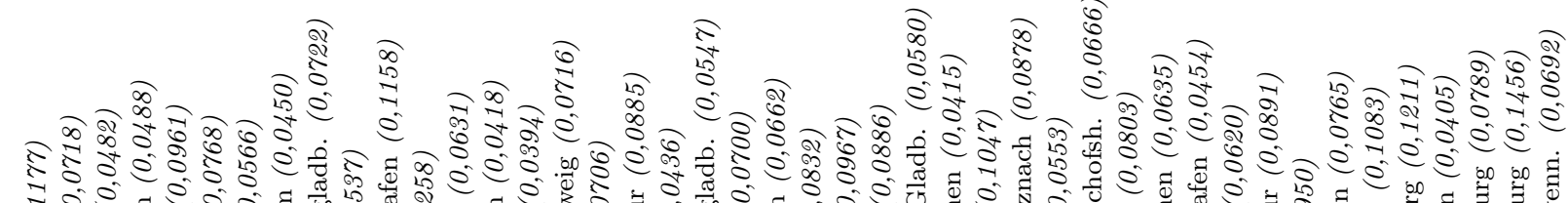
7 é

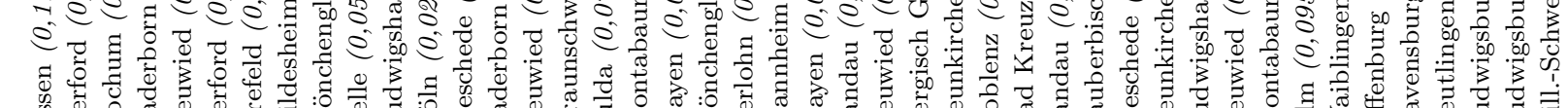

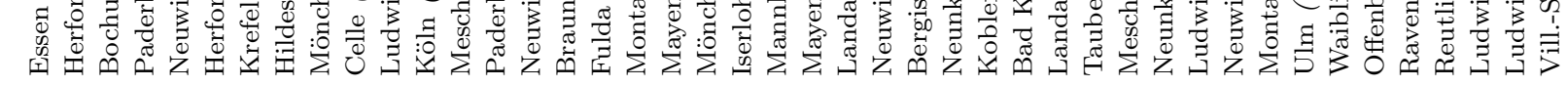

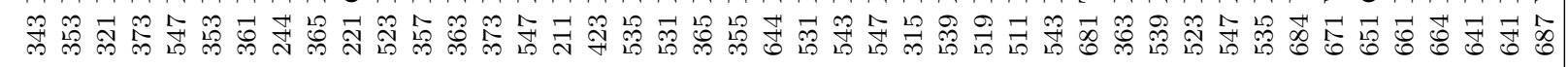

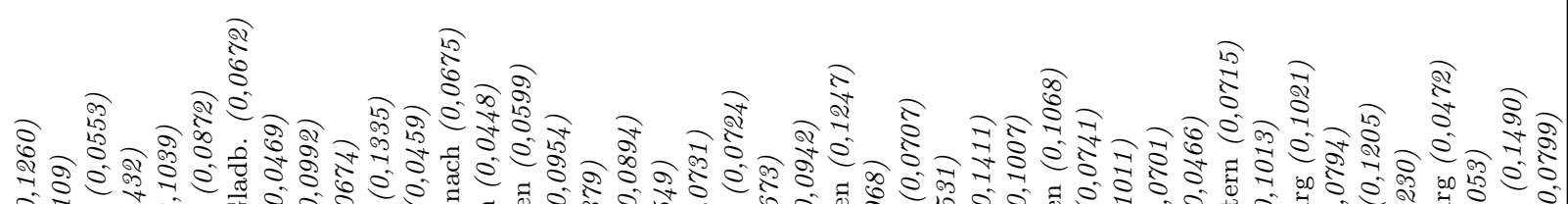
ét.

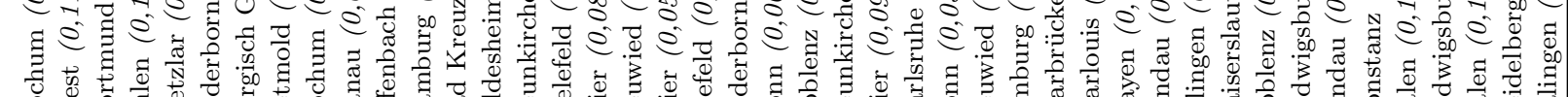

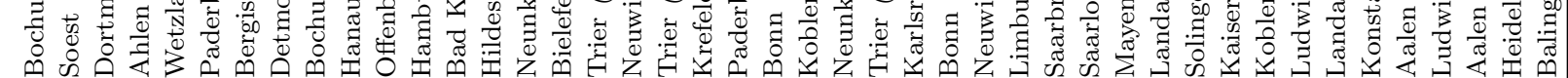

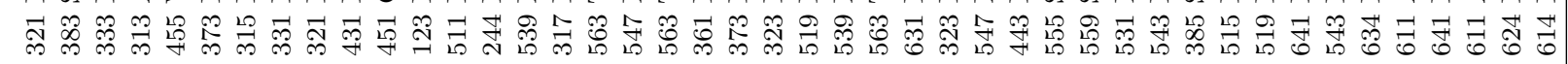

(2)

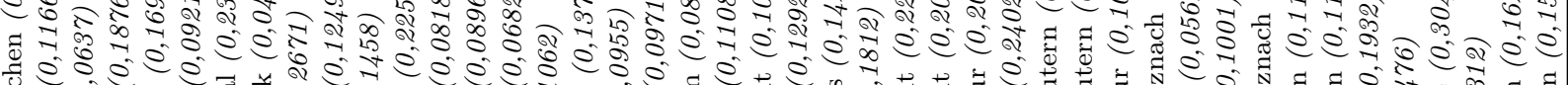

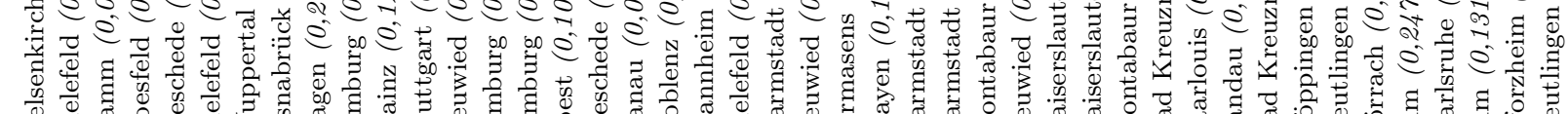

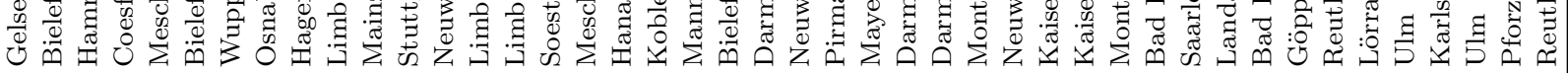

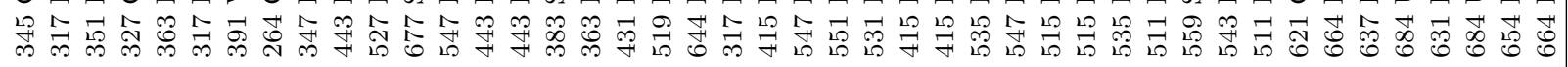

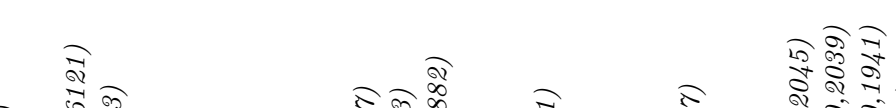

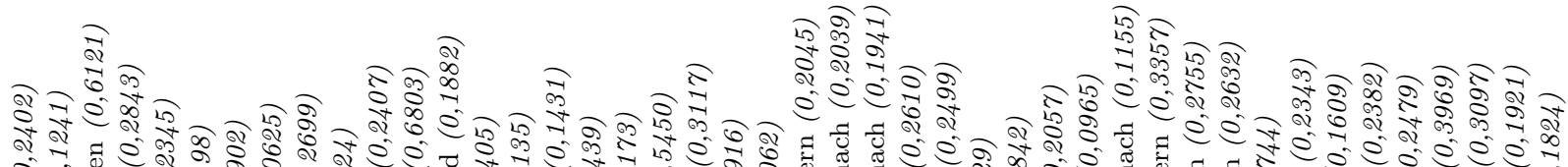

$\sqrt{50} \sqrt{10}$ é

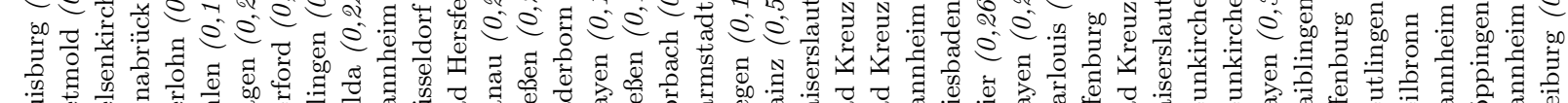

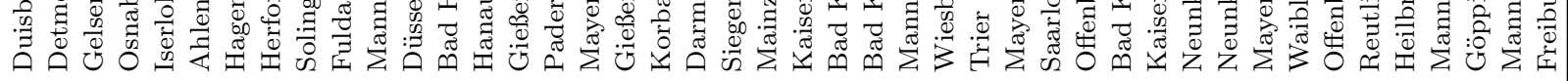

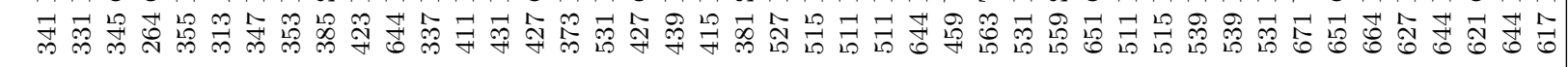

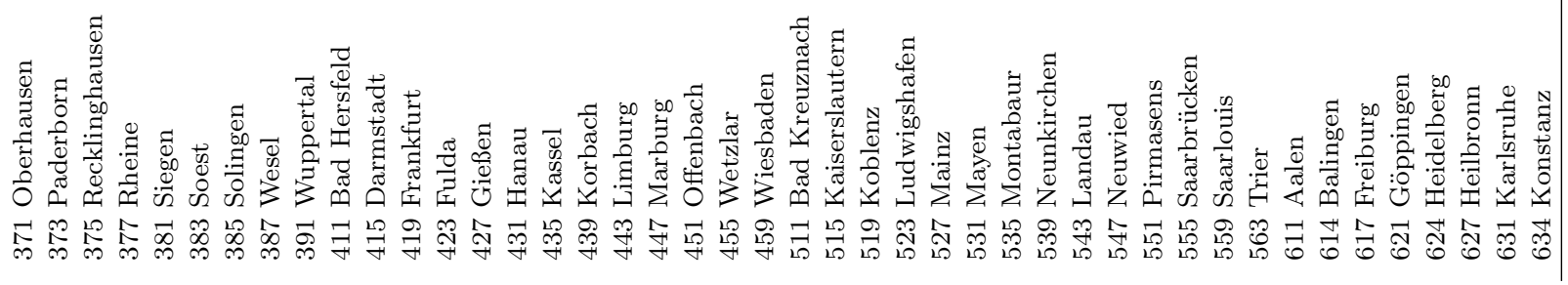




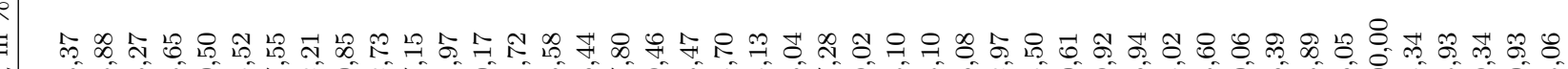

W की

尺

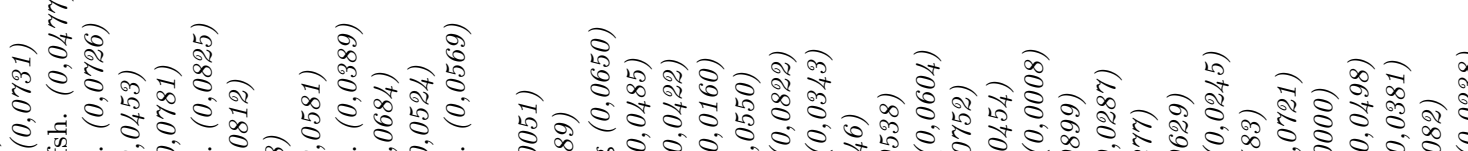

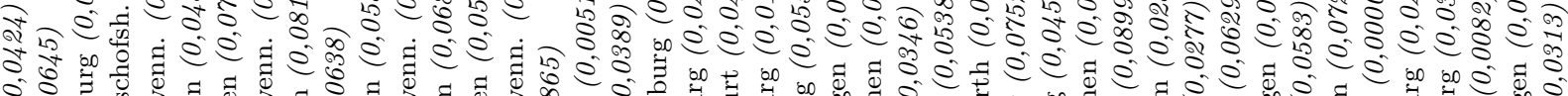
écon

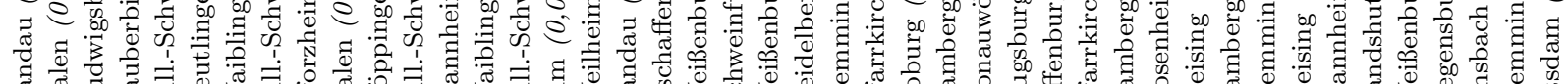

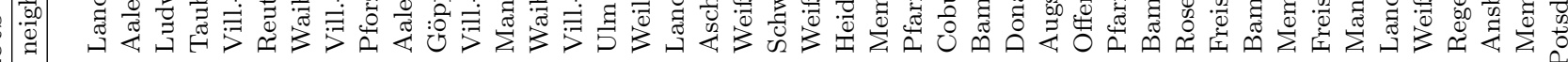

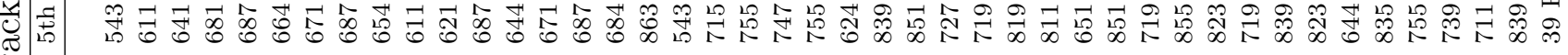

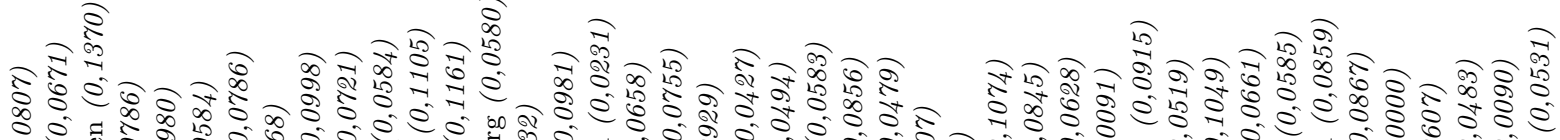

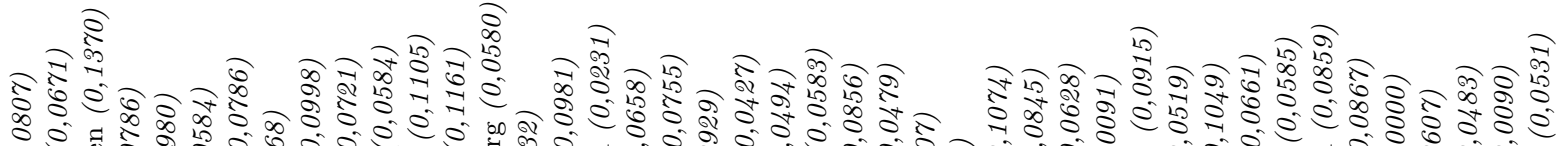

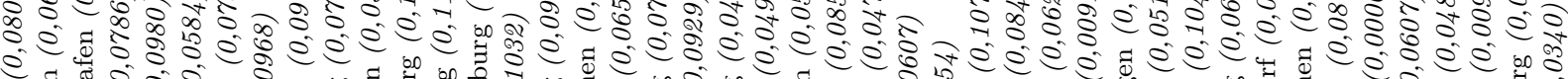

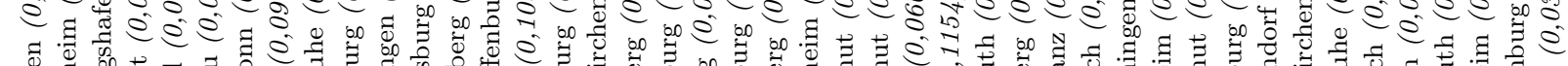

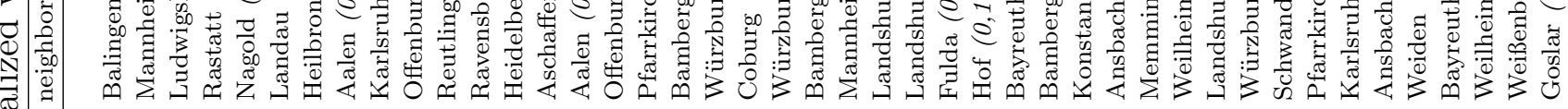

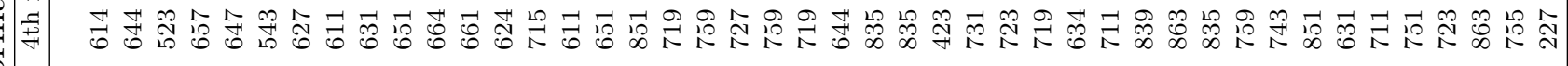

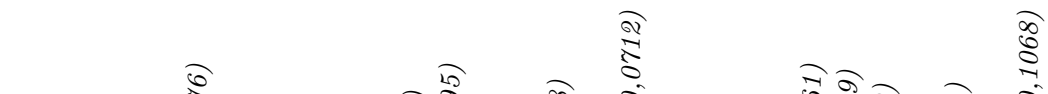

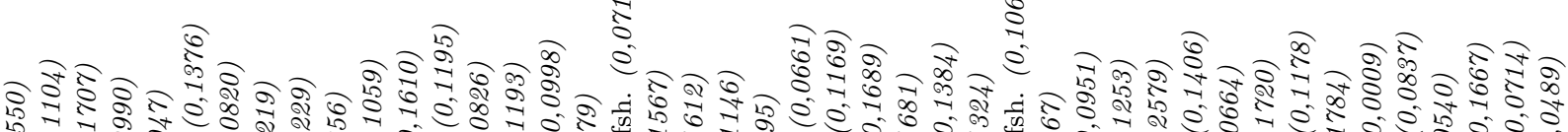

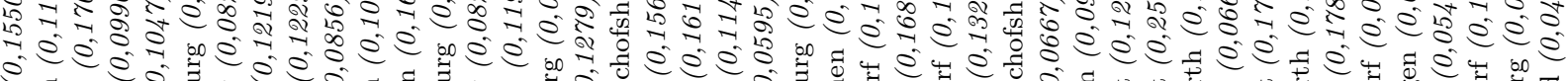
60.

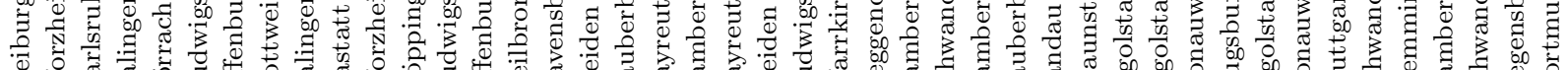

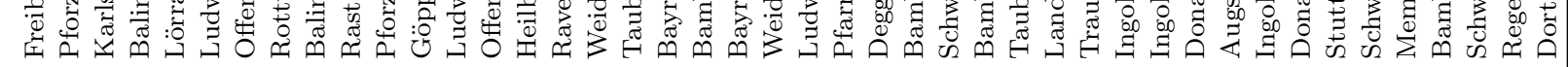

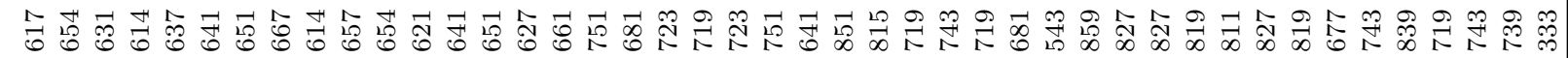

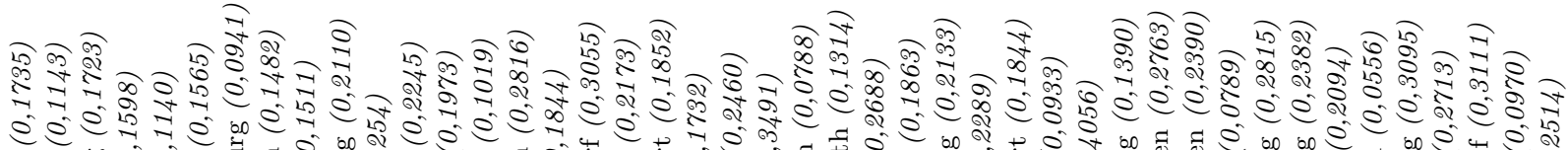

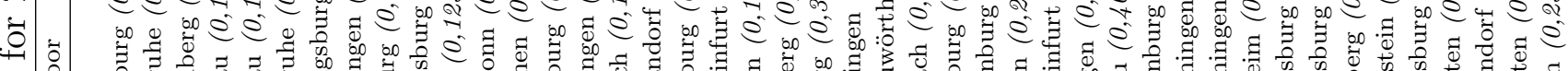

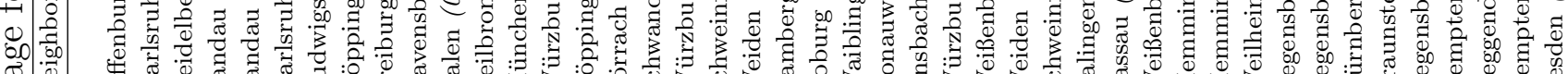

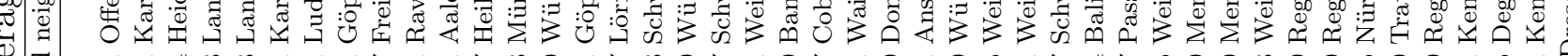

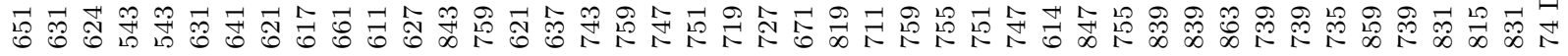

खิ

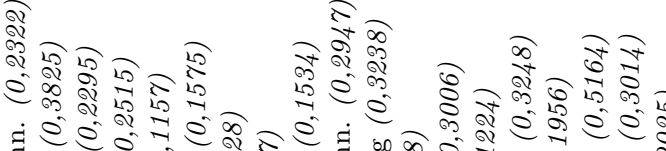

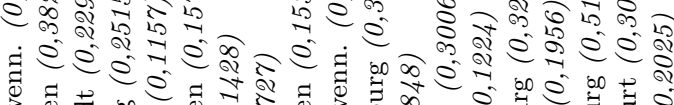

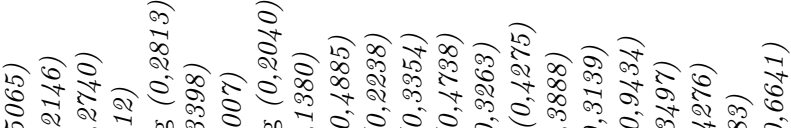

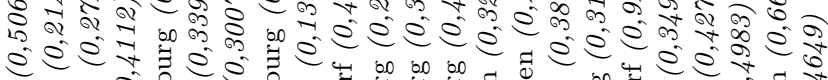

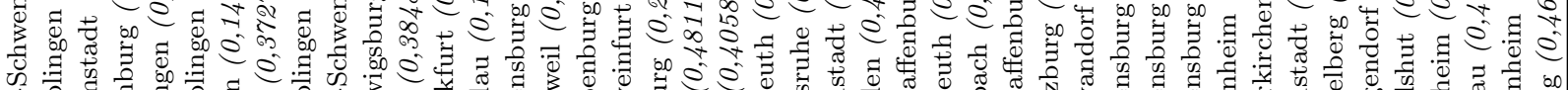

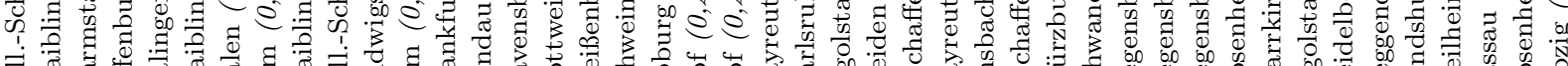

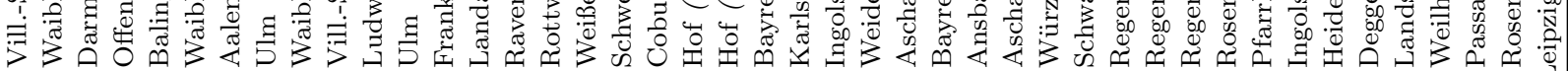

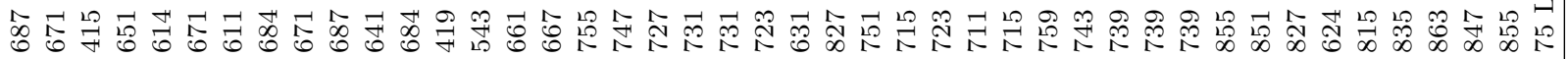

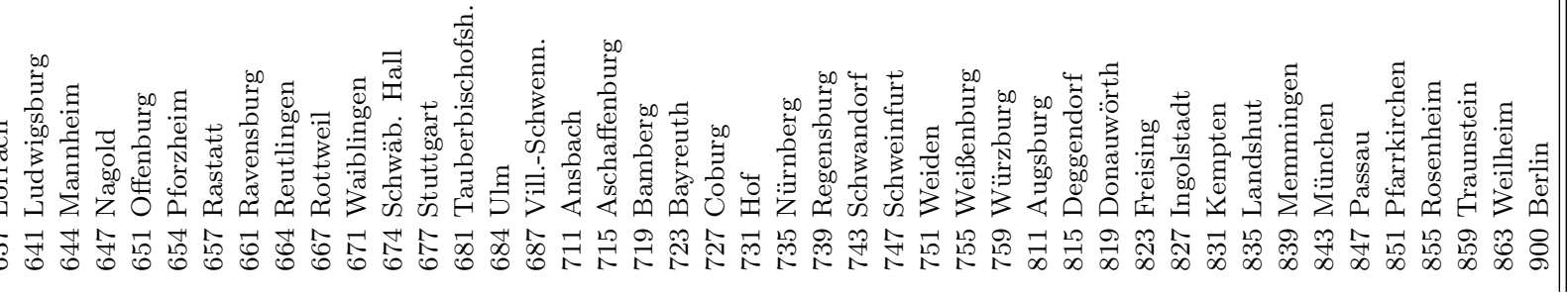




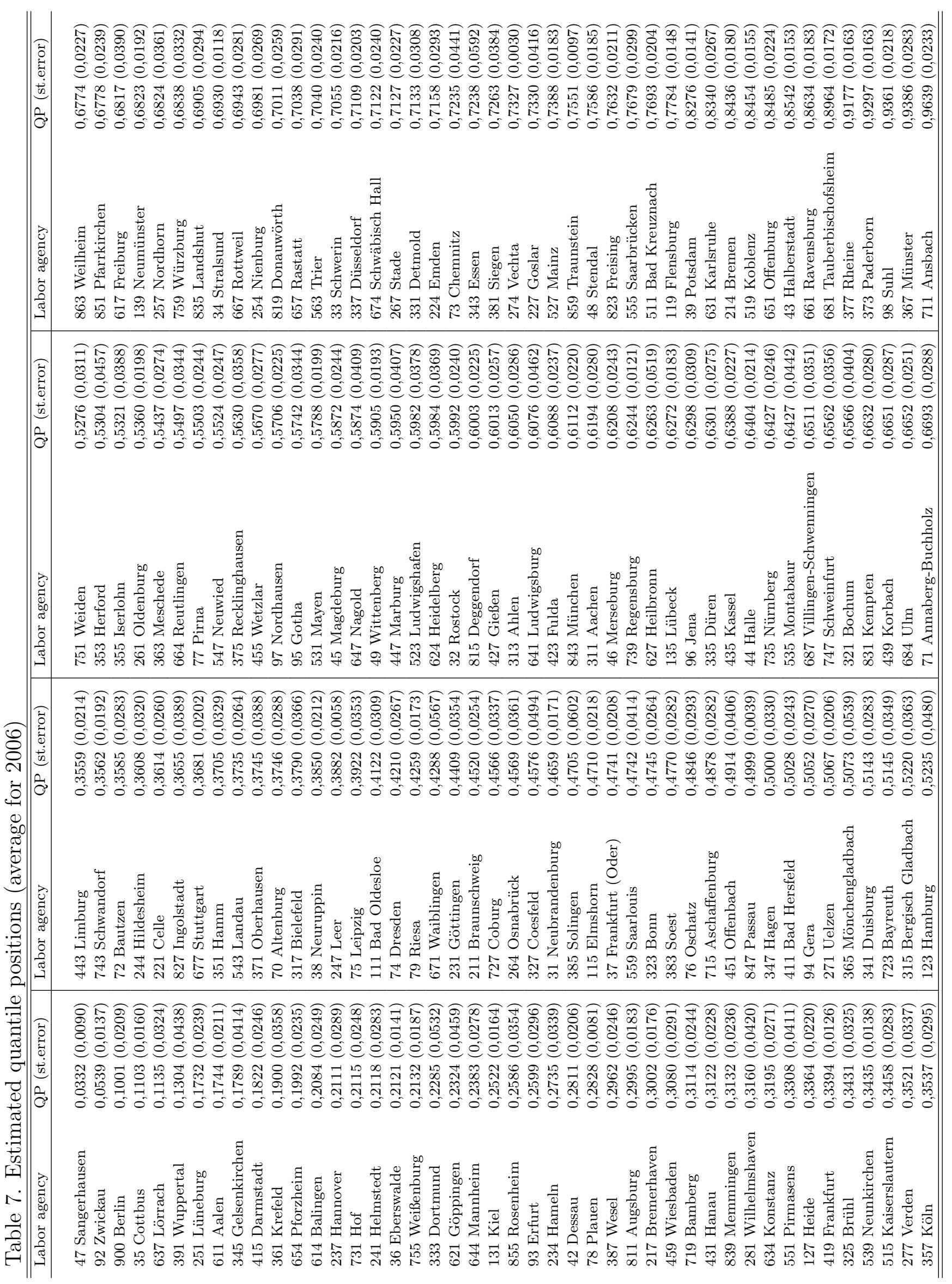




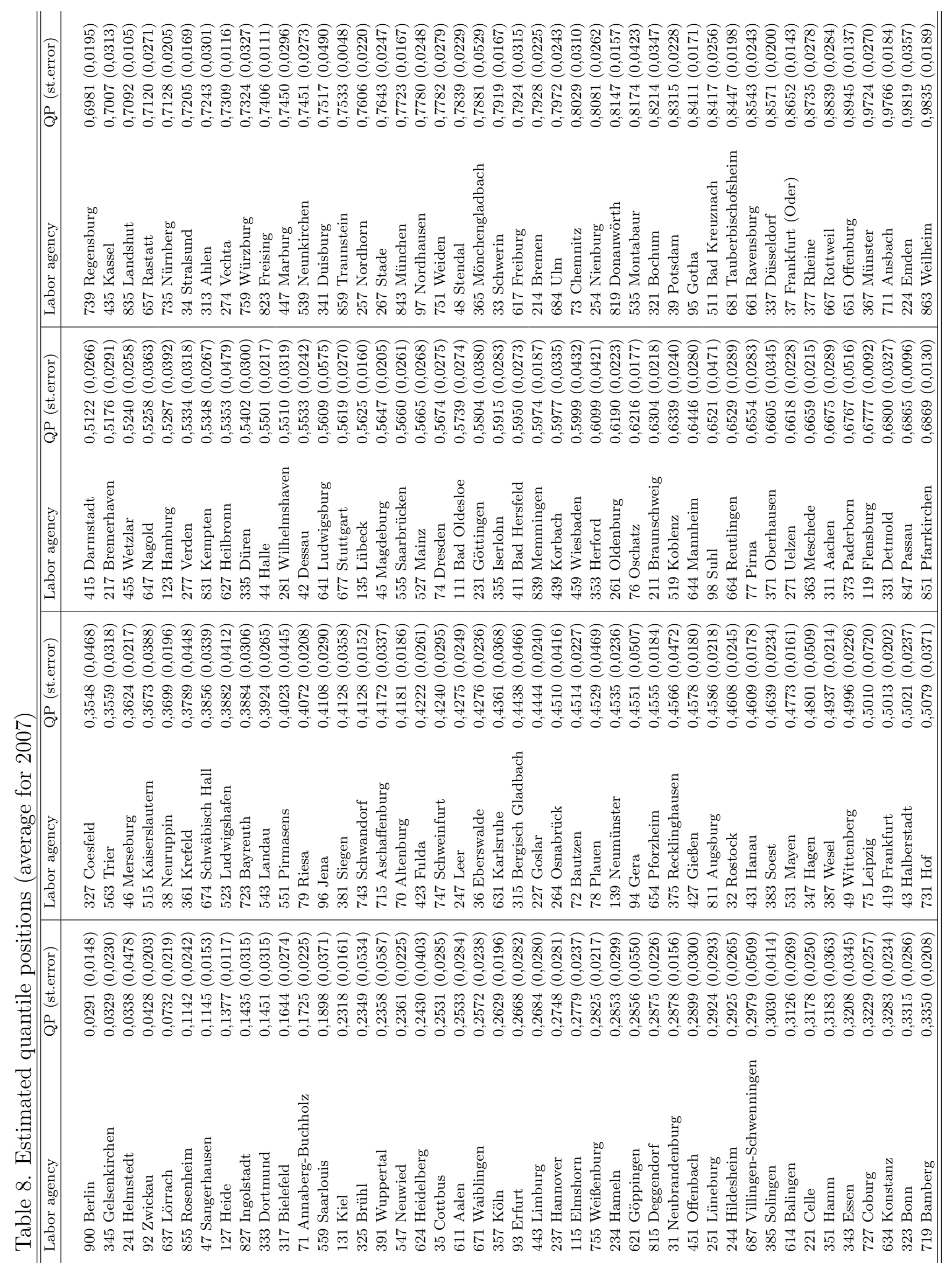




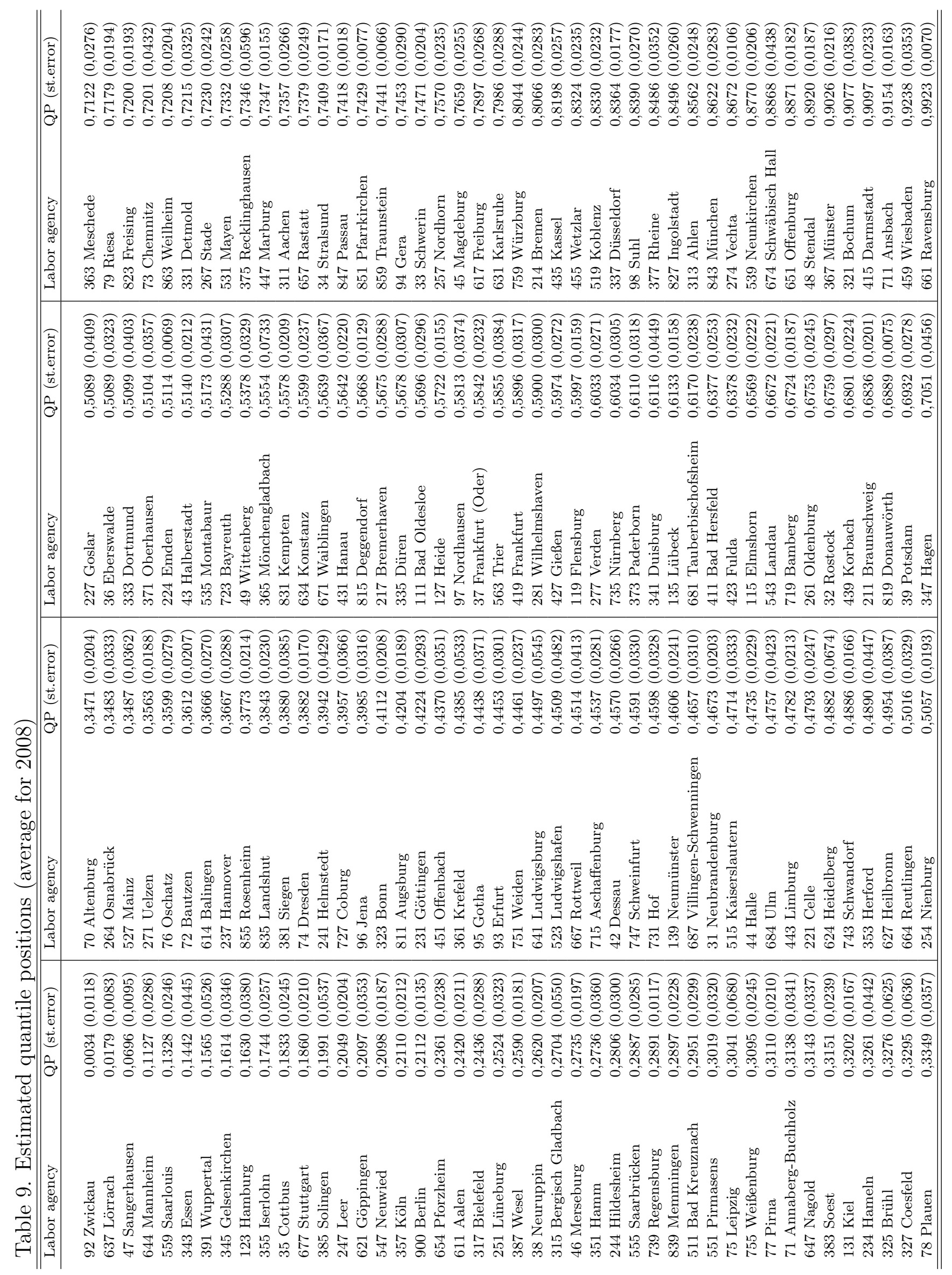


Table 10. Matching quality of explanatory variables (standardized differences (2006-2008))

\begin{tabular}{|c|c|c|c|c|c|c|}
\hline Variable & Mean & Median & St.dev & Min & $90 \%$ Qnt & Max \\
\hline East-West dummy & 0.0143 & 0.0000 & 0.0765 & 0.0000 & 0.0096 & 0.6652 \\
\hline Unemployment rate & 0.1907 & 0.1493 & 0.1390 & 0.0270 & 0.3932 & 0.7944 \\
\hline \multicolumn{7}{|l|}{ Share of registered unemployed (SGB III) by age } \\
\hline $15-24$ years old & 0.4432 & 0.4102 & 0.2230 & 0.0950 & 0.7200 & 1.3659 \\
\hline $25-54$ years old $^{a)}$ & 0.4941 & 0.4268 & 0.2798 & 0.1259 & 0.8820 & 1.9339 \\
\hline $55-64$ years old $^{b)}$ & 0.4476 & 0.3857 & 0.2664 & 0.1195 & 0.7782 & 1.9851 \\
\hline Share of registered female unemployed (SGB III) & 0.4742 & 0.4095 & 0.2624 & 0.1211 & 0.8190 & 1.4858 \\
\hline Share of female em & 4227 & 3421 & 0.3218 & 0.0314 & 0.8368 & 1.8137 \\
\hline \multicolumn{7}{|l|}{ Share of employees by education } \\
\hline Elementary and secondary school $(\mathrm{w} / \mathrm{o} \mathrm{VT})^{d)}$ & 0.3295 & 0.2681 & 0.2686 & 0.0283 & 0.7040 & 1.7022 \\
\hline High school without $\mathrm{VT}^{e}{ }^{e}$ & 0.3726 & 0.2661 & 0.3619 & 0.0263 & 0.8230 & 1.9400 \\
\hline Elementary and secondary school (with VT) $\left.{ }^{f}\right)$ & 0.3558 & 0.2551 & 0.2923 & 0.0340 & 0.7147 & 1.8464 \\
\hline High school with $\mathrm{VT}^{g}$ ) & 0.3085 & 0.2285 & 0.2795 & 0.0162 & 0.6409 & 1.8259 \\
\hline Techr & 0.4388 & 0.3 & 0.3536 & 0.0328 & 0.8393 & 2.3173 \\
\hline Univer: & 0.3972 & 84 & 23 & 0.0389 & 0.7361 & 3.0654 \\
\hline Education unkno & 556 & & 977 & 0.0440 & .0226 & .5278 \\
\hline \multicolumn{7}{|l|}{ Shares of employees by sectors (NACE 2003) } \\
\hline Agriculture, hunting and forestry $\left.{ }^{k}\right)$ & 0.3382 & 0.2279 & 0.3384 & 0.0196 & 0.7852 & 1.9180 \\
\hline Fishing $l$ ) & 0.2622 & 0.1062 & 0.5877 & 0.0039 & 0.4414 & 5.5727 \\
\hline Mining and & 0.4911 & 0.2769 & 0.7711 & 0.0086 & 0.2107 & 6.5713 \\
\hline Manufa & 0.4560 & 0.3904 & 0.3437 & 0.0437 & 0.8546 & 1.9727 \\
\hline Electricity, gas and water supply $\left.{ }^{o}\right)$ & 0.6072 & 0.4514 & 0.5444 & 0.0317 & 1.2800 & 3.1355 \\
\hline Construction & 0.3775 & 0.2717 & 0.3055 & 0.0444 & 0.8198 & 1.8578 \\
\hline Who & 2 & & & & & 2.4175 \\
\hline Hotels & 3 & & 26 & 0.0374 & 41 & 4.7307 \\
\hline communication $^{s)}$ & 0.5634 & 0.4298 & 0.7497 & 0.0456 & 1.0267 & 8.3847 \\
\hline Financ & 0.4098 & 0.2413 & 0.5280 & 0.0178 & 0.9680 & 3.4483 \\
\hline Real estate, renting and business activity ${ }^{u}$ & 0.4702 & 0.4038 & 0.3315 & 0.0496 & 0.8853 & 1.9199 \\
\hline Public administration and defense $e^{v)}$ & 0.5178 & 0.3950 & 0.4862 & 0.0377 & 1.0335 & 3.9215 \\
\hline Education $\left.^{w}\right)$ & 0.4739 & 0.3515 & 0.3970 & 0.0236 & 0.9760 & 2.5127 \\
\hline Health and social work ${ }^{x}$ & 0.6070 & 0.5637 & 0.4475 & 0.0522 & 1.1429 & 2.8084 \\
\hline Other c & & & & 0.0424 & 1.0775 & 3.8378 \\
\hline Priva & & & & 0.0409 & & 2.0945 \\
\hline Others ${ }^{a a)}$ & 0.3744 & 0.1813 & 0.8996 & 0.0238 & 0.8236 & 10.6131 \\
\hline Flow into une & 0.2225 & 0.1712 & 0.1565 & 0.0412 & 0.4128 & 1.0978 \\
\hline Non-subsidized vacancies (Share; UN SGB III) ${ }^{a b)}$ & 0.3612 & 0.2839 & 0.2727 & 0.0638 & 0.6788 & 2.0364 \\
\hline Average wages (in logarithm) & 0.1716 & 0.1376 & 0.1249 & 0.0251 & 0.3271 & 0.8552 \\
\hline Seasonal spar & 0.1972 & 0.1649 & 0.1257 & 0.0252 & 0.3635 & 0.7508 \\
\hline Density of population (in logarithm) $)^{a c)}$ & 0.3114 & 0.2468 & 0.2660 & 0.0191 & 0.5848 & 2.0896 \\
\hline
\end{tabular}

Notes: Regions with mismatch in ${ }^{a)}$ Brühl, Ludwigshafen; ${ }^{b)}$ Brühl; $\left.{ }^{c}\right)$ Helmstedt; ${ }^{d)}$ Iserlohn ${ }^{e}$ Aachen, Marburg, Münster, Freising; ${ }^{f)}$ Berlin; ${ }^{g)}$ Münster; ${ }^{h}$ Stuttgart, Pirna, Dresden; ${ }^{i)}$ Heidelberg, Jena, Dresden; ${ }^{j)}$ München, Freising, Berlin; $\left.{ }^{k}\right)$ Vechta, Stendal;

${ }^{l)}$ Heide, Bremerhaven, Stade, Stralsund, Neubrandenburg, Frankfurt (Oder); ${ }^{m}$ Cottbus, Nienburg, Rheine, Wesel, Oberhausen, Gelsenkirchen, Bochum, Dortmund, Bad Hersfeld, Saarlouis; ${ }^{n)}$ Helmstedt, Iserlohn, Freising; ${ }^{o}$ Flensburg, Elmshorn, Emden, Cottbus, Essen, Mönchengladbach, Nürnberg, Karlsruhe; ${ }^{p)}$ Pfarrkirchen; ${ }^{r}$ Verden, Helmstedt, Oberhausen, Mönchengladbach, Brühl, Düren, Limburg, Ludwigshaven, Heidelberg; ${ }^{s}$ Stralsund, Rostock, Halberstadt, Goslar, Nagold, Freising, Kempten; ${ }^{t}$ Bremerhaven, Bremen, Hamm, Duisburg, Frankfurt, Freising; $\left.{ }^{u}\right)$ Münster, Dortmund, Köln, Koblenz, Wiesbaden, Frankfurt, Coburg; ${ }^{v)}$ Essen ${ }^{w)}$ Kiel, Wilhelmshaven, Leipzig, Koblenz, Wiesbaden; ${ }^{x)}$ Neubrandenburg, Neuruppin, Marburg; ${ }^{y)}$ Elmshorn, Korbach, Aschaffenburg, Neunkirchen, Heidelberg, Freiburg; ${ }^{z)}$ Kiel, Düsseldorf, Köln, Bonn, Mainz, Rastatt ${ }^{a a}$ ) München, Rosenheim; ${ }^{a b)}$ Weiden, Kaiserslautern, Neunkirchen, Pirmasens; ${ }^{a c)}$ Berlin. 
Table 11. Absolute performance and quantile positions

\begin{tabular}{|c|c|c|c|c|c|c|}
\hline \multirow[b]{2}{*}{ Labor agency } & \multicolumn{3}{|c|}{ Absolute performance } & \multicolumn{3}{|c|}{ Quantile position } \\
\hline & 2006 & 2007 & 2008 & 2006 & 2007 & 2008 \\
\hline 31 Neubrandenburg & 0,0089 & $-0,0041$ & 0,0040 & 0,4659 & 0,2878 & 0,4673 \\
\hline 32 Rostock & $-0,0001$ & 0,0001 & 0,0058 & 0,5992 & 0,4608 & 0,6759 \\
\hline 33 Schwerin & 0,0069 & 0,0071 & 0,0080 & 0,7055 & 0,7919 & 0,7471 \\
\hline 34 Stralsund & 0,0227 & 0,0272 & 0,0328 & 0,6930 & 0,7205 & 0,7409 \\
\hline 35 Cottbus & $-0,0055$ & $-0,0047$ & $-0,0045$ & 0,1103 & 0,2531 & 0,1833 \\
\hline 36 Eberswalde & $-0,0069$ & $-0,0032$ & 0,0004 & 0,2121 & 0,4276 & 0,5089 \\
\hline 37 Frankfurt (Oder) & 0,0013 & 0,0118 & 0,0012 & 0,4741 & 0,8652 & 0,5842 \\
\hline 38 Neuruppin & $-0,0055$ & $-0,0026$ & $-0,0048$ & 0,3850 & 0,3699 & 0,2620 \\
\hline 39 Potsdam & 0,0122 & 0,0045 & 0,0040 & 0,8276 & 0,8315 & 0,6932 \\
\hline 42 Dessau & $-0,0085$ & $-0,0007$ & $-0,0003$ & 0,2811 & 0,5533 & 0,4570 \\
\hline 43 Halberstadt & 0,0153 & 0,0021 & 0,0032 & 0,8542 & 0,5021 & 0,5140 \\
\hline 44 Halle & $-0,0051$ & 0,0003 & $-0,0011$ & 0,6404 & 0,5501 & 0,4735 \\
\hline 45 Magdeburg & 0,0010 & 0,0036 & 0,0094 & 0,5872 & 0,5647 & 0,7659 \\
\hline 46 Merseburg & 0,0017 & $-0,0050$ & $-0,0097$ & 0,6208 & 0,3624 & 0,2735 \\
\hline 47 Sangerhausen & $-0,0161$ & $-0,0147$ & $-0,0153$ & 0,0332 & 0,1145 & 0,0696 \\
\hline 48 Stendal & 0,0162 & 0,0065 & 0,0138 & 0,7586 & 0,7839 & 0,8920 \\
\hline 49 Wittenberg & 0,0043 & 0,0002 & 0,0022 & 0,5905 & 0,4996 & 0,5378 \\
\hline 70 Altenburg & 0,0001 & $-0,0023$ & $-0,0059$ & 0,3746 & 0,4181 & 0,3471 \\
\hline 71 Annaberg-Buchholz & 0,0035 & $-0,0066$ & $-0,0018$ & 0,6693 & 0,1725 & 0,3138 \\
\hline 72 Bautzen & $-0,0049$ & 0,0004 & $-0,0050$ & 0,3585 & 0,4514 & 0,3612 \\
\hline 73 Chemnitz & 0,0066 & 0,0141 & 0,0126 & 0,7235 & 0,8029 & 0,7201 \\
\hline 74 Dresden & $-0,0097$ & 0,0031 & $-0,0043$ & 0,4210 & 0,5674 & 0,3882 \\
\hline 75 Leipzig & $-0,0061$ & $-0,0010$ & $-0,0021$ & 0,3922 & 0,5010 & 0,3041 \\
\hline 76 Oschatz & 0,0029 & 0,0024 & $-0,0020$ & 0,4846 & 0,6216 & 0,3599 \\
\hline 77 Pirna & 0,0111 & 0,0062 & 0,0006 & 0,5503 & 0,6554 & 0,3110 \\
\hline 78 Plauen & $-0,0023$ & 0,0019 & 0,0001 & 0,2828 & 0,4529 & 0,3349 \\
\hline 79 Riesa & $-0,0093$ & $-0,0026$ & 0,0051 & 0,4259 & 0,4072 & 0,7179 \\
\hline 92 Zwickau & $-0,0074$ & $-0,0141$ & $-0,0126$ & 0,0539 & 0,0428 & 0,0034 \\
\hline 93 Erfurt & $-0,0052$ & $-0,0074$ & $-0,0045$ & 0,2599 & 0,2668 & 0,4453 \\
\hline 94 Gera & 0,0048 & $-0,0019$ & 0,0112 & 0,5052 & 0,4551 & 0,7453 \\
\hline 95 Gotha & $-0,0042$ & 0,0097 & $-0,0062$ & 0,5742 & 0,8411 & 0,4438 \\
\hline 96 Jena & 0,0020 & 0,0004 & $-0,0016$ & 0,6298 & 0,4108 & 0,3985 \\
\hline 97 Nordhausen & 0,0086 & 0,0114 & 0,0017 & 0,5706 & 0,7780 & 0,5813 \\
\hline 98 Suhl & 0,0152 & 0,0105 & 0,0072 & 0,9361 & 0,6521 & 0,8390 \\
\hline 111 Bad Oldesloe & $-0,0009$ & 0,0021 & 0,0018 & 0,4122 & 0,5739 & 0,5696 \\
\hline 115 Elmshorn & $-0,0015$ & $-0,0040$ & 0,0016 & 0,4710 & 0,2779 & 0,6569 \\
\hline 119 Flensburg & 0,0208 & 0,0194 & 0,0122 & 0,7784 & 0,6777 & 0,5997 \\
\hline 123 Hamburg & $-0,0014$ & $-0,0003$ & $-0,0070$ & 0,5235 & 0,5287 & 0,1630 \\
\hline 127 Heide & $-0,0061$ & $-0,0147$ & 0,0135 & 0,3364 & 0,1377 & 0,5722 \\
\hline 131 Kiel & $-0,0082$ & $-0,0062$ & $-0,0048$ & 0,2522 & 0,2318 & 0,3202 \\
\hline 135 Lübeck & 0,0140 & 0,0129 & 0,0163 & 0,6272 & 0,5625 & 0,6133 \\
\hline 139 Neumünster & 0,0030 & $-0,0008$ & $-0,0037$ & 0,6823 & 0,4535 & 0,4606 \\
\hline 211 Braunschweig & $-0,0022$ & 0,0047 & 0,0072 & 0,4520 & 0,6304 & 0,6836 \\
\hline 214 Bremen & 0,0076 & 0,0121 & 0,0068 & 0,8436 & 0,7928 & 0,8066 \\
\hline
\end{tabular}

(continued) 
Table 11. Absolute performance and quantile positions (continued)

\begin{tabular}{|c|c|c|c|c|c|c|}
\hline \multirow[b]{2}{*}{ Labor agency } & \multicolumn{3}{|c|}{ Absolute performance } & \multicolumn{3}{|c|}{ Quantile position } \\
\hline & 2006 & 2007 & 2008 & 2006 & 2007 & 2008 \\
\hline 217 Bremerhaven & $-0,0189$ & $-0,0033$ & $-0,0082$ & 0,3002 & 0,5176 & 0,5675 \\
\hline 221 Celle & $-0,0028$ & $-0,0056$ & $-0,0003$ & 0,3614 & 0,3178 & 0,4793 \\
\hline 224 Emden & 0,0134 & 0,0124 & 0,0224 & 0,7158 & 0,9819 & 0,5114 \\
\hline 227 Goslar & 0,0028 & $-0,0060$ & 0,0037 & 0,7330 & 0,4444 & 0,5089 \\
\hline 231 Göttingen & $-0,0027$ & 0,0020 & $-0,0003$ & 0,4409 & 0,5804 & 0,4224 \\
\hline 234 Hameln & $-0,0063$ & $-0,0046$ & $-0,0019$ & 0,2735 & 0,2853 & 0,3261 \\
\hline 237 Hannover & $-0,0044$ & $-0,0093$ & $-0,0036$ & 0,2111 & 0,2748 & 0,3667 \\
\hline 241 Helmstedt & $-0,0080$ & $-0,0112$ & $-0,0054$ & 0,2118 & 0,0338 & 0,3942 \\
\hline 244 Hildesheim & $-0,0052$ & $-0,0060$ & $-0,0068$ & 0,3608 & 0,2925 & 0,2806 \\
\hline 247 Leer & $-0,0176$ & $-0,0026$ & $-0,0149$ & 0,3882 & 0,4275 & 0,2049 \\
\hline 251 Lüneburg & $-0,0106$ & $-0,0051$ & $-0,0069$ & 0,1732 & 0,2924 & 0,2524 \\
\hline 254 Nienburg & 0,0070 & 0,0153 & 0,0080 & 0,6981 & 0,8081 & 0,5057 \\
\hline 257 Nordhorn & 0,0159 & 0,0197 & 0,0187 & 0,6824 & 0,7606 & 0,7570 \\
\hline 261 Oldenburg & 0,0001 & 0,0065 & 0,0089 & 0,5360 & 0,6190 & 0,6753 \\
\hline 264 Osnabrück & $-0,0020$ & $-0,0029$ & $-0,0048$ & 0,4569 & 0,4510 & 0,3483 \\
\hline 267 Stade & 0,0125 & 0,0145 & 0,0098 & 0,7127 & 0,7643 & 0,7230 \\
\hline 271 Uelzen & 0,0094 & 0,0069 & 0,0009 & 0,5067 & 0,6618 & 0,3563 \\
\hline 274 Vechta & 0,0176 & 0,0107 & 0,0126 & 0,7327 & 0,7309 & 0,8672 \\
\hline 277 Verden & $-0,0020$ & $-0,0004$ & 0,0027 & 0,3521 & 0,5334 & 0,6033 \\
\hline 281 Wilhelmshaven & $-0,0019$ & 0,0047 & 0,0101 & 0,3160 & 0,5510 & 0,5900 \\
\hline 311 Aachen & 0,0069 & 0,0075 & 0,0087 & 0,6194 & 0,6675 & 0,7357 \\
\hline 313 Ahlen & 0,0014 & 0,0070 & 0,0175 & 0,6050 & 0,7243 & 0,8562 \\
\hline 315 Bergisch Gladbach & 0,0019 & $-0,0013$ & $-0,0057$ & 0,5220 & 0,4438 & 0,2704 \\
\hline 317 Bielefeld & $-0,0064$ & $-0,0129$ & $-0,0123$ & 0,3790 & 0,1644 & 0,2436 \\
\hline 321 Bochum & 0,0019 & 0,0253 & 0,0153 & 0,6566 & 0,8214 & 0,9077 \\
\hline 323 Bonn & $-0,0013$ & $-0,0033$ & $-0,0030$ & 0,4745 & 0,3315 & 0,4112 \\
\hline 325 Brühl & $-0,0025$ & $-0,0043$ & $-0,0035$ & 0,3431 & 0,2349 & 0,3276 \\
\hline 327 Coesfeld & $-0,0066$ & $-0,0067$ & $-0,0052$ & 0,4576 & 0,3548 & 0,3295 \\
\hline 331 Detmold & 0,0095 & 0,0076 & 0,0044 & 0,7133 & 0,6800 & 0,7215 \\
\hline 333 Dortmund & $-0,0038$ & $-0,0065$ & 0,0011 & 0,2285 & 0,1451 & 0,5099 \\
\hline 335 Düren & 0,0037 & 0,0025 & 0,0020 & 0,6301 & 0,5402 & 0,5678 \\
\hline 337 Düsseldorf & 0,0019 & 0,0057 & 0,0120 & 0,7109 & 0,8571 & 0,8364 \\
\hline 341 Duisburg & 0,0018 & 0,0036 & 0,0036 & 0,5143 & 0,7517 & 0,6116 \\
\hline 343 Essen & 0,0033 & $-0,0046$ & $-0,0102$ & 0,7238 & 0,3208 & 0,1442 \\
\hline 345 Gelsenkirchen & $-0,0014$ & $-0,0068$ & $-0,0035$ & 0,1789 & 0,0329 & 0,1614 \\
\hline 347 Hagen & 0,0001 & 0,0012 & 0,0053 & 0,5000 & 0,4801 & 0,7051 \\
\hline 351 Hamm & $-0,0032$ & $-0,0014$ & $-0,0089$ & 0,3705 & 0,3183 & 0,2736 \\
\hline 353 Herford & $-0,0004$ & 0,0037 & 0,0015 & 0,5304 & 0,6099 & 0,4890 \\
\hline 355 Iserlohn & 0,0012 & 0,0023 & $-0,0145$ & 0,5321 & 0,5915 & 0,1744 \\
\hline 357 Köln & $-0,0019$ & $-0,0032$ & $-0,0117$ & 0,3537 & 0,2629 & 0,2110 \\
\hline 361 Krefeld & $-0,0031$ & $-0,0029$ & $-0,0028$ & 0,1900 & 0,3789 & 0,4385 \\
\hline 363 Meschede & 0,0148 & 0,0103 & 0,0089 & 0,5437 & 0,6659 & 0,7122 \\
\hline 365 Mönchengladbach & $-0,0002$ & 0,0052 & 0,0028 & 0,5073 & 0,7881 & 0,5554 \\
\hline 367 Münster & 0,0144 & 0,0169 & 0,0140 & 0,9386 & 0,9724 & 0,9026 \\
\hline
\end{tabular}


Table 11. Absolute performance and quantile positions (continued)

\begin{tabular}{|c|c|c|c|c|c|c|}
\hline \multirow[b]{2}{*}{ Labor agency } & \multicolumn{3}{|c|}{ Absolute performance } & \multicolumn{3}{|c|}{ Quantile position } \\
\hline & 2006 & 2007 & 2008 & 2006 & 2007 & 2008 \\
\hline 371 Oberhausen & $-0,0020$ & 0,0038 & 0,0009 & 0,3745 & 0,6605 & 0,5104 \\
\hline 373 Paderborn & 0,0180 & 0,0079 & 0,0064 & 0,9297 & 0,6767 & 0,6110 \\
\hline 375 Recklinghausen & 0,0008 & $-0,0022$ & 0,0035 & 0,5630 & 0,4566 & 0,7346 \\
\hline 377 Rheine & 0,0160 & 0,0108 & 0,0114 & 0,9177 & 0,8735 & 0,8486 \\
\hline 381 Siegen & 0,0038 & $-0,0022$ & $-0,0038$ & 0,7263 & 0,4128 & 0,3880 \\
\hline 383 Soest & 0,0030 & $-0,0023$ & $-0,0093$ & 0,4770 & 0,4639 & 0,3151 \\
\hline 385 Solingen & $-0,0002$ & $-0,0022$ & $-0,0081$ & 0,4705 & 0,3030 & 0,1991 \\
\hline 387 Wesel & $-0,0124$ & $-0,0007$ & $-0,0139$ & 0,2962 & 0,4937 & 0,2590 \\
\hline 391 Wuppertal & $-0,0052$ & $-0,0043$ & $-0,0116$ & 0,1304 & 0,2358 & 0,1565 \\
\hline 411 Bad Hersfeld & $-0,0075$ & 0,0002 & 0,0075 & 0,5028 & 0,5950 & 0,6377 \\
\hline 415 Darmstadt & $-0,0067$ & $-0,0038$ & 0,0101 & 0,1822 & 0,5122 & 0,9097 \\
\hline 419 Frankfurt & $-0,0055$ & 0,0036 & 0,0021 & 0,3394 & 0,5013 & 0,5896 \\
\hline 423 Fulda & 0,0083 & 0,0030 & 0,0071 & 0,6088 & 0,4222 & 0,6378 \\
\hline 427 Gießen & 0,0029 & 0,0021 & 0,0042 & 0,6013 & 0,4578 & 0,5974 \\
\hline 431 Hanau & $-0,0087$ & $-0,0021$ & 0,0024 & 0,3122 & 0,4609 & 0,5642 \\
\hline 435 Kassel & 0,0098 & 0,0089 & 0,0120 & 0,6388 & 0,7007 & 0,8198 \\
\hline 439 Korbach & 0,0132 & 0,0072 & 0,0045 & 0,6651 & 0,5977 & 0,6801 \\
\hline 443 Limburg & $-0,0104$ & $-0,0051$ & 0,0040 & 0,3559 & 0,2684 & 0,4782 \\
\hline 447 Marburg & $-0,0035$ & 0,0128 & 0,0117 & 0,5950 & 0,7450 & 0,7347 \\
\hline 451 Offenbach & 0,0013 & $-0,0033$ & $-0,0036$ & 0,4914 & 0,2899 & 0,4370 \\
\hline 455 Wetzlar & 0,0027 & 0,0043 & 0,0127 & 0,5670 & 0,5240 & 0,8324 \\
\hline 459 Wiesbaden & $-0,0039$ & 0,0007 & 0,0105 & 0,3080 & 0,5999 & 0,9238 \\
\hline 511 Bad Kreuznach & 0,0127 & 0,0119 & $-0,0001$ & 0,7693 & 0,8417 & 0,2951 \\
\hline 515 Kaiserslautern & $-0,0067$ & $-0,0061$ & $-0,0020$ & 0,3458 & 0,3673 & 0,4714 \\
\hline 519 Koblenz & 0,0208 & 0,0154 & 0,0222 & 0,8454 & 0,6339 & 0,8330 \\
\hline 523 Ludwigshafen & 0,0027 & $-0,0047$ & $-0,0019$ & 0,5982 & 0,3882 & 0,4509 \\
\hline 527 Mainz & 0,0056 & 0,0018 & $-0,0028$ & 0,7388 & 0,5665 & 0,3487 \\
\hline 531 Mayen & 0,0087 & 0,0045 & 0,0149 & 0,5788 & 0,4773 & 0,7332 \\
\hline 535 Montabaur & 0,0105 & 0,0113 & $-0,0014$ & 0,6427 & 0,8174 & 0,5173 \\
\hline 539 Neunkirchen & 0,0039 & 0,0110 & 0,0143 & 0,3435 & 0,7451 & 0,8770 \\
\hline 543 Landau & $-0,0060$ & $-0,0016$ & 0,0036 & 0,3735 & 0,3924 & 0,6672 \\
\hline 547 Neuwied & 0,0009 & $-0,0069$ & $-0,0079$ & 0,5524 & 0,2361 & 0,2098 \\
\hline 551 Pirmasens & 0,0004 & 0,0008 & $-0,0025$ & 0,3308 & 0,4023 & 0,3019 \\
\hline 555 Saarbrücken & 0,0061 & 0,0019 & $-0,0079$ & 0,7679 & 0,5660 & 0,2887 \\
\hline 559 Saarlouis & 0,0009 & $-0,0119$ & $-0,0145$ & 0,4742 & 0,1898 & 0,1328 \\
\hline 563 Trier & 0,0128 & $-0,0026$ & 0,0021 & 0,7040 & 0,3559 & 0,5855 \\
\hline 611 Aalen & $-0,0026$ & $-0,0076$ & $-0,0011$ & 0,1744 & 0,2533 & 0,2420 \\
\hline 614 Balingen & $-0,0077$ & $-0,0093$ & $-0,0063$ & 0,2084 & 0,3126 & 0,3666 \\
\hline 617 Freiburg & 0,0029 & 0,0154 & 0,0141 & 0,6817 & 0,7924 & 0,7897 \\
\hline 621 Göppingen & $-0,0048$ & $-0,0039$ & $-0,0121$ & 0,2324 & 0,2856 & 0,2097 \\
\hline 624 Heidelberg & 0,0018 & $-0,0051$ & $-0,0016$ & 0,5984 & 0,2430 & 0,4882 \\
\hline 627 Heilbronn & 0,0035 & 0,0022 & 0,0032 & 0,6263 & 0,5353 & 0,4954 \\
\hline 631 Karlsruhe & 0,0063 & 0,0003 & 0,0079 & 0,8340 & 0,4361 & 0,7986 \\
\hline 634 Konstanz & $-0,0042$ & $-0,0053$ & 0,0049 & 0,3195 & 0,3283 & 0,5599 \\
\hline
\end{tabular}

(continued) 
Table 11. Absolute performance and quantile positions (continued)

\begin{tabular}{|c|c|c|c|c|c|c|}
\hline \multirow[b]{2}{*}{ Labor agency } & \multicolumn{3}{|c|}{ Absolute performance } & \multicolumn{3}{|c|}{ Quantile position } \\
\hline & 2006 & 2007 & 2008 & 2006 & 2007 & 2008 \\
\hline 637 Lörrach & $-0,0161$ & $-0,0219$ & $-0,0244$ & 0,1135 & 0,0732 & 0,0179 \\
\hline 641 Ludwigsburg & 0,0047 & 0,0024 & 0,0008 & 0,6076 & 0,5609 & 0,4497 \\
\hline 644 Mannheim & $-0,0065$ & 0,0061 & $-0,0092$ & 0,2383 & 0,6446 & 0,1127 \\
\hline 647 Nagold & 0,0037 & 0,0068 & $-0,0049$ & 0,5874 & 0,5258 & 0,3143 \\
\hline 651 Offenburg & 0,0147 & 0,0307 & 0,0246 & 0,8485 & 0,8945 & 0,8871 \\
\hline 654 Pforzheim & $-0,0111$ & $-0,0032$ & $-0,0060$ & 0,1992 & 0,4555 & 0,2361 \\
\hline 657 Rastatt & 0,0084 & 0,0104 & 0,0148 & 0,7038 & 0,7120 & 0,7379 \\
\hline 661 Ravensburg & 0,0208 & 0,0132 & 0,0243 & 0,8634 & 0,8543 & 0,9923 \\
\hline 664 Reutlingen & 0,0021 & 0,0018 & $-0,0025$ & 0,5497 & 0,6529 & 0,5016 \\
\hline 667 Rottweil & 0,0106 & 0,0136 & $-0,0016$ & 0,6943 & 0,8839 & 0,4514 \\
\hline 671 Waiblingen & $-0,0020$ & $-0,0055$ & $-0,0009$ & 0,4288 & 0,2572 & 0,5639 \\
\hline 674 Schwäbisch Hall & 0,0125 & $-0,0026$ & 0,0146 & 0,7122 & 0,3856 & 0,8868 \\
\hline 677 Stuttgart & $-0,0009$ & $-0,0008$ & $-0,0103$ & 0,3681 & 0,5619 & 0,1860 \\
\hline 681 Tauberbischofsheim & 0,0175 & 0,0180 & 0,0124 & 0,8964 & 0,8447 & 0,6170 \\
\hline 684 Ulm & 0,0087 & 0,0224 & 0,0010 & 0,6652 & 0,7972 & 0,4757 \\
\hline 687 Villingen-Schwenningen & 0,0071 & $-0,0113$ & 0,0008 & 0,6511 & 0,2979 & 0,4657 \\
\hline 711 Ansbach & 0,0284 & 0,0233 & 0,0258 & 0,9639 & 0,9766 & 0,9154 \\
\hline 715 Aschaffenburg & 0,0019 & $-0,0110$ & $-0,0034$ & 0,4878 & 0,4172 & 0,4537 \\
\hline 719 Bamberg & $-0,0069$ & $-0,0079$ & 0,0131 & 0,3114 & 0,3350 & 0,6724 \\
\hline 723 Bayreuth & $-0,0109$ & 0,0026 & 0,0053 & 0,5145 & 0,3884 & 0,5288 \\
\hline 727 Coburg & $-0,0059$ & $-0,0051$ & $-0,0098$ & 0,4566 & 0,3229 & 0,3957 \\
\hline 731 Hof & 0,0030 & 0,0005 & $-0,0073$ & 0,2115 & 0,5079 & 0,4598 \\
\hline 735 Nürnberg & 0,0101 & 0,0083 & 0,0052 & 0,6427 & 0,7128 & 0,6034 \\
\hline 739 Regensburg & 0,0033 & 0,0027 & $-0,0063$ & 0,6244 & 0,6981 & 0,2891 \\
\hline 743 Schwandorf & $-0,0006$ & 0,0044 & 0,0107 & 0,3562 & 0,4128 & 0,4886 \\
\hline 747 Schweinfurt & 0,0041 & $-0,0037$ & $-0,0006$ & 0,6562 & 0,4240 & 0,4591 \\
\hline 751 Weiden & 0,0107 & 0,0205 & 0,0039 & 0,5276 & 0,7782 & 0,4461 \\
\hline 755 Weißenburg & $-0,0284$ & $-0,0093$ & $-0,0175$ & 0,2132 & 0,2825 & 0,3095 \\
\hline 759 Würzburg & 0,0074 & 0,0131 & 0,0115 & 0,6838 & 0,7324 & 0,8044 \\
\hline 811 Augsburg & 0,0023 & $-0,0011$ & $-0,0087$ & 0,2995 & 0,4586 & 0,4204 \\
\hline 815 Deggendorf & $-0,0030$ & $-0,0095$ & 0,0073 & 0,6003 & 0,2875 & 0,5668 \\
\hline 819 Donauwörth & 0,0072 & 0,0112 & 0,0075 & 0,7011 & 0,8147 & 0,6889 \\
\hline 823 Freising & 0,0022 & 0,0105 & 0,0088 & 0,7632 & 0,7406 & 0,7200 \\
\hline 827 Ingolstadt & $-0,0033$ & $-0,0027$ & 0,0068 & 0,3655 & 0,1435 & 0,8496 \\
\hline 831 Kempten & $-0,0068$ & 0,0011 & 0,0038 & 0,6632 & 0,5348 & 0,5578 \\
\hline 835 Landshut & 0,0116 & 0,0079 & $-0,0035$ & 0,6905 & 0,7092 & 0,3843 \\
\hline 839 Memmingen & $-0,0057$ & $-0,0003$ & $-0,0100$ & 0,3132 & 0,5974 & 0,2897 \\
\hline 843 München & 0,0076 & 0,0076 & 0,0082 & 0,6112 & 0,7723 & 0,8622 \\
\hline 847 Passau & 0,0030 & 0,0095 & 0,0139 & 0,4999 & 0,6865 & 0,7418 \\
\hline 851 Pfarrkirchen & 0,0218 & 0,0118 & 0,0122 & 0,6778 & 0,6869 & 0,7429 \\
\hline 855 Rosenheim & $-0,0100$ & $-0,0073$ & $-0,0047$ & 0,2586 & 0,1142 & 0,3773 \\
\hline 859 Traunstein & 0,0086 & 0,0074 & 0,0088 & 0,7551 & 0,7533 & 0,7441 \\
\hline 863 Weilheim & 0,0100 & 0,0073 & 0,0042 & 0,6774 & 0,9835 & 0,7208 \\
\hline 900 Berlin & $-0,0130$ & $-0,0151$ & $-0,0091$ & 0,1001 & 0,0291 & 0,2112 \\
\hline
\end{tabular}


Appendix B

Figures 
Figure 1. Convexity of cross validation function

Geographical distance

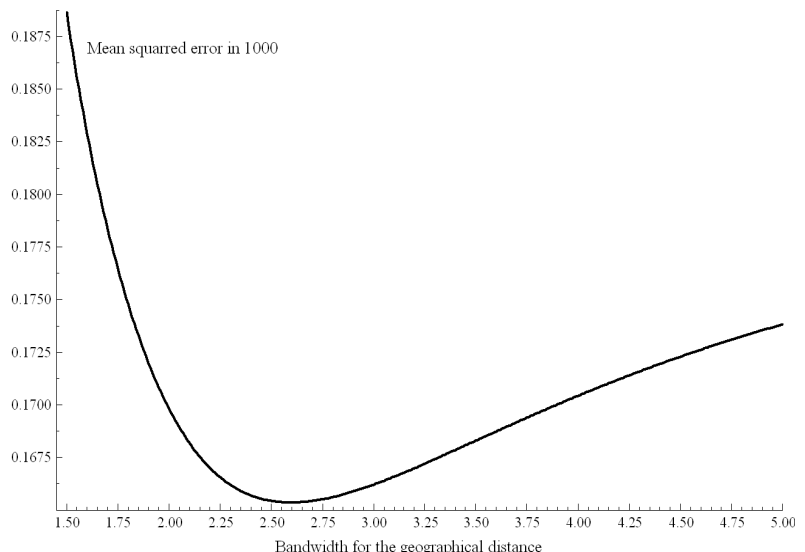

Figure 3. Sum of absolute weights (2006-2008)

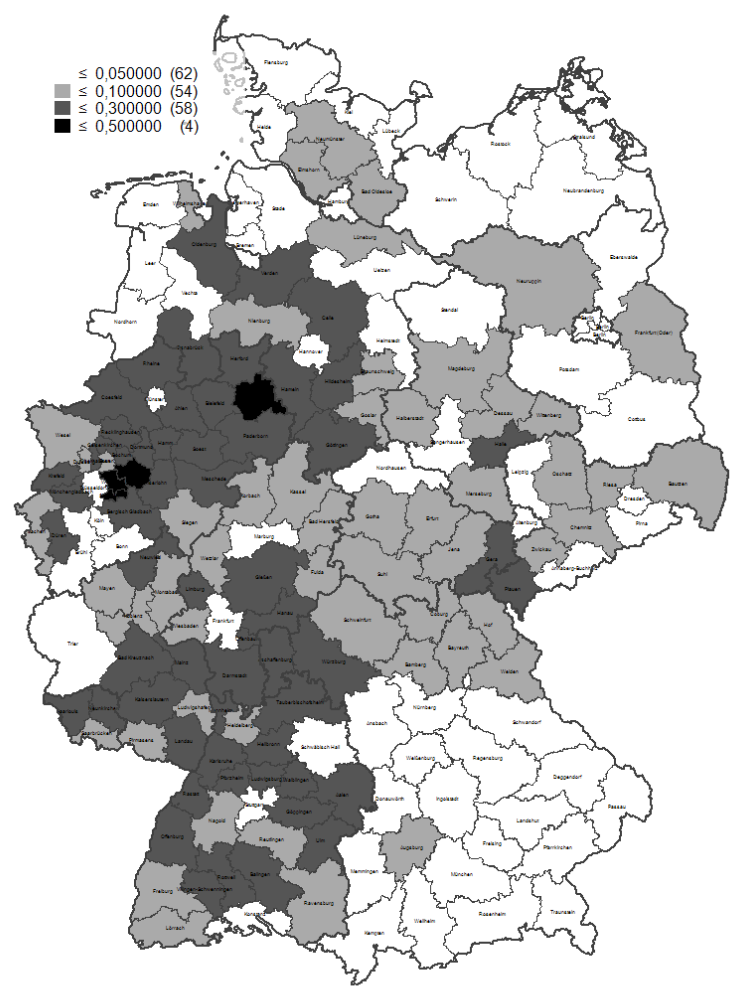

Statistical distance

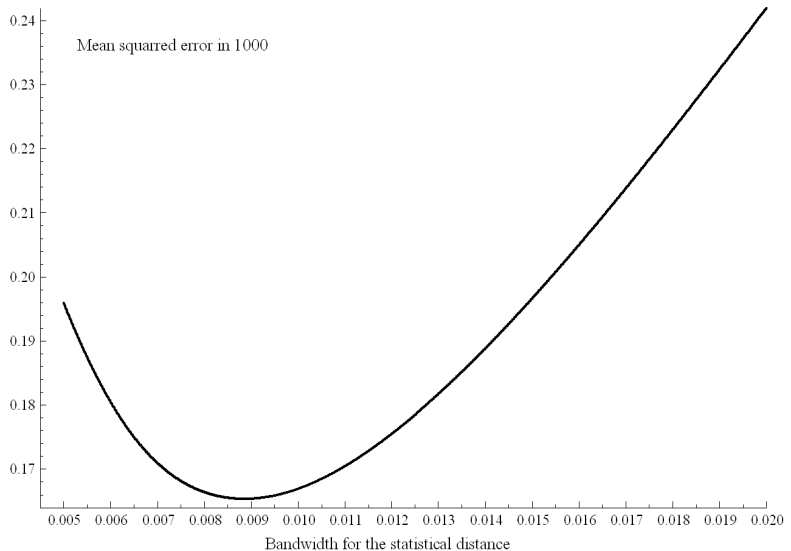


Figure 4. Estimated quantile positions and $90 \%$ confidence intervals

2006

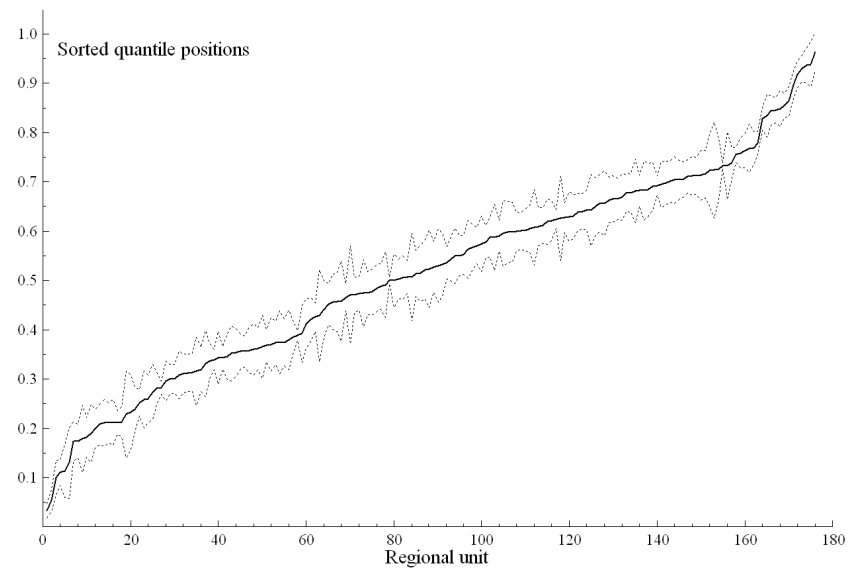

2007

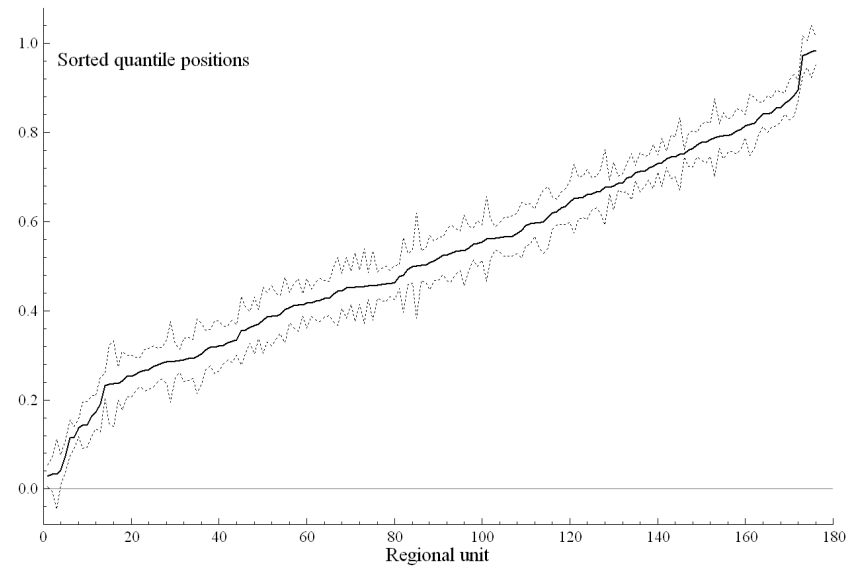

2008

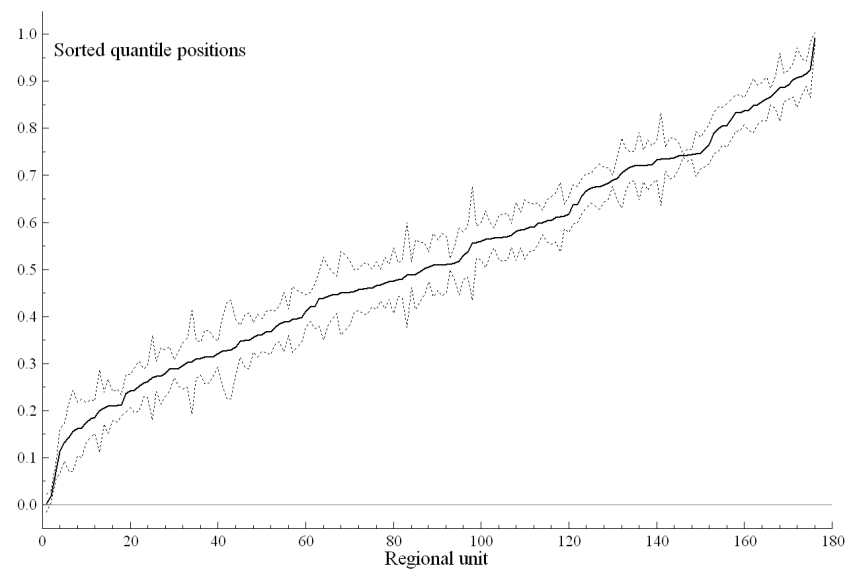



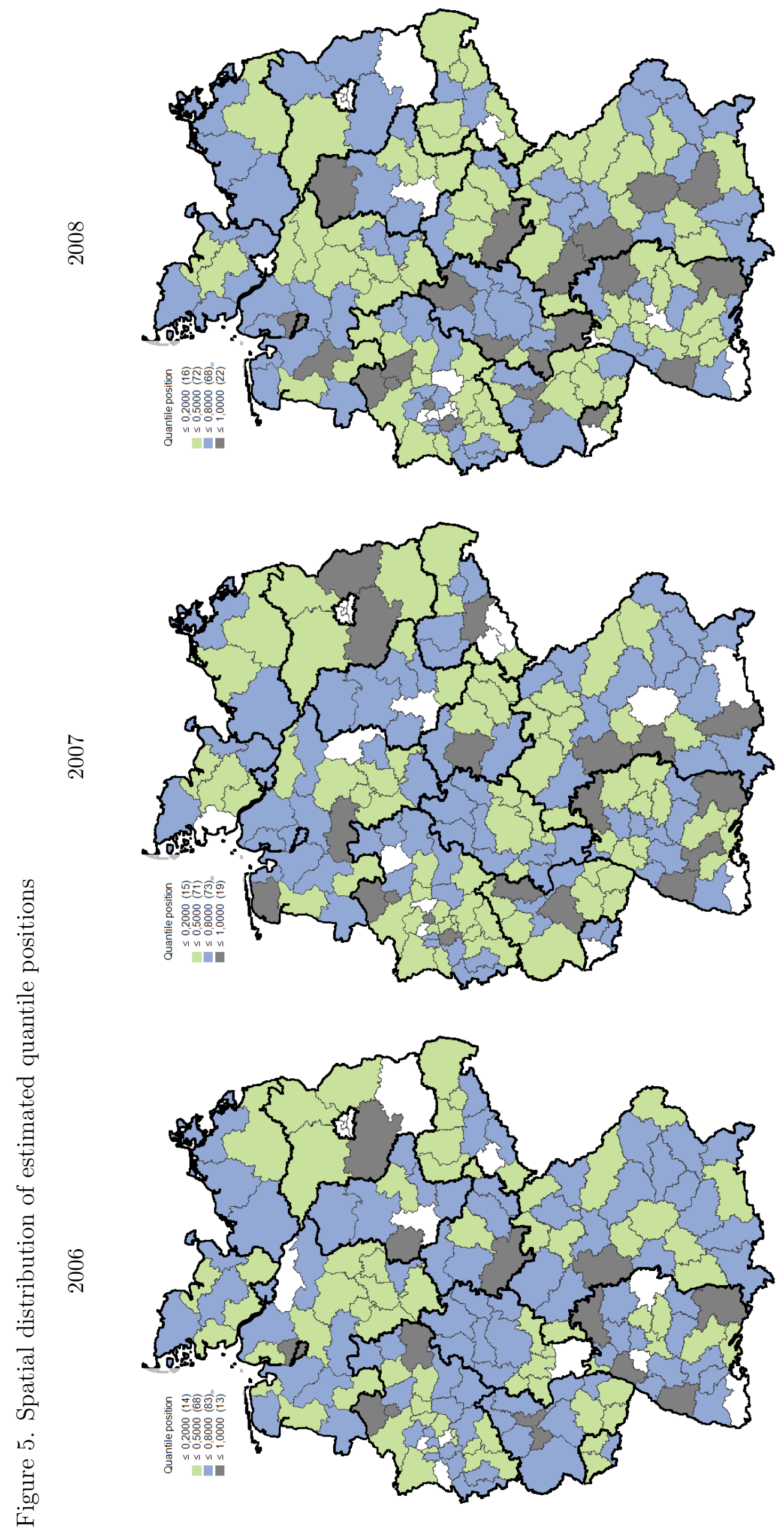


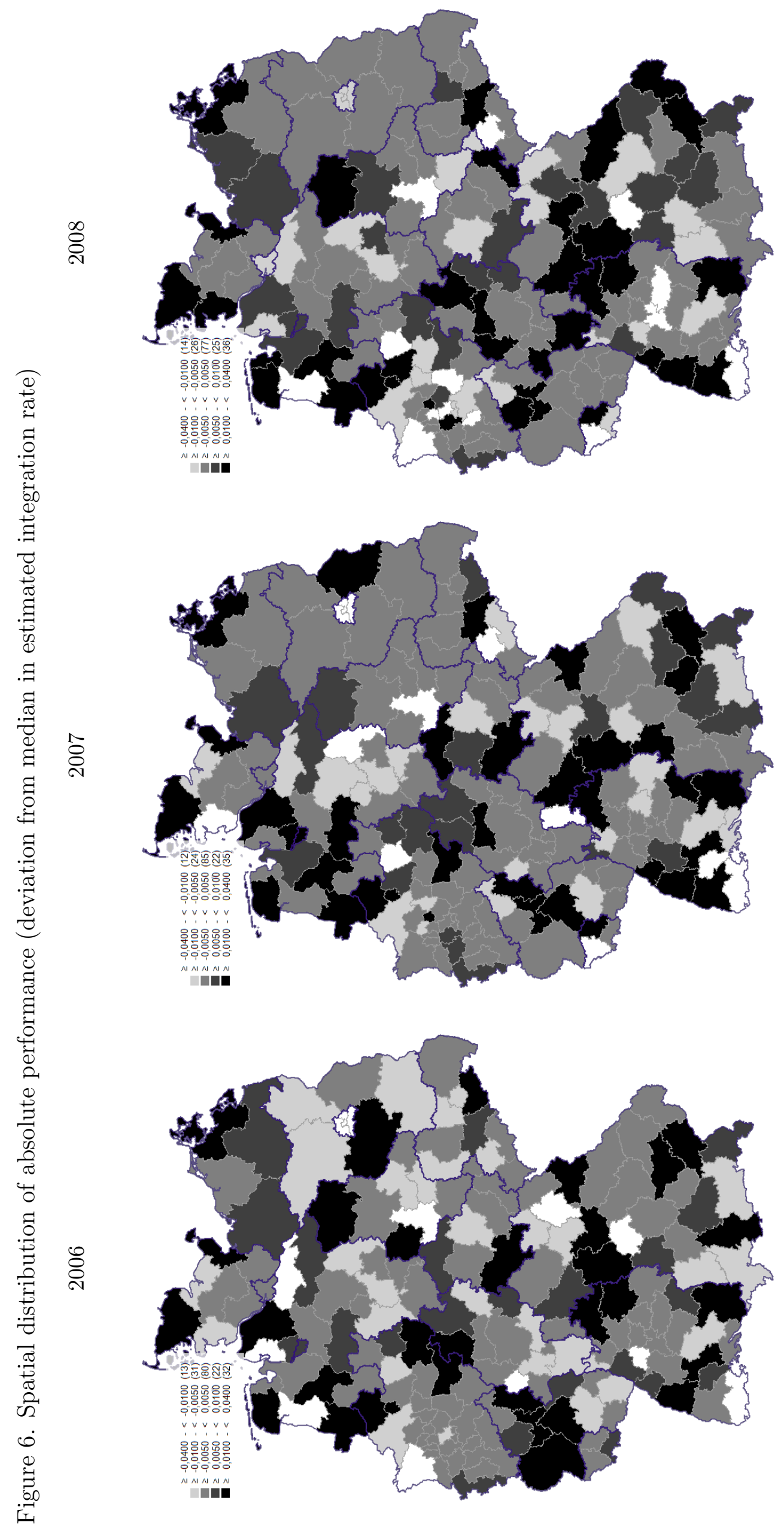

